\title{
Le totémisme en Afrique noire
}

Totemism in sub-Saharan Africa

Alfred Adler

\section{OpenEdition}

\section{Journals}

Édition électronique

URL : http://journals.openedition.org/span/1549

DOI : $10.4000 /$ span. 1549

ISSN : 2268-1558

\section{Éditeur}

École pratique des hautes études. Sciences humaines

\section{Édition imprimée}

Date de publication : 1 décembre 1998

Pagination : 13-106

ISSN : 0294-7080

\section{Référence électronique}

Alfred Adler, «Le totémisme en Afrique noire », Systèmes de pensée en Afrique noire [En ligne], 15 | 1998, mis en ligne le 28 mai 2014, consulté le 21 décembre 2020. URL : http://journals.openedition.org/ span/1549; DOI : https://doi.org/10.4000/span.1549 


\section{LE TOTÉMISME EN AFRIQUE NOIRE}

par

\section{Alfred Adler}

Le choix d'un tel thème pour un numéro de nos Cahiers en 1998 ne va pas de soi. A quoi bon rouvrir un tel dossier qui doit sembler à quelques-uns académique et plutôt poussiéreux et à beaucoup sans la moindre actualité qui en justifierait l'adoption ? Certes, nous savons que des africanistes de grand renom lui ont consacré des conférences, des articles, de longs passages ou même des chapitres entiers de leurs ouvrages les plus importants : nous songeons à M. Griaule $(1948,1954)$ et G. Dieterlen $(1954,1962)$, à M. Fortes $(1945,1966)$, E.E. Evans-Pritchard (1956) et G. Lienhardt (1961), L. de Heusch (1966) et, pour mentionner un exemple plus récent, à M. Dupire (1991). Il nous faut aussi dire, puisque notre propre contribution à ce Cahier en reprend toute la substance, que nous n'avions pas eu la moindre hésitation à intituler * totémisme " une longue partie du chapitre de notre thèse (Adler, 1982) consacré à l'organisation clanique des Moundang du Tchad. Toutefois, il ne fait guère de doute que parmi nos collègues, nombreux sont ceux qui penseront qu'il n'est pas possible aujourd'hui d'aborder un tel sujet sans prendre les plus élémentaires précautions théoriques ou plutôt, par rapport à la théorie de Lévi-Strauss qui, semble-t-il, fait toujours autorité. La plupart d'entre eux, en effet, ont lu en leur temps Le totémisme

\section{Totémismes}

Systèmes de pensée en Afrique noire, 15, 1998 
aujourd'bui (1962a) et La pensée sanvage (1962b), les deux ouvrages formant, au dire même de leur auteur, un tout indissociable, le premier s'étant fixé une tâche critique et le second faisant œuvre constructive, et ils en ont conclu qu'après ces travaux qui marquèrent une étape dans le développement du structuralisme lévi-straussien, l'usage du mot totem et, à plus forte raison, du mot totémisme, sauf à l'entourer de guillemets destinés à satisfaire on ne sait quel besoin de prophylaxie intellectuelle, était pour ainsi dire proscrit du vocabulaire des ethnologues de profession. On peut d'ailleurs s'étonner, à la lecture de certaines de ses formulations relevées dans chacun des deux livres, que Lévi-Strauss n'ait pas recommandé de façon explicite cette proscription, mais peut-être est-ce simplement parce qu'il savait qu'il n'aurait pas pu s'y conformer luimême et il prévient d'ailleurs son lecteur (1962a, 6-7) qu'il n'y a pas lieu d'en tirer argument contre lui. Considérons, cependant, ce qu'il écrit dans La Pensée sauvage (p.129) :

" [...] on se demandera peut-être pourquoi ces représentations (totémiques) sont accompagnées de règles d'action : à première vue au moins, le totémisme ou prétendu tel déborde le cadre d'un simple langage, il ne se contente pas de poser des règles de compatibilité ou d'incompatibilité entre des signes; il fonde une éthique, en prescrivant ou interdisant des conduites. [...] Nous répondons d'abord que cette association supposée procède d'une pétition de principe. Si l'on a convenu de définir le totémisme par la présence simultanée de dénominations animales ou végétales, de prohibitions portant sur les espèces correspondantes, et d'interdiction du mariage entre gens partageant le même nom et la même prohibition, alors il est clair que la liaison entre ces observances pose un problème. Mais, comme on l'a remarqué depuis longtemps, chacune peut se rencontrer sans les autres, ou deux quelconques d'entre elles sans la troisième. "

Nous n'allons évidemment pas ouvrir immédiatement la discussion sur le fond du problème du totémisme tel qu'il est posé par Lévi-Strauss. Nous voulons seulement, compte tenu de l'influence durable qu'a eu son attitude de rejet, soumettre au lecteur quelques questions d'ordre logique en nous demandant, par exemple, si ce dernier argument est aussi décisif qu'il en a l'air. Toute démarche théorique, dans les sciences humaines, comme dans les autres, suppose, à un moment donné, que le chercheur fasse choix d'une définition et qu'il s'y tienne aussi longtemps que les 
faits qu'elle conduit à examiner ne la mettent pas en cause. C'est encore plus évident quand il s'agit d'une notion forgée par les anthropologues à partir d'un terme indigène choisi précisément pour marquer le caractère de nouveauté et de singularité des phénomènes ainsi nommés. La multiplicité des définitions du totémisme qui se sont succédées et plus ou moins contredites entre elles était, pensons-nous, inévitable dès lors que I'on cherchait à savoir quel degré d'universalité avaient ces phénomènes dont l'observation ethnographique semblait prouver qu'ils étaient assez largement répandus à travers le monde et dans les aires culturelles les plus variées. Faut-il rappeler que si l'extension et la compréhension d'un concept varient en sens inverse, il n'y a pas lieu pour autant d'en conclure que le totémisme qui fut effectivement très tiraillé dans les deux sens, n'est qu'un leurre et en frapper la notion même d'illégitimité ? Nous ne croyons pas braver les règles du raisonnement valide en disant que ce n'est pas parce qu'une définition donnée nous conduit, par la façon dont elle est formulée, à poser tels problèmes particuliers et non tels autres, que ceux-ci sont de faux problèmes sous prétexte qu'il y aurait pétition de principe dans la définition elle-même. On connaît les paradoxes de la définition qui prétendrait éviter toute présupposition et donc se dégager complètement des contraintes inhérentes aux langues naturelles (seules les axiomatiques élaborées par les mathématiciens, telle celle de Peano, par exemple, pour fonder l'arithmétique, peuvent y échapper) ; en anthropologie, où l'on a affaire à une discipline dans laquelle, en définitive, il n'y a peut- être pas d'autre vocabulaire spécialisé - technique ou prétendu tel, si l'on préfère - que ces mots empruntés aux langues des peuples qu'elle étudie et que, tout bien pesé, elle juge intraduisibles ${ }^{1}$ comme, par exemple, totem, tabou, mana, potlatch, manitou, nyama, etc., l'acte de définir résulte obligatoirement d'un choix (que l'on espère bien sûr dûment motivé, mais dont l'arbitraire ne peut être totalement

1 Meyer Fortes, dans l'exorde d'une conférence prononcée en 1966 et intitulée "Totem and Taboo" (Fortes, 1987 : 111), dit quelque chose du même ordre pour justifier le choix de son sujet. Le totémisme est " un exemple d'un objet de recherche qui est spécifique des données, des méthodes et des théories de l'anthropologie sociale, et caractéristique aussi de son développement historique ". 
éliminé) qui associe tel et tel élément empirique dont l'observation nous apprend qu'ils sont, dans les faits, associés plus ou moins fréquemment mais de façon significative. C'est à la réflexion théorique qu'il incombe de chercher à comprendre comment et pourquoi cette association s'est produite et demeure durable.

Nous persistons donc à penser et souhaitons montrer ici que les Moundang possèdent un système clanique qu'il serait difficile sinon impossible de décrire sans l'aide de la notion de totémisme. Nous nous disons en même temps que les lecteurs un peu pressés de Lévi-Strauss n'ont peut-être pas pensé que les ensembles de faits qu'elle servait habituellement à désigner et qu'elle continue encore à désigner sous la plume de chercheurs chevronnés, risquaient du même coup de perdre en tant que tels, tout droit de cité dans le champ de la réflexion anthropologique. Est-on si sûr, a-t-on envie de leur demander, que le cadre conceptuel ou la sous-discipline de l'ethnologie dans laquelle ces ensembles de faits ont été ou sont récupérés aux fins d'analyse, a permis une véritable avancée scientifique ? Peut-on seulement affirmer que cette " récupération " existe (par exemple, ce qui pourrait sembler le plus probable, dans des travaux trouvant précisément leur inspiration dans La pensée sauvage ou dans d'autres relevant du cognitivisme) et prendre la mesure du gain obtenu ? Jusqu'à plus ample informé, il ne semble pas que ce soit le cas. I ne suffit pas d'éliminer un mot dont on peut certes dire qu'il n'est plus à la mode et dont on peut également dire qu'il n'est autre chose, à l'origine, qu'un malencontreux contresens fait par J. K. Long dans la traduction de l'expression ojibwa ototeman, pour se débarrasser d'un problème. Au demeurant, l'expérience historique de notre discipline ne manque pas d'exemples de ces rejets souvent fortement et justement motivés et qui sont parfois suivis de surprenants retours qui font symptôme de ce qu'il $\mathrm{y}$ a de difficile et même de pénible à penser dans le champ qui est le nôtre. On pourrait évoquer en particulier le mot fétiche dont plusieurs de nos Cahiers précédents ont montré tout l'intérêt qu'il conservait en dépit de l'opinion de M. Mauss lui-même qui l'avait cru à jamais entaché du préjugé colonialiste, sans parler d'autres aujourd'hui, qui vont jusqu'à lui trouver un relent d'idéologie esclavagiste parce qu'il pouvait servir à mettre au ban de l'humanité ceux à qui il était appliqué. 
Dans une première séance du séminaire qui est à l'origine de certains des travaux réunis dans ce numéro, nous nous étions donc efforcé de montrer que les faits moundang que nous avions recueillis sur le terrain, et en particulier ceux touchant à l'organisation clanique qui constitue un trait essentiel de cette société, non seulement se passeraient difficilement d'une telle notion mais l'exigeraient bien plutôt, sous peine de laisser apparaitre comme disparates et secondaires des caractères qui manifestement forment un ensemble cohérent et que l'on peut appréhender comme un système. Nous nous sommes contenté, pour commencer, de rappeler une proposition simple et qui a pour nous valeur de définition minimale : elle est tirée d'un texte dans lequel A. R. Radcliffe-Brown (1952) s'attache à donner corps à une théorie sociologique du totémisme :

" Je donnerai au mot totémisme, écrit-il, son sens le plus large désignant toutes les situations où, dans une société divisée en groupes, il existe une relation particulière entre chacun d'eux et une ou plusieurs classes d'objets, habituellement des espèces naturelles d'animaux ou de plantes mais, à l'occasion des objets artificiels ou des parties d'un animal. Le mot désigne quelquefois, dans un sens plus étroit, les cas où les groupes sont des clans, ensembles exogames dont tous les membres sont étroitement liés par une descendance unilinéaire. Ce totémisme "clanique " est seulement une variété du totémisme entendu dans le sens le plus large ".

C'est précisément cette variété de totémisme que Radcliffe-Brown appelle " totémisme clanique " que l'on trouve chez les Moundang et, je l'ajoute dès maintenant, dans la totalité des exemples africains dont il sera question dans cette étude. Le cas des Joola du Sénégal et des Feloup de la Guinée-Bissau qu'examine dans ce recueil Odile Journet, est d'autant plus intéressant qu'il semble, jusqu'à plus ample informé, faire seul exception, y compris dans la zone géographique qu'ils occupent, comme on le verra avec l'article que M. Dupire a consacré aux Sereer du Sénégal.

La description du cas moundang qu'on lira plus loin permet de dégager un fait intéressant, caractéristique peut-être de certaines formes africaines du totémisme dans lesquelles il faudrait voir des variétés très 
différentes $^{2}$ de celles qui ont fait l'objet des études " classiques " dans ce domaine, à savoir celles rencontrées en Amérique du nord et en Australie. Si, comme le veut Lévi-Strauss, l'homologie interne entre la série des unités sociales constitutives de l'ensemble socio-politique considéré et celle des espèces ou objets totémiques est le minimum indispensable à l'établissement du " fait totémique ", il est nécessaire d'y adjoindre un troisième terme dont l'existence extérieure permet l'articulation entre les deux séries. Celles-ci, en effet, s'effondreraient sur elles-mêmes si la correspondance entre les termes de l'une et de l'autre se réduisait à une construction arbitraire purement sémiologique. Ce terme extérieur aux deux séries est, en l'occurrence, en pays moundang, le roi de Léré auquel revient le rôle d'opérateur de la "clanification " comme modalité d'entrée dans le champ social et politique du royaume de Léré. Une situation analogue se présente chez les Baganda de l'Ouganda où c'est aussi par rapport au roi, le kabaka, que s'ordonnent les fonctions rituelles et économiques spécifiques de chacun des clans. Nous essaierons de montrer que dans les analyses de Fortes, comme dans celles d'Evans-Pritchard

2 Alain Testart (1987), dans une longue analyse consacrée aux rapports du totémisme et des modes de production, associe la forme australienne à ce qu'il appelle le " communisme primitif " (celui des sociétés de chasseurs-cueilleurs) dont il voit une expression dans les rites de l'intichiuma; quant à la forme africaine (il prend justement l'exemple du totémisme nuer), elle se rattache pour lui au mode de production agro-pastoral. Nous ne nous sentons guère en mesure de discuter cette vue théorique tout à fait étrange pour un africaniste. Nous n'ignorons pas qu'il existe des liens certainement très étroits entre les modes de production et la " superstructure idéologique " mais nous pensons que, dans l'état actuel de nos connaissances, nous nous trouvons sur un terrain plus solide en envisageant seulement les rapports entre totémisme et organisation sociale et politique. Tout le monde s'accorde sur l'idée que totémisme et organisation sociale sont absolument inséparables. Nous espérons montrer que les exemples africains invitent à prendre en compte la dimension politique des sociétés que nous disons totémiques mais nous ne pensons pas qu'il soit possible de mettre exactement sur le même plan leur dimension économique. Nous verrons que telle forme de pouvoir politique peut déterminer une forme de division sociale du " travail ", par exemple, l'attribution de fonctions spécifiques, rituelles et éventuellement techniques, aux différents clans qui, selon les cas, conservent ou non leurs caractéristiques totémiques. Mais il ne faudrait pas rapprocher, et encore moins confondre, cette division très spéciale du " travail " avec un quelconque système économique dont elle constituerait un trait différentiel. 
et de Lienhardt respectivement, un rôle de même nature est dévolu aux ancêtres (eux-mêmes liés aux autels de la puissance Terre) chez les Tallensi du nord du Ghana, aux ancêtres et à la divinité Chair chez les Dinka du Soudan et à Dieu ou à l'Esprit suprême chez les Nuer leurs voisins.

Dans le séminaire consacré au totémisme en Afrique orientale et plus spécialement aux Nuer étudiés par E. E. Evans-Pritchard (Nuer Religion, 1956) et aux Dinka étudiés par G. Lienhardt (Divinity and Experience, 1961), nous sommes parti précisément de la constatation que chez chacun de ces deux auteurs le totémisme fait l'objet d'un chapitre complet de l'ouvrage qu'ils ont consacré l'un et l'autre à l'étude de la religion de leur population. Nous ne pouvions manquer de relever qu'il nous aurait été impossible de procéder de la même manière chez les Moundang. C'est tout naturellement, dirions-nous, qu'en décrivant l'organisation clanique de la société, nous avons ressenti la nécessité d'en exposer de la façon la plus complète les aspects incontestablement totémiques qui sont les siens. Mais du même coup, nous n'avions pas à nous soucier de savoir si les rites et les croyances associés à ces aspects constituaient un ensemble spécifique de faits religieux, car l'essentiel était de dégager le caractère systématique d'une somme de traits formels appartenant à une nomenclature et impliquant pour chacune des classes définies des conduites et des attitudes distinctes, comme c'est le cas pour les classes qui se dégagent de l'analyse des terminologies de parenté. Il semblerait, au premier abord, qu'une différence aussi décisive dans le traitement des faits de totémisme devrait impliquer une différence de nature telle entre eux qu'elle ne pourrait que nous faire retomber sous les arguments de la critique lévi-straussienne que nous venons de mettre en cause. Nous pensons qu'il n'en est rien et espérons montrer qu'il n'y a pas solution de continuité entre les systèmes de relations totémiques que nous allons étudier, que le terme central ou troisième terme autour duquel ils pivotent soit un culte d'esprits (ancêtres, Terre, divinité céleste) ou bien un culte lié à une forme ou une autre de souveraineté politique. 
Approche comparative du totémisme chez les Nuer et chez les Dinka

La manière dont le totémisme des Nuer et celui des Dinka nous sont présentés semble donc annoncer qu'il n'y a pas d'échappatoire : il existe bel et bien une catégorie de faits religieux qu'on doit et qu'on ne peut penser qu'à l'aide de cette notion. Dépêchons-nous de dire, au risque de nous mettre nous-même en fâcheuse posture, qu'à cet égard l'intérêt redouble parce que nous sommes, pour ainsi dire, soumis à un test de validation du point de vue, disons " conservateur ", qui est le nôtre : il y eut, en effet, un désaccord des plus significatifs entre nos deux auteurs sur la pertinence de l'emploi du mot totem. Evans-Pritchard (1956) conserve le terme (qu'il a employé depuis ses premiers articles publiés sur les Nuer et qu'il emploie aussi dans deux courts textes consacrés aux Zande, Man, 1956 et Man 1961) tout en sachant que son disciple et ami G. Lienhardt (1961) répugne à le faire. Quand ce dernier publiera quelques années plus tard l'ouvrage mentionné plus haut, il remplacera, sous l'influence des positions que Frazer avait adoptées dans Totemism and Exogamy (1910) sur ce sujet, totem par "clan divinity" pour parler des conceptions dinka ; le piquant de l'affaire est qu'Evans-Pritchard nous apprend que le totémisme nuer est, pour une large part, d'origine dinka. A la vérité, une lecture attentive des deux auteurs nous montre que cette divergence de vocabulaire est sans grande portée, mais qu'elle est plutôt le symptôme d'une divergence de nature philosophique et même religieuse entre eux deux. La différence vraiment décisive que présentent leurs interprétations respectives peut se résumer ainsi : en prenant le contre-pied de la thèse de Durkheim qui faisait du totémisme la forme élémentaire de la religion, Evans-Pritchard tire le totémisme nuer vers les formes les plus élevées de la religion, une sorte de monothéisme laissant place au culte des esprits conçus comme autant de facettes du dieu souverain et unique. A cette fin, il fait usage à sa façon de l'argument de l'Un et du Multiple :

"[...] on peut dire que le Nuer sacrifie à l'esprit-lion et pas à l'espritcrocodile mais pas qu'il sacrifie à l'esprit-lion et pas à Dieu. Aucune des modalités sous lesquelles se présente l'esprit n'est pensée comme séparée de Dieu mais comme séparée seulement d'une autre modalité. Le lion-esprit et Dieu sont la même chose considérée de façon différente". 
G. Lienhardt, quant à lui, s'efforce de faire entrer la notion de "divinité de clan" dans le champ de l'expérience sociale vécue ${ }^{3}$, individuelle et collective. L'animal ou l'objet qu'il appelle "emblématique" (en reprenant d'ailleurs un terme essentiel dans l'analyse durkheimienne ${ }^{4}$ ) représente pour le Dinka non pas une modalité de Dieu, mais la divinité de " son " clan et comme telle, la source de vie et de fécondité à l'intérieur de son clan. La notion de divinité ne renvoie donc pas ici à une entité individualisée mais à un principe que l'on peut presque confondre avec celui de la puissance liée à l'ancestralité. Mais ce n'est là qu'un aspect partiel du fait religieux dinka, car au-dessus des divinités claniques il y a la divinité suprême avec laquelle les hommes ne peuvent communiquer que par la médiation d'un clan particulier dont la divinité propre est appelée Chair. " Maîtres de la lance de pêche " est le titre donné aux anciens de ce clan qui sont les " prêtres" de Chair et l'on peut considérer ces personnages, que les anciennes coutumes vouaient au suicide rituel quand ils atteignaient le grand âge, comme des espèces de rois sacrés de la tribu et de son territoire. C'est en participant aux grands sacrifices

${ }^{3}$ On pourrait dire qu'Evans-Pritchard a une conception plutôt cognitive du totem (manière de connaître le divin en l'honorant sous une de ses modalités déterminée en fonction des divisions claniques de la société) tandis que Lienhardt s'en fait une idée existentielle qui s'oppose, quant à elle, de façon radicale au point de vue lévistraussien. Qu'on nous permette de le citer en anglais: "A clan-divinity thus does not face outwards to other clans, so to speak, appearing as a label or sign by which outsiders may know with whom they have to deal, but relates inwards to the clansmen. By knowing from genealogical evidence that they are agnatically related, they know also that they are united in relation to a common divinity, which for them symbolises their relationship " (Lienhardt, op. cit. p. 113)

${ }^{4}$ On a l'impression d'assister à un chassé-croisé entre la terminologie frazérienne et celle de Durkheim. Lienhardt renonce au mot totem en raison de la définition qu'en donne Frazer et utilise le mot emblème dans un sens très proche de celui de Durkheim qui en fait une notion fondamentale du totémisme. On relève dans Les formes élémentaires de la vie religieuse (1912) les formules suivantes : " [...] sa source (du principe totémique) n'a pu être la nature intrinsèque de la chose dont le clan portait le nom [...] mais seulement [...] la représentation figurative de cet animal ou de cette plante, c'est-à-dire l'emblème totémique [...].Cet emblème est la forme sensible du principe ou dieu totémique; mais d'un autre côté, il est aussi le symbole de cette société déterminée qu'on appelle le clan. " et un peu plus loin, on lit encore : " [..] car le principe totémique est le clan pensé sous une forme matérielle que l'emblème figure." 
dont ces dignitaires ont la charge que les membres des autres clans peuvent invoquer le dieu suprême et espérer bénéficier de ses faveurs. En somme, la divinité clanique, qui a pour emblème n'importe quel représentant de l'espèce ou de la classe d'objets dont elle porte le nom, est aux individus membres de ce clan, ce que la "Chair " est à l'ensemble des clans d'une même tribu ou groupement territorial de tribus. Assurément, au regard de la théorie lévi-straussienne exposée dans la Pensée sauvage et reprise dans le Finale de l'Homme nu, l'un des problèmes que pose le "totémisme" (nous utilisons ici, à notre tour, les guillemets car le problème en question n'est peut-être que la conséquence des définitions restrictives retenues par cette théorie) de ces peuples nilotiques est celui de l'articulation de leur système sacrificiel, qui occupe dans leur religion une place centrale, avec la logique des classifications totémiques qui, selon Lévi-Strauss, exclut toute notion de sacrifice. Ce point de vue lévistraussien, entièrement tributaire, nous semble-t-il, d'une certaine lecture de l'Essai bien connu rédigé par Hubert et Mauss sur le sacrifice (texte publié en 1899 d'où, nous nous permettons de le rappeler, les données de l'ethnographie de terrain sont presque totalement absentes) demande à être réexaminé.

Voyons maintenant les choses de plus près en commençant par les Nuer auxquels Evans-Pritchard prête des spéculations sur la notion d'“ esprit " dont nous pensons, sans jeu de mots douteux, qu'elles sont d'un grand intérêt spéculatif pour le champ entier de l'anthropologie religieuse. On peut en juger en questionnant la valeur de l'argument de l'Un et du Multiple : s'agit-il d'une coquetterie philosophique de l'ethnologue ou bien d'une fine et fidèle analyse des données conduisant par elle-même à ce thème si important de la pensée antique ? Les prémisses sont claires : il existe un mot kwoth qui signifie Esprit, écrit avec une majuscule pour indiquer le plus haut degré d'abstraction dans l'ordre des puissances avec lesquelles l'homme est aux prises : universalité, unicité, suprématie et souveraineté exercée sur la totalité des êtres, au ciel comme sur la terre. Concrètement, il s'agit d'un mot qu'il faut, selon notre auteur, traduire par Dieu, terme auquel correspondent les prédicats suivants : créateur de toute chose, père de tous les humains et juge de toutes leurs actions. Ce même mot sert également à désigner les deux catégories d'esprits que distinguent les Nuer : les esprits d'en haut 
(esprits de l'air et esprits colwic qui se manifestent à certaines personnes par la possession) et les esprits d'en bas dont font partie les espèces ou objets totémiques. A l'opposé de ces derniers qui sont associés à des clans et à des lignages, les premiers, dont nous ne parlerons que très brièvement, concernent tout le monde mais ne sont effectivement associés qu'à des individus. Ainsi, ceux qui ont été tués par l'éclair, qui ont disparu dans un tourbillon ou que l'on a retrouvés morts en brousse sans que l'on puisse savoir à qui ou à quoi en imputer la cause, se transforment en esprits colwic et la famille de la ou des victimes se trouve liée à au moins un esprit de cette nature dont elle invoque le nom dans certaines circonstances et auquel elle consacre une vache ou sacrifie un taurillon. Par ailleurs, les guérisseurs et ceux qu'on appelle des prophètes (dont l'apparition chez les Nuer ne remonte qu'aux toutes dernières années du siècle passé) sont des personnes possédées par un esprit de l'air de façon permanente; c'est cette transformation radicale de leur être qui les rend aptes à exercer efficacement leurs fonctions, celles des prophètes ${ }^{5}$ étant de guider les hommes dans leurs expéditions guerrières traditionnelles (contre leurs voisins Dinka, par exemple) mais aussi et surtout dans leur résistance armée aux envahisseurs arabes venus du nord du Soudan.

Venons-en aux " esprits d'en bas " autrement dit, aux totems. Si l'on comprend immédiatement pourquoi les esprits de l'air sont dits d'en haut, qu'en est-il de ceux d'en bas, sont-ils des esprits de la terre ? Evidemment non puisqu'en vertu de leur essence divine, tous les esprits sont d'en haut, c'est-à-dire de nature céleste. On verra qu'il n'est pas tout à fait sûr qu'Evans-Pritchard ait réussi à lever cette difficulté. Il nous présente, en tout cas, les esprits comme des puissances rangées sur une échelle descendante dont les degrés inférieurs comportent les esprits totémiques, d'autres dont il nous dit qu'ils sont " totémistiques " (il entend par là qu'ils sont liés à des individus et non à des lignages), d'autres qu'il appelle nature sprites, lutins ou follets et enfin au degré le

${ }^{5}$ Evans-Pritchard oppose de façon nette le prophète par la bouche duquel l'esprit qui le possède parle aux hommes et les guide vers le succès, notamment dans leurs entreprises guerrières, et le prêtre (" le chef à peau de léopard ", par exemple) dont la bouche invoque l'esprit au nom de la communauté, afin qu'il répare le désordre provoqué par les actions des hommes tel l'homicide dont la conséquence est le déclenchement de la vengeance qui risque d'entraîner une suite de violences sans fin. 
plus bas, les fétiches, des objets (des faisceaux de baguettes, par exemple, et des plantes médicinales) chargés d'une certaine puissance auxquels leur propriétaire fait, à l'occasion, des sacrifices de chèvres. On remarquera d'emblée que dans la démarche de l'auteur, le totémisme n'est pas une forme première de classification mais une catégorie parmi d'autres dans un ensemble ordonné et hiérarchisé d'esprits. Il insiste, d'ailleurs, pour nous dire que les clans et les lignages nuer ne sont pas en manque, si l'on ose dire, de signes diacritiques pour marquer les différenciations sociales, car ils ont des noms d'ancêtres, des noms de lances (symboles éminents du lien de patrifiliation), des noms de bovins et des titres honorifiques comparables à des devises. Qu'est-ce donc qu'un totem nuer ? quels rapports a l'esprit qui se manifeste dans les représentants de l'espèce animale ou de la classe d'objets élus au rang de totems (étant entendu qu'il s'agit toujours d'une modalité de l'Esprit divin) avec le groupe social correspondant ? S'agissant des espèces animales, le rapport est le plus souvent pensé comme un lien de gémellité. Les Nuer affirment qu'une femme peut mettre au monde une paire de jumeaux dont l'un est un hippopotame, par exemple, auquel cas l'animal nouveau-né est placé dans l'eau d'une rivière tandis que le bébé humain est déposé dans un arbre parce que "les jumeaux sont des oiseaux ", selon la proposition bien connue et dont sait le sort théorique que lui a réservé Lévi-Strauss (1960a : 114-118). Pourquoi un tel événement extraordinaire se produitil ? Une réponse courante est que le mari de cette femme avait tué plusieurs hippopotames et que leurs congénères les avaient vengés en imprimant leur image sur l'un des jumeaux. Les Nuer donnent une interprétation réaliste de cette croyance ${ }^{6}$ en décrivant le bébé assimilé au

${ }^{6}$ On a donc affaire chez les Nuer à une conception plutôt tératologique de la gémellité dans ses rapports avec le totémisme, la gémellité comme telle étant valorisée comme signe d'une plus grande proximité avec le divin. Il n'y a pas là, à proprement parler, une contradiction car le monstrueux n'est nullement assimilable au mal. On sait que le lien entre totémisme et gémellité est aussi très fortement marqué chez les Dogons où il s'inscrit dans le cadre beaucoup plus vaste d'un système complexe de " correspondances cosmo-biologiques". Rappelons ces paroles de Dieu d'eau où il est dit que le rôle de l'animal était lié à la gémelliparité originelle : " Donc, à chaque naissance d'homme naît un animal interdit. Mais ce dernier a lui-même un jumeau, un animal interdit. Ce dernier aussi et ainsi de suite. Chaque famille d'hommes vient en tête d'une classe entière d'animaux. " (Griaule, 1948 : 154-155). 
pachyderme comme un petit être monstrueux, c'est-à-dire présentant effectivement une certaine ressemblance avec cet animal. Cette ressemblance est le signe de la présence sensible de l'esprit dans le monde humain et, en même temps, la révélation de l'espèce qui a été élue espèce totémique pour le groupe au sein duquel une telle naissance a eu lieu. Le monstrueux, l'anormal, précise-t-on, est ici comme la preuve évidente de l'action de l'esprit. Cela étant, quelle que soit la manière dont un totem se retrouve associé à un groupe, le lien formé entre eux est conçu comme un rapport entre lignages collatéraux. Comme les humains, les animaux sont censés vivre dans leurs "villages" en constituant des communautés composées de familles et de lignages. Evans-Pritchard ébauche même une brève et peu précise taxinomie zoologique : les grogneurs carnassiers, pourvus de crocs et de griffes (lion, panthère, chacal, hyène, etc.) sont une communauté dont l'un des lignages, par exemple, comprendrait des mangoustes, des servals et des genettes. Les serpents sont un lignage qui appartient aux "sans pieds". Une autre classe est celle des habitants de l'eau, qu'ils soient seulement des riverains ou qu'ils vivent dans les rivières, les lacs et les marais : crocodiles, lézards monitor, oiseaux et serpents aquatiques, poissons, etc. Curieusement, à cette classe de créatures liées à l'eau appartiennent les Anuak et les Balak Dinka, populations qui vivent de la pêche et d'un peu d'agriculture et, chose frappante pour les Nuer qui y voient presque une différence de nature par rapport à eux, ils ne possèdent pas de bétail. Est-ce à dire que de telles différences entre des groupes humains peuvent être du même ordre que celles qui séparent les hommes des animaux ? Ce n'est certainement pas le point de vue de notre auteur qui prend toujours en considération non pas le rapport duel homme-animal mais un système à trois éléments : groupes sociaux, espèces totémiques et esprits dont les représentants de l'espèce éponyme sont les emblèmes. Nous y reviendrons, mais voyons maintenant ce qu'il en est du rapport entre les hommes et leurs totems tel qu'il est empiriquement observable à travers les attitudes et les comportements qui en sont l'expression. Soit le lignage appelé Leng et son totem esprit-lion (Evans-Pritchard, 1956 : 64-65). Un homme avait tué un lion avec une lance appartenant à l'un de ses voisins Leng et peu après, il arriva que des lions tuèrent quelques bêtes du troupeau de ce Leng qui avait prêté son arme. On se proposait de faire une chasse à ces 
fauves quand, réflexion faite, on s'avisa qu'il s'agissait d'une juste vengeance des esprits-lions en réponse à une agression imputable à un lignage-lion. La solution adoptée fut la suivante : le tueur de lion versa à son ami Leng une compensation pour le bétail perdu et un sacrifice fut fait pour apaiser l'esprit-lion ; ensuite, tout rentra dans l'ordre. Dans d'autres circonstances, le tueur de lion sera possédé par l'esprit au point de perdre le sien et se prendre pour un lion, se mettant à rugir et imitant la posture du fauve, les doigts tenus recourbés comme des griffes et les jambes ployées comme dans l'instant où il est prêt à bondir sur sa proie. Là encore, un sacrifice expiatoire à l'esprit-lion suffit à délivrer le possédé. Un autre cas intéressant, dont l'auteur fut témoin, est celui d'une jeune fille Leng dont la possession par l'esprit-lion se manifesta par de spectaculaires crises d'hystérie. La guérison vint lorsqu'on se souvint qu'on avait négligé de consacrer, comme il se doit, une vache à l'esprit totémique et que réparation fut faite et, qu'en outre, la famille de l'intéressée offrit un mouton en sacrifice.

Passons aux aspects fonctionnels du totémisme nuer. Le clan Gaanwar " respecte " deux totems végétaux, le tamarinier et l'arbre nyuot (cordia rotbii), ce dernier ayant pour caractéristique de garder ses feuilles humides même en saison sèche. Pour cette raison, une branche de nyuot, posée dans la maison d'anciens du clan, sert d'autel pour des invocations et des sacrifices destinés à implorer la pluie, c'est-à-dire un bienfait pour tout le monde. Il existe des clans et des lignages qui ont pour totems des petits cours d'eau et des rivières. On raconte qu'un de ces lignages fut contraint jadis de fournir une fiancée à l'esprit de la rivière Nyanding, son totem, et qu'il s'acquitta de cette obligation en noyant une jeune fille qui donna son nom à la rivière. Mais Nyanding ne mourut pas noyée, elle devint une partie de l'esprit de la rivière et jusqu'aujourd'hui les anciens de son lignage ont l'obligation de lui sacrifier régulièrement une chèvre en la précipitant dans l'eau. Outre ce rite lignager, ceux-ci ont aussi pour tâche de protéger les hommes d'autres clans qui organisent d'importantes campagnes de pêche dans cette rivière, en déposant bracelets et coquillages dans la boue de son lit. Mais en l'occurrence, la fonction protectrice contre les dangers de l'eau n'est pas leur exclusivité ; les clans ou les lignages qui ont le crocodile pour totem doivent naturellement, si l'on peut dire, faire le nécessaire, par des invocations et des rites 
magiques, pour que les représentants de l'espèce éponyme qui infestent certains cours d'eau se montrent inoffensifs vis-à-vis des personnes qui y pêchent ou qui ont seulement à les traverser. C'est évidemment le lien rituel effectif que chaque segment de la société entretient avec son esprit totem, qui le rend apte à rendre de tels services aux autres. Mais le caractère fonctionnel du totémisme nuer ne constitue pas un trait central du système et nous y verrions plutôt comme une sorte de bénéfice secondaire qui échoit à la société qui pallie ainsi les effets du principe de segmentarité qui est au fondement de son organisation. Ce principe, nous dit Evans-Pritchard, oblige les Nuer à concevoir l'Esprit, Dieu (et nous savons à quel point il insiste sur l'idée de son unité et de sa souveraineté), comme " brisé " en de multiples réfractions correspondant aux espritstotems que les clans ou les lignages reconnaissent comme leurs. Nous rencontrons là une des difficultés de la pensée de notre auteur et nous voudrions nous arrêter un moment pour essayer de comprendre le véritable acharnement dont il fait preuve pour " sauver " son argument de l'Un et du Multiple. Disons tout de suite que si l'on prend à la lettre ses énoncés sur le parallélisme entre la segmentation au niveau des esprits totémiques et la segmentation sociale au niveau des clans et des lignages, on ne peut manquer de lui objecter que les notions de multiplicité et d'unité ne sauraient avoir le même sens, la même portée, dans le domaine de l'organisation sociale et dans la sphère de l'Esprit. D'un point de vue sociologique, l'unité de la société est une abstraction forgée pour les besoins de l'analyse (ou bien un thème idéologique répondant aux nécessités politiques d'un groupe ou d'un leader parlant ou prétendant parler en son nom) ; mieux que quiconque, le théoricien des structures segmentaires propres aux Nuer comme à de nombreuses autres populations nilotiques (Evans-Pritchard, 1940) a montré qu'il n'existe dans ces sociétés que des unités relatives à un niveau de segmentation et donc des unités relationnelles et jamais une unité une qui soit une totalité. Il en va tout autrement sur le plan religieux (et quasiment théologique dans l'optique adoptée dans Nuer religion) où l'Unité appartient à l'essence même du concept d'esprit en tant qu'il diffère (de) et s'oppose à toutes ses manifestations particulières (ou affirmées siennes) que sont les esprits d'en haut qui ne se font connaître que par des signes et les esprits-totems qui se matérialisent en des espèces vivantes ou des objets. 
C'est dans le chapitre V de Nuer Religion intitulé " Le problème des symboles " que la démarche que nous ne pouvons qualifier autrement que de spiritualiste est menée à son terme. Suivons-en les principales étapes. Première question : que veut dire un Nuer quand il dit que ceci " est " Esprit ou Dieu (e kwoth) ? ou que Dieu ou Esprit " est " ceci ou cela ? L'analyse des énoncés nous montre que les prédicats sont des métaphores: Dieu est invisible et omniprésent comme l'air et le vent, il est grand comme le vaste monde qui nous entoure et grandiose comme les plus belles cornes de vache, etc. Cependant, il est certaines choses dont on peut dire qu'elles « sont "Dieu, telles, par exemple, la pluie, l'éclair, la peste et la mort qui ont en commun de mettre en action des forces qui affectent tous les hommes dans leurs conditions de vie et leur condition de mortels. $n$ est clair que dans ces énoncés, le verbe " être " n'a pas le même sens que dans celui où le Nuer affirme que le crocodile est l'esprit-totem de tel lignage, le lion de tel autre, etc. Quelle est cette différence de sens, peut-elle vraiment être pensée en référence à une ontologie telle qu'elle a été élaborée dans la philosophie occidentale ? On sent bien qu'Evans-Pritchard est tenté de répondre par l'affirmative, mais qu'il bute précisément sur l'inadéquation du discours et du vocabulaire ontologiques pour décrire avec fidélité ce qu'il saisit de la pensée des Nuer. Il hésite entre un dualisme de la matière et de l'immatériel et un dualisme du naturel et du surnaturel et finit par renoncer à attribuer aux Nuer toute idée abstraite de dualité pour nous proposer ceci : " Quand un Nuer dit que la pluie ou l'éclair est Dieu, il parle de façon elliptique. Ce qu'il entend par là n'est pas que la chose en elle-même est Esprit mais qu'elle est ce que nous appellerions un médium ou une manifestation ou un signe de l'activité divine en relation avec les hommes et porteuse de signification (of significance) pour eux. " (Evans-Pritchard, 1956 : 125). II faut ici insister sur le fait que la signification a une portée universelle, qu'elle concerne tous les êtres humains alors que le totem crocodile n'est esprit (c'est-à-dire puissante agissante) que pour le clan ou le lignage éponyme. Encore faut-il préciser, comme l'attestent les aspects fonctionnels du totémisme mentionnés plus haut, que nombreux sont les totems qui ont, par la force des choses, une signification concrète pour tout le monde. Mais la question demeure et l'auteur la formule ainsi : "Comment une chose que nous voyons peut-elle être quelque chose de 
plus que ce qu'elle apparaît être ?" C'est pour y répondre qu'il avance l'argument des jumeaux que nous résumons ainsi : d'une part, les jumeaux ne sont pas deux mais une seule personne (cette affirmation mise en acte par le rituel - dans les funérailles, en particulier - suppose une démarche intellectuelle fort complexe puisqu'elle contredit les données des sens) et, d'autre part, ils ne sont pas des personnes mais des oiseaux. Il s'agit là d'un argument a fortiori : on pourra mieux comprendre ce que veut dire qu'un crocodile (être visible) est un esprit (entité invisible) si l'on comprend comment des jumeaux (visibles) peuvent être des oiseaux (tout aussi visibles). Le raisonnement implicite, semble-t-il, est que l'opération de l'esprit grâce à laquelle l'homme établit une identité entre des objets distincts du monde phénoménal (ce qu'il fait en contrariant là aussi l'expérience sensible immédiate) constitue une abstraction plus forte que celle par laquelle il identifie un objet concret à un référent abstrait (ce qu'il fait sans contredire le principe d'identité, en subsumant un objet perçu sous un concept). Que les jumeaux soient des oiseaux, cela est dit par les attitudes qu'adoptent vis-à-vis d'eux les Nuer et surtout par les rites qu'ils accomplissent. Les jumeaux " respectent " les oiseaux, il leur est strictement interdit de les chasser aussi bien que de manger les cufs. Si l'un des jumeaux meurt en bas âge, l'on dit qu'il s'est envolé et l'on place son corps dans un panier que l'on dépose sur un arbre, séjour habituel des oiseaux. Un adulte est déposé sur une plateforme et son cadavre est recouvert de peaux de bœuf tandis que son âme s'envole dans le ciel comme un oiseau. Réciproquement, les oiseaux respectent les jumeaux et même les charognards évitent de s'attaquer à leur cadavre. Comment expliquer cette assimilation? On invoque une "ressemblance " considérée comme essentielle : le fait de la naissance multiple, mais cela est peu satisfaisant puisqu'il existe de nombreuses espèces de mammifères également multipares. Plus importante est l'idée de leur commune association au domaine céleste qui conduit à dire que jumeaux et oiseaux sont les uns et les autres " enfants de Dieu ". Nous n'avons donc pas affaire à une relation dyadique qui resterait pour nous une pure énigme mais à une relation triadique dans laquelle c'est Dieu, le troisième terme qui rend intelligible la relation entre les deux autres. Cette façon de voir les choses nous ramène au totémisme que nous semblions quelque peu perdre de vue. On se souvient, en effet, que 
l'association d'un clan à tel animal est imputée à une naissance gémellaire d'un humain et d'un représentant de l'espèce éponyme. Un événement extraordinaire de cette nature est par lui-même, nous dit Evans-Pritchard, une manifestation directe de l'Esprit. Il y a donc dans toute relation totémique, comme dans celle entre jumeaux et oiseaux, une triade. $\mathrm{Si}$ cette dernière relation était fondée sur une ressemblance perceptible, même ténue, entre ces deux catégories d'êtres, avec le totémisme nous passons de "l'observation de ressemblances à la pensée au moyen de symboles". Ceci dit, nous nous souvenons également que dans la naissance gémellaire à l'origine de la relation, il était déjà question de ressemblance mais sous les espèces de la monstruosité (telle malformation d'un nouveau-né évoquant telle forme animale) qui est par elle-même une théophanie. On a, en fin de compte, le sentiment de tourner un peu en rond et c'est au moment où l'auteur reconnaît lui-même que sa démarche $n$ 'est pas très concluante qu'il nous livre une réflexion à laquelle nous pouvons pleinement souscrire pour autant qu'elle ouvre une piste extrêmement prometteuse. Après avoir dit et redit que " dans le système de pensée religieuse des Nuer les choses ne sont pas simplement ce qu'elles semblent être mais sont telles qu'ils les conçoivent en relation avec Dieu ", il se tourne vers l'imaginaire " où l'esprit humain (mind) se meut au milieu de figures, symboles, métaphores, analogies et maintes créations du langage et de la fantaisie poétique ". Avec juste raison il rattache l'incompréhension qu'ont montrée les observateurs européens qui ont voulu expliquer des faits tels que le totémisme, ou plus généralement, les croyances et les rites de peuples tels les Nuer ou d'autres, à la méconnaissance de cette dimension poétique de leur rapport au monde (vis-à-vis de leur bétail, des espèces sauvages, des arbres, des fleuves, des objets éminemment symboliques tels leurs lances ou bien encore d'humbles ustensiles, etc.) qui s'exprime dans des hymnes, des chants, des prières, des invocations, des devises et jeux verbaux de toutes sortes. La solution du problème que soulève le totémisme a incontestablement à voir avec le pouvoir de symbolisation ainsi qu'avec la puissance poétique qui sont le propre du langage, mais encore faut-il mettre en évidence la spécificité de l'application de ce pouvoir et de cette puissance à la mise en forme de la division de la population en groupes distincts constitutive de l'ordre social. La solution se trouve-t-elle dans l'analyse célèbre (et, à première 
vue, très élogieuse pour notre auteur) que Lévi-Strauss donna du passage consacré à la relation entre jumeaux et oiseaux. Résumons-la aussi succinctement que possible. Entre jumeaux et oiseaux, il ne s'agit ni d'êtres qui se confondent ni même d'êtres qui se ressemblent mais de rapports qui s'établissent à la suite " d'une série d'enchaînements logiques unissant des rapports mentaux " (Lévi-Strauss, 1962a : 116). Le raisonnement met en relation quatre termes de la manière suivante : comme hommes, les jumeaux sont des personnes d'en haut car ils sont comme les oiseaux " enfants de dieu " donc " célestes " et s'opposent du même coup aux personnes d'en bas; comme oiseaux, ils sont des oiseaux d'en bas (parmi les noms qu'on leur donne, on rencontre souvent celui de la pintade et du francolin qui sont des gallinacés qui volent à peine et sont quasiment "terrestres ") et s'opposent en conséquence aux oiseaux d'en haut. Ainsi, le grand mérite d'Evans-Pritchard est-il d'avoir fait avancer la réflexion théorique des ethnologues sur les représentations dites totémiques, en passant du point de vue de "l'analogie externe à l'homologie interne" (loc. cit. : 112). Quant au rôle du troisième terme, l'Esprit, la divinité suprême, il est superflu car il est particulier aux Nuer. L'exemple des Kwakiutl d'Amérique du Nord qui n'ont pas de croyances théologiques de ce genre mais partagent les mêmes idées sur les rapports entre jumeaux et saumons, prouve bien qu'il s'agit d'une " démarche fondée sur un principe plus général " (ibid. 116). L'analyse est élégante mais les données nuer, sous la plume de Lévi-Strauss (comme cela est normal dans un ouvrage de ce type), apparaissent plus comme un prétexte pour avancer vers sa propre solution (ou dissolution) structuraliste de la question du totémisme que comme un objet à examiner en lui-même, ou du moins, au travers du texte que lui consacre Evans-Pritchard et dont nous venons de voir quelles difficultés il soulève ${ }^{7}$. Mais d'un point de vue formel

7 Nous ne pouvons manquer de faire observer au lecteur que Lévi-Strauss nous donne ici l'impression de mettre sur le même plan la relation jumeaux-oiseaux qui a, pour Evans-Pritchard, valeur d'argument logique destiné à nous faire entrer dans un mode de pensée qui trouve une illustration particulière dans le totémisme des Nuer et les faits totémiques proprement dits qui concernent les clans et les lignages mais non pas les individus. Il est vrai qu'Evans-Pritchard parle "d'esprit totémistique " lorsqu'il s'agit d'un rapport personnel entre un esprit et un homme qui s'est trouvé, dans des circonstances extraordinaires, saisi et temporairement lié à un animal particulier. Mais, en ce cas précisément, la gémellité n'est pas en cause. 
seulement, on peut lui objecter qu'il ne réussit pas à évacuer l'Esprit car le moyen terme autour duquel tourne la relation entre jumeaux et oiseaux est la notion de hauteur dont la place est finalement la même que celle de Dieu ou l'Esprit. En effet, l'opposition entre le haut et le bas, qu'elle s'applique aux personnes ou au oiseaux, n'est pas symétrique mais hiérarchique : le bas est borné par la surface de la terre, le haut est la détermination d'une position sur un axe vertical s'élevant vers l'infini et qui rejoint la notion d'Être suprême. Le haut est donc haut non seulement par rapport au bas mais par rapport à une hauteur toujours plus élevée. Nous en concluons que la solution structuraliste, qualifiée aussi, en l'occurrence, d'intellectualiste par Lévi-Strauss lui-même, n'est pas plus satisfaisante que la solution que l'on pourrait qualifier de " spiritualiste " à laquelle Evans-Pritchard s'est efforcé de tenir. Notre position critique est proche de celle de l'ethnologue océaniste R. Firth dont les matériaux tikopia avaient également retenu l'attention de LéviStrauss (1962 a). Dans un article intitulé " Twins, Birds and Vegetables : Problems of identification in primitive religious thought "(Man, 1966), il revient sur la question du totémisme dans la perspective théorique qu'indique clairement ce titre si évocateur de la problématique de LévyBruhl et il le fait en réexaminant avec minutie l'argument des jumeaux. Nous résumerons sa réponse en disant qu'il se tient également à distance de l'intellectualisme soutenu dans Le totémisme aujourd'bui et du spiritualisme de Nuer Religion. Sans chercher à polémiquer avec son collègue africaniste (mais celui-ci, piqué au vif, lui répondra néanmoins vertement dans la livraison suivante de Man), Firth nous fait clairement comprendre son point de vue en comparant Nuer et Tikopia de la manière suivante :

"Les Tikopia, qui ont un système politique développé de lignages, de clans et de chefs allant de pair avec une organisation sociale nettement hiérarchique et une autorité centralisée quoique partagée, possèdent également un système religieux tout aussi nettement composé d'esprits individuels organisés d'une façon hiérarchique pour ainsi dire parallèle. Ils n'ont pas le concept holiste d'une entité spirituelle englobante qui serait une et qui pourrait être appelée dieu sans autre qualification. "

Et notre auteur conclut par cette remarque à laquelle notre propre critique adressée à la notion d'Être suprême fait écho : " Evans-Pritchard 
attribue les réfractions des esprits au caractère segmentaire de l'ordre social nuer, mais trouve un concept unitaire d'Esprit dans une relation plutôt vague de ces diverses réfractions à la nature et à l'homme en général. Dans la mesure où les Nuer n'ont pas de système politique centralisé, le passage de ces réfractions au concept unitaire d'Esprit suppose un abandon des notions spécifiques de segmentation au profit d'une notion générale d'unité culturelle ". Il vaudrait la peine d'insister sur certaines idées exposées par Firth dans cet article extrêmement dense mais nous ne pouvons ici abandonner trop longtemps notre cheminement africain ; il nous faut donc examiner maintenant comment Lienhardt analyse les données qu'il a recueillies chez les Dinka d'où proviennent, nous l'avons vu, un certain nombre des totems nuer.

On se souvient qu'il bannit le mot totem (qu'il utilisait dans ses textes antérieurs) pour se conformer à la définition frazérienne qui exige qu'à l'entité totémique soit toujours associé un emblème correspondant à une espèce réellement existante. Dans la mesure où tel n'est pas le cas chez les Dinka, il emploie l'expression " divinité de clan " qu'il oppose à celle de " divinité libre ", opposition qui recoupe celle que font les Nuer entre esprits d'en haut et esprits d'en bas. "Les divinités libres " sont donc associées à des individus auxquels elles se manifestent et dont elles se font connaitre par les maladies qu'elles provoquent en eux ou dans les rêves qu'elles leur inspirent ; ceux-ci en sont possédés et c'est par leur bouche que les puissances " parlent ". Dans certains cas, on aura affaire à des prophètes, dans d'autres, à des devins ou à des féticheurs capables éventuellement de guérir telle maladie ou d'éloigner telle calamité.

Des divinités de clan dinka, on ne saurait dire qu'elles sont de rang inférieur par rapport aux précédentes. On va voir que Lienhardt, qui lui aussi analyse les rapports entre l'Être suprême (qu'il désigne comme la " divinité en elle-même ") et les divinités libres en référence à la problématique de l'Un et du Multiple, s'écarte de la démarche d'Evans-Pritchard lorsqu'il étudie ce que ce dernier, et nous à sa suite, appelons totémisme. Alors que les esprits d'en bas nuer sont tous, si l'on ose dire, placés sur le même plan, c'est la différence de puissance entre les totems qui caractérise le système dinka. Ce trait est à rattacher au fait qu'il existe deux catégories de clans: les bany, ceux qui exercent des fonctions rituelles particulières, une sorte de prêtrise, dirons-nous, et dont le symbole est la 
lance sacrée de pêche, et les kic qui sont les clans du commun, ceux qui fournissent les guerriers. Chacune des tribus dinka comprend plusieurs clans de prêtrise parmi lesquels un sous-clan qui a pour prérogative la maitrise de la terre et un autre celle de détenir la fonction de " maître de la lance de pêche ", et plusieurs clans guerriers dont l'un des sous-clans détient la fonction de maître de la guerre. Ces deux dignitaires tribaux sont dans un rapport d'oncle à neveu utérin, la position aînée et donc prééminente étant évidemment dévolue au " maître de la lance de pêche ".

Les objets totémiques ou, pour parler le langage de Lienhardt, les emblèmes des divinités claniques, sont des plus variés : le lion auquel est associé la grande fourmilière, son lieu de prédilection; la girafe, liée au hérisson ; l'hippopotame, l'éléphant et le chacal. Plusieurs variétés de serpents et de lézards; le poisson-chat qui est associé à la pluie qu'il est censé aller chercher au ciel ; l'huître d'eau douce et arec, " une petite chose dans la rivière qu'aucun homme n'a jamais vue ". Différentes sortes d'oiseaux, d'insectes et d'arbres; des éléments comme l'eau et le feu auquel se rattache la Chair; Vénus et les comètes ; certaines herbes dont on fait les anneaux de portage sur la tête. 11 y a aussi des parties du corps : la cuisse et le fémur liés à la Chair ; des objets usuels tels le pilon, la gourde et l'anneau de portage évoqué à l'instant et enfin, des objets européens censés être des entités totémiques pour les Blancs : camion, papier et machine à écrire - n'est-ce pas là ce que vous ont transmis vos ancêtres, disent les Dinka.

Comme chez les Nuer, c'est le lien de gémellité qui est au fondement de la relation entre le clan et l'espèce animale qui lui sert d'emblème totémique. Mais les mythes dinka disent aussi d'autres choses et il est intéressant d'en rapporter quelques-uns. Seligman (1911) à qui nous les empruntons, fait cette observation de portée générale que de nombreux récits ayant trait aux ancêtres-animaux renvoient à une époque où les hommes et les animaux, après avoir été longtemps associés par leurs groupes de filiation respectifs, ont commencé à se séparer. Cette séparation consommée, il était bon (et l'on peut considérer cela comme une raison d'être du totémisme) que les hommes sachent quels animaux leur étaient spécialement associés en fonction de leur clan. Voici, par exemple, l'un de ces récits : il y a très longtemps, une femme était étendue sur le sol et dormait lorsque soudain une hyène surgit et bondit sur elle. 
Certains des proches de la femme s'apprêtaient à tuer l'animal mais d'autres les retinrent en faisant valoir que cet animal devait avoir de bonnes raisons pour agir de cette façon. Quand le fils qui naquit de cette union se mit à marcher, on s'aperçut qu'il présentait une légère claudication qui rappelait la démarche de l'hyène. On lui donna le nom de Den (hyène) qui devint la divinité clanique de ses descendants. Notons encore un autre trait remarquable du totémisme dinka : certains clans revendiquent une association non pas avec une espèce animale ou végétale mais avec des humains possédant des attributs supra ou non humains. Ainsi, il y a bien longtemps, des gens appartenant au «monde de la rivière " décidèrent de sortir de l'eau pour aller se marier et s'installer dans les villages des environs. La description de leur sortie de l'eau, écrit Seligman, évoque une naissance : la rivière devient extrêmement agitée et les eaux s'élèvent autour d'un être humain dont le cordon ombilical le rattache à un objet plat reposant sur le fond. Lorsque le cordon a été coupé, des boufs sont immolés et précipités dans la rivière, puis l'on conduit au village l'homme ou la femme tiré des eaux. Les descendants de ces êtres aquatiques, les gens du clan Faiyer, font jusqu'aujourd'hui des sacrifices sur le bord de cette rivière où ils viennent jeter une vache vivante après lui avoir donné à boire un pot de lait dans lequel des anciens ont craché. Un autre petit mythe, qui n'est pas exactement de la même eau, dirais-je, donne aussi à penser et à .. rêver : c'était dans des temps reculés, des jeunes gens s'amusaient au bord d'une rivière quand apparut une fille très belle nommée Alek, portée par l'eau jusqu'au rivage. Elle consentit à suivre les garçons jusqu'au village mais quand ceux-ci essayèrent de la toucher, elle se transforma en eau. Les villageois " la " ramenèrent à la rivière en emmenant avec eux des bœufs et des vaches qu'ils sacrifièrent à la rivière. Alors la jeune fille disparut dans l'eau emportant un veau avec elle. C'est pourquoi, à la fin de la saison des pluies, les gens du clan Boweng qui ont cette rivière pour totem y emmènent une vache, un veau et un bœuf ; ce dernier est immolé et sa chair consommée tandis que la vache et le veau sont précipités vivants dans la rivière qui les emporte et les ramène à l'état liquide comme ce fut le cas de la jeune fille.

L'attitude fondamentale exigée des hommes en présence des emblèmes éponymes de leur divinité de clan est celle du respect, thek, qui 
caractérise également les rapports vis-à-vis des aînés, de la belle-mère et des femmes menstruées qu'il faut éviter autant que possible. La pire des choses est de se trouver au contact du sang de son animal totémique, ce qui peut entraîner la stérilité, la cécité ou encore une grave maladie de peau appelée akeeth, mot qui signifie inceste. Akeeth est aussi la conséquence d'un contact avec le sang de l'oncle maternel, c'est-à-dire l'homme qui représente le groupe dont provient ma mère. En dehors de ces cas extrêmes, les règles d'observance du respect totémique sont peu contraignantes, quelques signes suffisent : éviter, par exemple, de marcher sur l'herbe avec laquelle on confectionne l'anneau de portage (ou de la brûler), ne pas briser le fémur quand on appartient au clan éponyme, etc. Concomitante de ces évitements et de ces interdits, qui traduisent l'aspect négatif du respect, est l'obligation de faire des sacrifices (dont les mythes totémiques que nous avons relatés ont montré toute l'importance) et de réserver certaines parts de l'animal immolé à l'autel de la divinité clanique. Ses emblèmes, c'est-à-dire chacun des spécimens de l'espèce totémique, ont le statut de membres du clan et l'espèce représente les pères, les ancêtres, donc la divinité elle-même, nous dit Lienhardt. Une autre expression symbolique de ces attitudes apparaît dans l'idée que les membres d'un même clan se joignent, vont ensemble avec leur divinité clanique; ce sont ces mots là que les Dinka emploient pour dire que les hommes se rassemblent et partent venger le sang versé de l'un des leurs. C'est leur façon d'indiquer que les liens de parenté agnatique qui les unissent entre eux, les unissent à leurs totems. Les personnes qui comme telles se différencient en tant qu'individus ou par leur appartenance à une unité familiale sont, en tant que membres d'un clan, des êtres indifférenciés comme apparaissent indifférenciés les individus d'une même espèce. Mais dans sa relation à la divinité clanique symbolisant l'Ancêtre commun, cette pure multiplicité se fond en une Unité qui transcende les divisions et les oppositions intérieures au clan et constitue pour ses membres la source de vie et de fécondité. C'est à cette source, à cette puissance de reproduction, que sont destinés les offrandes et les sacrifices. Lienhardt note au passage que c'est là la raison pour laquelle les animaux réservés aux sacrifices de type totémique doivent être non castrés : en effet, leurs organes génitaux font l'objet d'un rituel complexe au terme duquel ils sont découpés, les testicules 
étant mangés par des vieilles femmes et par des maîtres de la lance de pêche dont l'un s'approprie le pénis pour s'en faire un collier après l'avoir fendu, séché et torsadé. Le cheptel bovin d'où proviennent ces animaux sacrificiels constitue aussi l'essentiel des richesses qui circulent sous forme de compensation matrimoniale et c'est pourquoi les Dinka établissent une relation d'équivalence entre ces deux grandes fonctions du bétail qui permettent aux hommes d'accomplir leur devoir en acquittant les paiements nécessaires pour que la vie se perpétue. Ainsi peut-on, dans certains cas extrêmes, utiliser le bétail consacré à la divinité de clan comme paiement du prix de la fiancée bien que, comme l'expliquent les Dinka, cette consécration soit à prendre au sens le plus littéral du terme, c'est-à-dire comme un rapport de participation de l'animal à la divinité. Il y a donc bien plus qu'une simple analogie dans l'attitude de respect qu'il convient d'observer tant à l'égard de sa divinité de clan que vis-à-vis de ses beaux-parents et de son oncle utérin, représentants du clan donneur d'épouse. Comparant les aspects mystiques et rituels des totems des Dinka avec ceux des Tallensi, M. Fortes (1966:19, note) écrit : " les emblèmes dinka semblent représenter, beaucoup plus immédiatement que les objets totémiques tallensi, des agents personnifiés du pouvoir mystique attaché aux groupes de filiation agnatique ". Arrêtons-nous quelques instants sur ce rapprochement qui ne va pas de soi entre les faits dinka et tallensi car nous avons affaire à deux sociétés fort différentes par leur mode de vie, leurs structures économiques, leur organisation sociale et leurs institutions politiques. Pourtant, Fortes $(1966,13)$ n'hésite pas à affirmer que la ressemblance entre leurs institutions totémiques est tout à fait évidente ("[ ] needs no labouring ", écrit-il) et il ajoute que les interprétations que Lienhardt et lui-même proposent de leurs données respectives sont " congruentes ". Dans la note déjà citée, il précise : " Dans la mesure où les divinités de clan dinka font l'objet d'un culte et qu'on leur adresse des sacrifices, ils ont des qualités rituelles et mystiques apparentées à celles que les Tallensi attribuent à ceux de leurs ancêtres qu'ils vénèrent ". Nous dirions, quant à nous, que Fortes a tendance ici à forcer ce rapprochement parce qu'il conforte, à ses yeux, sa thèse sur la primauté du point de vue de l'acteur et du sujet dans son rapport à l'objet totémique, thèse qu'il oppose au point de vue structuraliste de Lévi-Strauss qui, selon lui, prévilégierait le message. Mais nous avons là 
un joli paradoxe, si l'on songe que ce dernier avait utilisé les analyses de Fortes pour conduire son lecteur "vers l'intellect " et ainsi, vers le terme de sa critique des conceptions fonctionnalistes du totémisme. Nous ne pensons pas que cette façon de comparer des sociétés aussi éloignées que ces Nilotiques et ces Voltaïques soit tout à fait convaincante. On ferait un parallèle plus satisfaisant en disant qu'il y a, d'une part, chez les Dinka, un totémisme emblématique du type segmentaire consistant dans un culte clanique ayant pour objet les valeurs attachées à la filiation agnatique et, d'autre part, chez les Tallensi, un totémisme métaphorique ${ }^{8}$ appuyé sur des récits relatant comment, dans des circonstances particulières, tel animal s'est montré secourable pour l'ancêtre qui, du coup, l'a érigé en symbole à respecter, pour tous ses descendants. Ces récits comportent une sorte de raisonnement dont l'énoncé est le suivant : l'interdit (alimentaire ou autre) est la conséquence d'un vœu formulé par un ancêtre pour marquer sa reconnaissance à un être qui lui a rendu un service. Ce service est expliqué par un détail de l'anatomie ou du comportement de l'animal en question. L'interdit totémique, symbole du respect que doivent les membres du clan à leur aïeul à travers l'animal qui l'a secouru, est ainsi directement articulé avec le culte des ancêtres qui n'est pas seulement un culte lignager mais un culte communautaire adressé aux autels de la Terre. Nous avons donc ici à tenir compte d'une dimension territoriale, opposée et complémentaire de la dimension lignagère (ce trait est commun à toute l'aire culturelle voltaïque) qui met en rapport les symboles totémiques non pas avec un seul clan mais avec plusieurs formant congrégation. Celle-ci est associée à ce que les Tallensi appellent le bosquet sacré extérieur (" external bogar" dont les interdits spécifiques sont de grands reptiles) qui se distingue du " bogar de la chambre ", autel consacré aux ancêtres lignagers exclusivement. L'imbrication du totémisme avec le culte des ancêtres et celui de la Terre se fait ainsi à

${ }^{8}$ Une manière d'opposer le caractère emblématique au caractère métaphorique du symbole totémique est de voir dans l'emblème un signe plutôt arbitraire par rapport au référent (les espèces totémiques sont sans rapport particulier avec les ancêtres du clan dont ils sont les éponymes) et dans la métaphore, un signe fortement motivé soit par le récit, soit par des propriétés attribuées aux deux termes (les crocs des fauves évoquent l'agressivité des ancêtres) soit, enfin, par une propriété générale telle que l'aspect chthonien de certains grands reptiles. 
plusieurs niveaux et met en jeu des rapports hiérarchiques entre ces niveaux. Nous ne pouvons guère ici nous étendre sur les problèmes complexes que soulève cette imbrication; nous tenons cependant à signaler l'attitude de réserve adoptée vis-à-vis du point de vue de M. Fortes par Danouta Liberski (1993), notre collègue spécialiste des Kasena, population du Burkina Faso appartenant à l'aire culturelle voltaïque et, à bien des égards, très proche des Tallensi. Dans un exposé remarquable consacré à ce sujet, cette ethnologue examine la notion de bogar externe qu'elle rapproche de la notion kasena de " peau de la terre". Observant qu'il est difficile de réduire le culte adressé à cette instance à un culte des ancêtres, voire de l'ancestralité dans son sens le plus large, le plus englobant, elle nous dit ceci : " Aussi quand on fait un sacrifice à un bogar externe, l'officiant va invoquer tous les bogar du pays tallensi en les énumérant par leur nom car ils possèdent un nom propre, comme les peaux de la terre, pour les interpeller et pour que le sacrifice qu'il fait à un bogar particulier atteigne tous les bogar tallensi. On est donc dans quelque chose de très différent du culte des ancêtres. D'autant que c'est ce culte au bogar, en ce même lieu, c'est cette même puissance, qui attire annuellement en pays tallensi, des milliers de pèlerins venant se mettre sous la protection de tel ou tel bogar externe ". Est-il possible de mettre en évidence, dans cette imbrication de l'ancestralité, du totémisme et du culte rendu à la terre, des rapports de hiérarchie entre ces instances ? Nous verrons plus loin que ce r'est pas M. Fortes lui-même mais l'un de ses commentateurs, I. Karp, qui a essayé de comprendre d'un point de vue totémique, les relations de hiérarchie et de complémentarité qui unissent et opposent les Talis, les clans de la terre, aux Namoos, groupe aristocratique issu du clan fondateur du royaume mamprusi de Gambaga. Mais revenons dans la zone nilotique et voyons maintenant ce qu'il en est des niveaux hiérarchiques dans le système totémique des Dinka.

Les divinités de clan les plus puissantes, nous l'avons vu, sont celles des clans maîtres de la lance de pêche. Ce sont ces maîtres et non les hommes possédés par des " divinités libres " qui sont les médiateurs autorisés entre la Divinité suprême et les tribus et sous-tribus qu'ils représentent. Leur divinité de clan qui n'appartient qu'à eux seuls (alors que des clans différents à travers le pays dinka peuvent partager le même emblème totémique) s'appelle Chair, ring. La chair, comme totem, 
renvoie, selon Lienhardt, à l'idée de vie qui continue après la mise à mort, idée attachée à l'image impressionnante de la palpitation des chairs, des mouvements convulsifs qui agitent encore le corps de l'animal qui vient d'être immolé et dont on retire la peau. La Chair est associée au feu, à la lumière et à la couleur rouge ; l'un de ses emblèmes est un petit serpent inoffensif de cette couleur, un autre, l'on peut s'en étonner, est le corps même d'un nouveau-né au teint très clair, tirant vers le rouge. Mais les plus emblématiques de ces représentants de la divinité clanique ne sont autres que la chair réelle et le sang d'un homme, et plus particulièrement d'un maître de la lance de pêche. Pour ce dernier, il existe un rituel où l'on "nourrit " la chair de son corps. Il s'agit d'une cérémonie nocturne où l'on accomplit un sacrifice (normalement les sacrifices ne peuvent pas avoir lieu pendant la nuit) après lequel il consomme de façon très solennelle des morceaux de viande crue de l'animal immolé. Ainsi, les maîtres de la lance du clan Paghol qui ont Cuisse et Fémur comme principaux emblèmes doivent-ils manger trois (chiffre mâle) morceaux de viande crue qu'ils mordent dans la cuisse. En mentionnant ce fait, G. Lienhardt va jusqu'à dire que le prêtre du clan Chair "mange sa divinité de clan " et évoque à ce propos la fameuse thèse de Robertson Smith qui provoqua les polémiques que l'on sait. Il poursuit sa réflexion en observant que ce qui nous apparait comme formel et extérieur dans les attitudes de respect et d'évitement qu'adoptent communément les autres hommes vis-à-vis de leur divinité de clan, se révèle, en ce cas, comme une authentique expérience intérieure des maîtres de la lance de pêche dans leur relation à Chair. Tandis qu'entre les hommes d'un clan et leur emblème totémique, c'est une relation d'extériorité qui prévaut, pour les hommes du clan Chair, leur divinité est au dedans d'eux-mêmes. La description qui nous est donnée d'un sacrifice destiné à favoriser la guérison d'un maître de la lance de pêche (Lienhardt, 1961 : 137) nous pousserait même à parler d'une forme de transe sinon de possession. $\mathrm{Au}$ cours de ce rituel auquel il a assisté, les sacrificateurs du clan faisaient des invocations en direction d'un taurillon qu'ils allaient égorger. À mesure que les invocations étaient proférées (dans lesquelles le sacrifiant doit scander ses prières à la Puissance en implorant de façon lancinante : "Vous Chair de mon père, vous divinité, vous allez faire quelque chose pour nous, vous allez travailler vous seul...), les hanches et les cuisses de 
certains maîtres de la lance étaient saisies de tressaillements et leurs jambes se mettaient à trembler de plus en plus violemment. C'est ainsi, disent les Dinka, que Chair se manifestait en eux ou plutôt, commençait à se " réveiller " dans leur corps dont il pouvait prendre entièrement possession. Une précision intéressante nous est apportée quand l'auteur se sent tenu de nous dire que cette possession par Chair n'est pas " hystérique " comme le serait celle par une " divinité libre"; on peut comprendre que la possession en tant que fait individuel et contingent n'est pas un phénomène du même ordre que la possession totémique qui répond à une nécessité institutionnelle et demeure donc, à ce titre, une manifestation contrôlée. Nous apprenons cependant, que lorsque les tremblements provoqués par Chair deviennent trop violents (hystériques ?), les femmes s'approchent des possédés pour leur donner leurs bracelets et leur baiser les mains.

Le lecteur se souvient que dans l'analyse des rites sacrificiels liés au totémisme nuer, Evans-Pritchard était, selon nous, embarrassé par ce qu'il désignait comme la question de l'Un et du Multiple. La vision que Lienhardt nous offre de l'univers religieux des Dinka, si proche à tant d'égards de celui des Nuer, nous semble éviter l'écueil d'un tel recours à une abstraction métaphysique sans prise sur le donné ethnographique. $C^{\prime}$ est dans la manière dont les rites eux-mêmes sont accomplis qu'il trouve la solution du problème de la cohérence et de l'unité du système de croyances et de pratiques religieuses propres à ces populations nilotiques. Dans la plupart des sacrifices qu'il a observés et des descriptions qu'il a obtenues de ses meilleurs informateurs, il apparait que les invocations et les prières que prononcent les maîtres de la lance de pêche ne sont, pour ainsi dire, jamais adressées à une Puissance unique exclusivement, mais aux trois catégories que distinguent les Dinka : la Divinité (le dieu suprême), l'une des grandes "divinités libres " dont le culte dépasse les limites du territoire tribal et qui inspire tel prophète célèbre et enfin la ou plutôt les divinités claniques qui intéressent les groupes sociaux au bénéfice desquels le rite est accompli. Lienhardt donne un exemple d'un tel sacrifice où il observa qu'en même temps et, il insiste sur ce point, "dans un acte unique ", un taureau marron-rouge fut immolé en l'honneur des totems Chair et kigelia africana (l'arbre vulgairement dénommé saucissonnier), tandis qu'un bœuf blanc et un bœuf 
noir étaient immolés en l'honneur de la Divinité céleste et de Deng, l'une des " divinités libres ", respectivement. La façon dont est opéré le partage de la viande des bovins égorgés, révèle plus profondément encore la nature unitaire de l'acte sacrificiel. Il s'agit alors autant de l'unité ordonnée du groupe social engagé dans le rite que de l'unité des destinataires divins symbolisée par l'animal lui-même. " Les gens sont mis ensemble, put together, (c'est-à-dire réunis, rassemblés en un tout) comme le taureau est mis ensemble (c'est-à-dire incarne par lui-même et en luimême cette unité) ", ainsi s'exprime un chef dinka désireux de faire comprendre à Lienhardt (loc. cit.: 23) ce qui se passe dans un sacrifice. C'est le statut de tout taureau, de tout bœuf, chez les Dinka, que d'être voué à un sacrifice et de représenter de ce fait même la communauté des personnes qui y prennent part, bien que, comme l'auteur prend soin de le préciser, "la manducation de sa chair ne constitue pas un repas communiel ou une communion mystique, selon le terme qui a été utilisé dans la littérature anthropologique " (il s'agit, bien entendu, d'une allusion à la célèbre analyse de Robertson Smith dans sa Religion of the Semites). Le code qui régit le partage et la consommation de la viande est de nature principalement sociologique et il est intéressant d'en indiquer deux des règles les plus significatives : la bosse dorsale du zébu, consacrée à la divinité de clan, est d'abord placée au pied de l'autel pour être ensuite mangée par la famille du sacrifiant, la partie considérée comme la plus noble de l'animal, la patte-arrière droite, est attribuée aux maternels. Cette réunion des paternels, éminemment symbolisés par le totem clanique, avec les maternels (c'est-à-dire les "donneurs d'épouses") est complétée par l'association à ces sacrifiants " primaires " des anciens de leur village et des gens du même campement de pasteurs. Il s'agit donc de quelque chose qui dépasse l'unité du groupe de filiation agnatique pour représenter une sorte de " totalité organique " contenant de façon ordonnée toutes les composantes de la société dinka, les hommes, les femmes, les différentes classes d'âge, les alliés et les voisins. Ainsi se trouve surmontée la difficulté du passage, si problématique dans la religion nuer telle qu'elle est vue par Evans-Pritchard, de la fragmentation de “l'esprit " dans le totémisme à l'unité ou plutôt, à l'unicité de l'Esprit dans la représentation de la Divinité suprême. Il ne s'agit nullement de réduire la conception que se fait Lienhardt de la religion dinka à un 
sociologisme pas plus que nous n'avons cherché à ramener celle d'EvansPritchard à un spiritualisme, bien qu'il ait eu un assez net penchant en ce sens tant il redoutait que leur "totémisme" ne fít ranger les Nuer dans la classe des sociétés primitives dépourvues d'une authentique idée du divin.

La grande question, celle que nous annoncions en commençant cette étude, est celle de la place du sacrifice dans l'ensemble des données que nous avons examinées, tant nuer que dinka. C'est en nous y attachant maintenant que nous serons en mesure, du moins nous l'espérons, d'évaluer l'apport de nos deux auteurs au débat décidément non encore clos du totémisme dans ses rapports avec la religion.

L'attitude de Lévi-Strauss, nous le savons, est tout à fait nette : la logique des classifications totémiques suppose qu'aux unités discrètes qui composent la société, correspondent des unités discrètes (des espèces) du monde naturel tandis que la logique du sacrifice ${ }^{9}$ est celle de la substitution qui implique un continuum entre les différents êtres susceptibles d'être élus au rôle de victimes (animaux, végétaux ou même humains) dont la fonction est d'établir une communication entre deux termes aussi éloignés l'un de l'autre qu'on voudra l'imaginer, l'homme et la divinité. Lévi-Strauss (s'appuyant là aussi sur un exemple emprunté à Nuer Religion) prend un malin plaisir à énumérer une petite série de substituts dans laquelle se mêlent des termes logiquement emboîtés et des termes

9 Rappelons qu'Alfred Loisy (1913), adversaire déclaré des idées de Durkheim, rejetait déjà catégoriquement tout rapport entre ces deux ordres de faits : " le sacrifice même n'est pas un élément du totémisme, et l'on pourrait dire que le totémisme comme tel exclut le sacrifice. " (cité par Van Gennep, 1920). Il est à noter, cependant, que dans Le totémisme aujourd'bui (pp. 37-38), Lévi-Strauss avait une position beaucoup moins tranchée sur ce point puisque un examen approfondi des données de R. Firth sur les Tikopia le conduit à reconnaitre que dans la culture de cette population on assiste à une projection du système classificatoire totémique sur le système sacrificiel qui constitue la religion des Tikopia. Une illustration tout à fait remarquable de cette relation nous est fournie par le traitement rituel que les Korokoro réservent à un dauphin échoué sur la plage, en raison d'une affinité spéciale existant entre cet animal et cette lignée du clan Tafua. Il s'agit d'un rite appelé " offrande sur le tombeau d'un mort récent". Après avoir " reçu " de la nourriture végétale fraîche, le dauphin est dépecé et la viande est partagée entre les clans. Les Korokoro ne peuvent y toucher car il est l'incarnation de leur atua, leur dieu clanique. 
sans rapport entre eux : " [...] en tant que victime sacrificielle, un concombre vaut un œuf, un œuf un poussin, un poussin une poule, une poule une chèvre, une chèvre un bœuf ". Assurément, quoiqu'en dise Durkheim, qui suit de très près sur ce point les idées de Robertson Smith, l'intichiuma que pratiquent certaines tribus australiennes n'est pas un sacrifice car ce rite de multiplication est confié précisément aux membres du clan dont la responsabilité est d'agir sur l'espèce à laquelle il est lié et dont il porte le nom, afin d'en faire bénéficier tous les autres clans. La relation clan-espèce totémique est, si l'on peut dire, donnée a priori et ce n'est pas au rite (même s'il comporte, ce dont Durkheim fait le plus grand cas, une effusion de sang que l'agent s'inflige à lui-même) qu'il revient de l'établir. Rien dans le schéma maussien auquel il se réfère implicitement ne permet, pense Lévi-Strauss (1962b : 296-97), d'identifier dans les descriptions qui nous sont fournies par les spécialistes de l'Australie le moindre élément constitutif d'un processus sacrificiel. Si cette affirmation nous paraît indiscutable, il n'en va pas de même lorsqu'il procède ensuite à des généralisations sur la nature du sacrifice dont on voit bien qu'elles relèvent chez lui tout autant sinon plus que d'un jugement de fait dont l'évaluation se veut purement intellectuelle, d'un jugement de valeur inavoué et qui n'est pas d'ailleurs sans provoquer chez beaucoup, et même chez les chercheurs qui se réclament de lui, un certain sentiment de malaise. C'est le cas quand on s'aperçoit que cette attitude le conduit, dans le célèbre finale de $L$ 'bomme nu, à une pure et simple dépréciation de la pratique rituelle comme telle. Mais dans La Pensée Sauvage on peut déjà lire ces propos dépourvus de toute indulgence : « Pour exprimer le décalage entre le totémisme et le sacrifice, il ne suffit donc pas de dire que le premier est un système de références, le second un système d'opérations; que l'un élabore un schème d'interprétation tandis que l'autre propose (ou croit proposer) une technique pour obtenir certains résultats : l'un est vrai, l'autre est faux. Plus exactement, les systèmes classificatoires se situent au niveau de la langue : ce sont des codes plus ou moins bien faits, mais toujours en vue d'exprimer des sens, tandis que le système du sacrifice représente un discours particulier, et dénué de bon sens quoiqu'il soit fréquemment proféré ". On nous accordera que nous sommes loin d'une analyse objective des rites sacrificiels tels que les pratiquent les sociétés africaines 
tant de l'Ouest que de l'Est et dont la structure complexe est aujourd'hui reconnue par tous les anthropologues ${ }^{10}$. Pas plus que l'on est en droit de penser, au niveau du code (c'est-à-dire des catégories sélectionnées), qui souvent s'exprime dans les termes d'un langage " codé " précisément (qui équivaudrait alors à un langage " surcodé ") ou en clair dans les discours des devins, que le sacrifiant ou le sacrificateur (qui est le mandant de ceux au nom et au bénéfice desquels il accomplit le rite) pourrait, en poussant les choses à la limite, substituer arbitrairement telle victime à la victime désignée par la règle coutumière, il n'est possible, au niveau du message, d'affirmer que tout sacrifice vise et s'épuise à combler le vide qui sépare l'homme de la divinité dans l'espoir que celle-ci comble les vœux de celui-là. Serait-ce ainsi qu'il faut considérer le sacrifice, cela ne signifierait pas pour autant que le message est dépourvu de sens, bon ou mauvais. Après tout, quand il nous dit que la communication entre les hommes et les dieux se fait dans les deux sens, des dieux vers les hommes par les mythes et des hommes vers les dieux par les rites (Lévi-Strauss,

10 Dans Nuer Religion, Evans-Pritchard propose une analyse du sacrifice chez les Nuer dont on peut s'étonner que Lévi-Strauss n'ait pas tenu compte alors qu'il faisait tant cas de l'exemple du concombre utilisé comme substitut du bouf. Il nous semble, en effet, qu'il serait difficile de faire admettre au lecteur que cette analyse du traitement codifié de la victime sacrificielle (il s'agit le plus souvent d'un bovin qui lui-même peut déjà être lié symboliquement à tel membre de la famille ou du segment de lignage propriétaire du troupeau) qui comprend les quatre temps suivants: la présentation, la consécration, l'invocation et l'immolation, ne se ramènerait, en définitive, qu'à un effort désespéré de l'ethnologue pour sauver un "discours dénué de bon sens". Dans ce domaine aussi, comme l'a prouvé le magistral et novateur ouvrage de Luc de Heusch (1986), il est possible de faire un bon usage de la méthode comparative pour apporter une contribution à la théorie du sacrifice en Afrique noire et donner une réponse aux arguments de Lévi-Strauss; nous pensons ainsi à un rapprochement entre la démarche plutôt inductive d'Evans-Pritchard et celle de Griaule qui, dans un article intitulé de façon significative "Remarques sur le mécanisme du sacrifice dogon "(1940), procède de façon déductive dans la mesure où il part de certains axiomes sur la nature et l'action du nyama, la puissance vitale qui met en branle et détermine les différents moments du processus sacrificiel. Cette comparaison serait d'autant plus intéressante qu'il s'agit de deux sociétés où l'on observe des formes de totémisme qui semblent complètement différentes, voire opposées. Enfin, il nous semble nécessaire aussi de mentionner les études réunies dans le volume intitulé Sous le masque de l'animal. Essais sur le sacrifice en Afrique noire (M. Cartry, 1987) qui fournissent des illustrations remarquables, en particulier, celle de G. Le Moal, de ce qu'on peut appeler de façon tout à fait précise, un code sacrificiel. 
1973), il admet que dans les deux sens il y a, si l'on ose dire, du sens qui circule. Nous ajouterons qu'il existe aussi des cas où le destinataire du rite n'est pas nécessa:rement un dieu ou telle puissance située dans une position équivalente, c'est-à-dire à une distance lointaine de celui qui l'accomplit, mais quelque chose d'un autre ordre et qui pourrait, à la limite, n'être plus identifiable qu'au rite lui-même.

Ecartons d'emblée tout malentendu : il n'y a pas, chez les peuples nilotiques, de sacrifice spécifique lié à l'esprit totémique. De même que cette catégorie d'esprits, nos deux auteurs sont en parfaite concordance sur ce point, n'est pas isolable, sur le plan de l'analyse des notions religieuses, des autres grandes manifestations de l'Esprit ou de la Divinité, le rite sacrificiel qu'à l'occasion elle exige est inséparable des pratiques analogues destinées aux autres entités qui ont de semblables exigences. Nous en avons donné un exemple en évoquant un triple sacrifice dinka associant simultanément la Divinité, une * divinité libre " et une " divinité de clan ", chacune se voyant consacré son animal distinctif. Il existe cependant, en dehors du choix de la victime, des traits particuliers qui permettent de reconnaître un sacrifice totémique. Evans-Pritchard (op.cit. : 217) nous donne les indications suivantes :

" Dans les sacrifices associés aux rivières, aux cours d'eau et aux animaux aquatiques tel le crocodile, parfois aussi dans ceux adressés à Dieu pour obtenir la pluie, la victime - un mouton ou une chèvre, jamais un bœuf - est attachée et précipitée dans l'eau au milieu des roseaux et des herbes folles. Quand on fait un sacrifice à l'espritpython, on étouffe la victime. Les ouvertures du corps (la bouche et l'anus) sont obstruées avec de l'herbe, puis on saute sur l'animal et on le frappe jusqu'à ce que la mort s'en suive. ".

Le commentaire, commun aux Nuer et aux Dinka, est que le sacrificateur doit tuer la victime de la même manière que le python tue sa proie $^{11}$. Il s'agit d'une action mimétique qui permet symboliquement

11 Le sacrifice par suffocation a fait l'objet d'une très intéressante polémique entre Arens et Burton, d'une part, et Beidelman, d'autre part (Man, 1975 et Man, 1976). Les premiers, prenant appui sur les scrupules qu'avait Evans-Pritchard à définir comme sacrifice une forme de mise à mort de la victime qu'il n'avait pas eu l'occasion d'observer, cataloguent comme rite magique de type mimétique un rite de mise à mort par suffocation (lequel a été observé par l'auteur qui le décrit à titre d'exemple 
d'exprimer une finalité ou un aspect particuliers de tel sacrifice mais ces différentes manières de mise à mort ne constituent pas pour autant des espèces différentes de sacrifice. La vérification la plus éclatante de cette proposition nous a été fournie par le sacrifice que font à Chair les maitres de la lance de pêche ; la description que nous en donne Lienhardt nous fait assister à une forme de possession où le sacrifiant est pris de tremblements qui " imitent ", si l'on peut dire, les tremblements caractéristiques du totem Chair dont l'idée, selon lui, serait venue aux Dinka de la perception même des chairs palpitantes de l'animal qui vient d'être sacrifié. Nous sommes donc fondé à dire que non seulement totémisme et sacrifice au sein d'une même société ne sont pas incompatibles mais encore qu'il est possible de repérer, dans les cas nuer et dinka, des traits distinctifs dans la procédure sacrificielle exigée par l'esprit totémique ou la divinité clanique. Nous voudrions, pour conclure provisoirement notre réflexion sur cette question, revenir sur le cas des Tallensi. Fortes n'établit aucune relation particulière entre leur totémisme clanique qu'il décrit dans son Dynamics of clanship et leur système sacrificiel. Curieusement, cette relation est mise en évidence par Ivan Karp (1977) qui, dans un court et incisif article intitulé : "Lévi-Strauss and Tallensi Totemism: $A$ reanalysis ", nous propose une interprétation qui se veut expressément lévi-straussienne (alors que se sentant plus proche de Fortes, il serait plutôt critique vis à vis du structuralisme) d'un aspect du totémisme des Tallensi qui aurait échappé à Fortes lui-même.

L'auteur nous explique qu'il existe une homologie entre, d'une part, les interdits totémiques propres à chacun des deux groupes constitutifs de la société, les Tale, gens de la terre et les Namoos, détenteurs d'une sorte de chefferie et, d'autre part, les relations structurales qui les unissent et les opposent l'un à l'autre, politiquement et rituellement. Les Talis se présentent comme des autochtones, ils sont placés sous l'autorité des

mais sans établir la moindre analogie avec un rite totémique) que les Nuer accomplissent pour éviter la stérilité à une jeune fille trop tôt mariée. Beidelman rejette, à juste titre selon nous, toute idée de séparation tranchée entre rite magique et sacrifice religieux et suggère de rapprocher la méthode par suffocation appliquée par les Nuer à la victime animale de celle des Dinka enterrant vivant leur vieux maitre de la lance de pêche, garant de la vitalité de son groupe, vitalité dont une des manifestations essentielles est précisément le souffle. 
Anciens, ânés de lignage et ils ont en charge le culte de la Terre confié à un dignitaire appelé tendaana. Les Namoos sont considérés comme des " envahisseurs " liés au clan détenteur du pouvoir royal chez les Mamprusi voisins et leur chef, résidant à Tongo, est un descendant en ligne directe de Mosuor, un membre du clan royal contraint à l'exil et qui, après une longue errance en brousse, contracta une alliance avec les ancêtres des maîtres de la terre. La collaboration rituelle (et donc la mutuelle dépendance) de ces deux groupes consiste en ceci : les Namoos ont besoin que soient accomplis les rites agraires incombant au tendaana pour que la terre produise d'abondantes récoltes, les Talis ont recours au chef de Tongo qui est " maitre de la pluie " et qui seul peut faire les sacrifices destinés à mettre fin à une sécheresse. Les interdits des Talis sont la tortue d'eau et la tortue de terre, les interdits des Namoos (valant seulement pour les fils et filles ainés) sont les poules, poulets et pintades. Les Talis justifient leur interdit par le mythe suivant : un homme avait sauvé sa réputation de mauvais mari en préférant donner à boire à une poule (il s'agit d'une calebasse d'eau de farine) plutôt que d'étancher sa propre soif. Les Namoos racontent comment leur ancêtre mourant de soif fut sauvé par une tortue qui lui fit découvrir une source. On a donc du côté des animaux, une poule assoiffée et une tortue pourvoyeuse d'eau (c'est le discours du mythe) et du côté des hommes, un Tali en quête d'eau et un Namoo garant de la pluie (ce sont les positions rituelles respectives de l'un et de l'autre). Ainsi la signification des interdits totémiques se lit dans le fait que chacun des deux groupes respecte l'espèce qui symbolise l'autre et parce qu'il symbolise l'autre. En effet, la poule est l'animal sacrificiel par excellence des Tallensi et l'eau de farine joue aussi un grand rôle rituel, notamment dans l'installation par le tendaana d'un nouveau chef de Tongo ; l'on sait, par ailleurs, que la tortue de terre et la tortue d'eau sont des symboles chthoniens qui constituent les principaux interdits totémiques pour une communauté territoriale réunie autour du culte d'un external bogar, "bosquet sacré extérieur ". Cette analyse est d'autant plus lévi-straussienne qu'elle n'est pas sans analogie avec celle que Le totémisme aujourd'bui consacre à un exemple australien, emprunté à Radcliffe-Brown, où le faucon et la corneille, deux oiseaux carnivores, sont respectivement les emblèmes totémiques de chacune des moitiés formant la société. Mais le premier étant chasseur et le deuxième 
charognard, il s'agit d'une relation non de compétition mais de collaboration, comme il convient entre deux moitiés. L'analogie va encore plus loin puisque nous apprenons qu'un mythe fait de Faucon le gardien jaloux du puits renfermant l'eau et de Corneille, l'oiseau qui en débouchant le puits sur lequel elle avait gratté sa tête pleine de vermine de telle sorte qu'elle se déversa dans l'eau, avait en même temps créé les rivières arrosant le pays et rempli celles-ci de poissons, nourriture des hommes (Lévi-Strauss, 1962a : 121). Karp cite alors la formule célèbre de LéviStrauss qui semble si bien s'appliquer aux rapports entre Talis et Namoos : "Le totémisme se ramène ainsi à une façon particulière de formuler un problème général : faire en sorte que l'opposition, au lieu d'être un obstacle à l'intégration, serve plutôt à la produire "(ibid.: 128).

Un examen très rapide du cas des Shilluk du Haut-Nil nous permettra de faire la transition entre ce totémisme cultuel des populations nilotiques et les formes que prennent les totémismes moundang et buganda que nous examinerons plus loin. Il s'agit, en effet, d'une société organisée en clans et en lignages mais dotée d'une institution politique centralisée qui s'incarne dans la personne du roi (reth); les clans sont exogames et certains d'entre eux au moins, sont totémiques car leurs interdits alimentaires portent sur des espèces naturelles. Dans un texte qu'il a consacré à la cosmogonie et au système religieux des Shilluk (African Worlds, 1954 : 138-163), G. Lienhardt observe que le totémisme et les cultes associés aux ancêtres n'occupent pas chez eux la première place qui est réservée aux sacrifices accomplis sur les tombes et les autels des ancêtres royaux dispersés à travers tout le pays. Ce culte que l'on rend aux différents rois qui se sont succédés depuis les origines de la dynastie qui règne jusqu'aujourd'hui, a pour destinataire ultime le héros mythique qui en est le fondateur, Nyikang. Il n'existe pas de culte de la divinité suprême Juok ; ce nom est seulement invoqué mais c'est à Nyikang, dont dépend le sort des humains, que sont adressés prières et sacrifices. Cette puissance est de nature céleste, selon certaines versions du mythe d'origine, mais dans la version la plus répandue, il est dit que Nyikang est le descendant d'une grande vache blanche créée par dieu dans le fleuve et que sa mère est un être à demi crocodile et à demi femme dont le nom est Nyakaya. Elle représente la totalité des choses associées à l'eau et elle reçoit des offrandes sur la berge du fleuve, aux endroits très 
herbeux où sortent les crocodiles. En dépit de cette origine en partie divine et céleste, en partie animale et aquatique qui fait de lui un immortel, Nyikang est considéré comme un être humain, fondateur de la nation shilluk. C'est lui qui l'a séparée des autres peuples et qui lui a fait traverser le fleuve (le Nil) pour la conduire là où elle vit maintenant. Il a également établi les distinctions en son sein en créant les clans et les lignages à chacun desquels il a assigné telle partie du territoire ethnique et attribué tel totern spécifique. Avant de séparer les Shilluk des autres nations et de les diviser eux-mêmes en clans, Nyikang, agissant en démiurge, a fabriqué le peuple de son royaume à partir d'insectes, de poissons et d'autres animaux qu'il a capturés pour les transformer en humains. Après quoi il a détruit des animaux appartenant au stock d'origine de façon à ce que les enfants humains ignorent pour toujours leurs origines. Ainsi, à l'exception du lignage royal issu de Nyikang et donc céleste pour moitié, les hommes du commun sont des animaux transformés en humains par l'action de Nyikang qui conserva la trace de cette transformation en affectant des totems à chacun des clans. Selon une autre version du mythe, il ne créa pas, à proprement parler, l'espèce humaine mais fut le seul à pouvoir reconnaitre sous les masques animaux dont ils s'affublaient les hommes qui cherchaient à cacher de cette façon leur véritable nature. Le totémisme n'est plus dès lors associé au passage de l'animalité à l'humanité mais résulte de la substitution d'une relation aux espèces animales voulue par Nyikang à un artifice mensonger voulu par les hommes. Quoi qu'il en soit, c'est toujours Nyikang et, par voie de conséquence, le pouvoir royal qui en procède, qui constitue l'instance ayant autorité pour décréter, si l'on peut dire, les distinctions totémiques, lesquelles sont, de ce fait, dépourvues du statut de puissances spirituelles qu'elles avaient chez les Nuer comme chez les Dinka

Dans un article beaucoup plus récent, B. Schnepel (Africa, 1991) se rallie complètement à l'opinion de Lienhardt sur la centralité du culte de Nyikang chez les Shilluk. Il est frappant de constater qu'indépendamment de toute référence au problème du totémisme, il est amené à faire l'observation suivante qui fait écho à nos propres remarques sur l'argument de l'Un et du Multiple :

* A la lumière de l'analyse d'Evans-Pritchard sur la relation entre esprits et ordre social chez les Nuer (1956 : chap. 4), il devient évident 
que dans la religion shilluk, en rapport analogique avec la centralisation de l'autorité politique, l'invocation des esprits est concentrée sur une réfraction (sic) unique et centrale de Dieu. Nyikang, comme réfraction de Dieu ou de Juok, est un être un et le même pour tous les Shilluk, car son image n'est pas dépendante de la dynamique et de la position relative qui est celle de l'acteur au sein de la structure sociale. " (Schnepel, 1991 : 53-54).

Il poursuit dans le même esprit en insistant sur la fonction d'intégration sociale et politique du culte de Nyikang dont il souligne que " les autels symbolisent unité et centralité en dépit de la segmentation et de la dynamique segmentaire " caractéristiques de la société shilluk comme des autres sociétés nilotiques. En fait, il n'est pas évident qu'il faille ici opposer centralité et segmentarité dans la mesure où cette dernière, qui est certes un trait morphologique d'une société organisée en clans et lignages, est entièrement réappropriée, si l'on peut dire, par l'autorité royale pour la mettre à son service. Les groupes locaux (au niveau villageois comme au niveau des provinces) expriment leur unité autour des sépultures et des autels de chefs et de rois qui marquent leur territoire ; de leur côté, les différents clans et lignages, dont certains, nous l'avons signalé, observent des interdits totémiques, reçoivent des fonctions spécifiques dans la répartition des tâches rituelles exigées précisément par le culte des autels royaux. Ainsi, dans un premier temps, celui du mythe, des emblèmes totémiques sont affectés aux différents clans constituant l'humanité primitive; ensuite, dans les temps historiques, les rois qui ont succédé à Nyikang et qui en incarnent à titre temporaire la royauté perpétuelle distribuent ces fonctions rituelles spécifiques à chacun des clans. Il s'agit des tâches variées requises par l'entretien, la réfection et, périodiquement (au moins tous les cinq ans), la reconstruction complète des huttes et monuments divers consacrés au culte dont le héros fondateur est l'objet. Le glissement d'un totémisme classificatoire dont l'origine serait dinka à une différenciation des groupes sociaux par des fonctions attachées au service cultuel de la royauté, est sans aucun doute un effet de la concentration du pouvoir dans une société qui 
préserve ainsi les caractères d'une organisation segmentaire ${ }^{12}$ qu'elle partage avec ses voisines nilotiques. Mais ce sont les institutions représentatives de la royauté qui ont absorbé, si l'on peut dire, toute l'activité rituelle et du même coup vidé de tout contenu substantiel les croyances spécifiquement totémiques. Avec les Moundang, nous aurons affaire à une situation qui n'est pas sans analogie puisque, comme les Shilluk, ils combinent organisation clanique et concentration du pouvoir politique ainsi que d'une certaine forme de pouvoir rituel dans la personne du roi. Mais il est tout à fait nécessaire d'indiquer qu'il s'agit, dans les deux cas, non d'une fusion dans un seul et même individu des pouvoirs de coercition du chef politique et des pouvoirs rituels du prêtre et/ou du magicien, mais d'un type tout à fait particulier de pouvoir que sanctionne, en principe, le régicide. Qu'il soit décidé et rituellement exécuté par ceux que l'on appelle les faiseurs de roi ou qu'il soit, dans certaines circonstances, pour ne pas dire dans un très grand nombre de cas, difficilement discernable d'un assassinat politique, le régicide signale, entre autres, l'inévitable jeu de bascule dans ce type de société contrainte à la quête permanente d'un compromis introuvable entre centralité et segmentarité.

Avant de quitter l'aire nilotique et d'en venir aux Moundang, nous voudrions signaler le cas de sociétés voisines qui sont localisées dans le Sud-Est du Soudan et chez lesquelles se rencontre également une répartition tout à fait remarquable des fonctions rituelles entre les clans mais en l'absence de toute référence à des croyances ou même tout simplement à des dénominations totémiques. Dans un important ouvrage d'ethnologie comparative qui met en évidence l'imbrication des caractères tant cosmologiques que politiques de la royauté dans cette partie du Haut-Nil jusque là fort peu étudiée, S. Simonse (1992 : 265)

12 Examinant en détail le déroulement des rites d'intronisation du nouveau roi désigné par le collège électoral des "faiseurs de roi ", Schnepel (1988) insiste sur le partage très strict des rôles et des tâches incombant alors aux différents clans. L'interprétation qu'il en propose est pour nous d'un grand intérêt : " Mais le message est clair : un reth élu ne peut devenir roi que si chacune des sections (claniques) accomplit le rite qui lui revient et si, en fin de compte, toutes les sections exécutent leurs rites dans l'ordre prescrit.... Chaque clan est temu pour responsable de la tâche que Nyikang lui a assignée... On peut dire que les relations qui s'établissent entre le roi et les sections au terme de l'intronisation sont des relations de droits et de devoirs réciproques". 
décrit ce qu'il appelle la " compartimentalisation des pouvoirs "à Lokirili, une localité Lulubo (l'une des ethnies de la région). Ces pouvoirs (opopi, terme qui inclut une référence à la fonction royale) se transmettent héréditairement dans un lignage particulier d'un clan particulier et rares sont les clans qui en sont dépourvus. Presque tous sont donc "maîtres" de tel ou tel domaine, une seule fonction absolument essentielle échappant aux clans, celle concernant la pluie, qui est une prérogative exclusive du roi. Citons en quelques exemples : les maîtres de la Terre ont en charge les rites agraires, les rites de purification quand le sang humain a été versé et aussi ceux qui protègent des serpents et des scorpions; les maîtres de la Montagne qui abrite des sites sacrés et des autels où sont pratiqués des rites de défense contre les insectes parasites des récoltes; les maîtres des sauterelles et les maîtres des mouches tsé-tsé qui sont aussi chargés de veiller sur la santé du bétail ; les maîtres des lions, ceux des léopards, ceux des vents, ceux des oiseaux; les maîtres des lances et des flèches (il s'agit de la magie propre à un clan de forgerons qui fait que vos traits atteignent leurs cibles et ceux des ennemis les manquent), etc. Cette énumération, on en conviendra n'est guère éloignée d'une liste totémique et la manière dont les Lulubo conçoivent la possession par un clan de son " pouvoir " montre bien que ces "fonctions" ne se réduisent pas à l'obligation de remplir une charge mais sont de véritables propriétés du groupe qui les détient et qui peut en faire un usage bénéfique pour la communauté ou au contraire maléfique, en n'écoutant que son intérêt égoïste. Ainsi, nous trouvons effectivement représenté dans le champ ethnographique un certain nombre de possibilités que nous pouvions logiquement considérer comme des moyens de déterminer la spécificité clanique $^{13}$ : chez les Nuer, on passe d'un totémisme de type classificatoire

13 Pour rester dans le domaine de l'Afrique orientale, il n'est pas inutile de signaler qu'il existe aussi une forme de quasi totémisme, si l'on peut dire (mais l'auteur emploie le mot totémisme sans faire la moindre restriction), appliquée non pas aux clans mais aux classes d'âge et aux classes générationnelles. C'est le cas chez les Mbeere du Kenya où l'ethnologue (Glazier, 1976) observe qu'aux deux classes générationnelles qui partagent la société correspond un dualisme dans les fonctions rituelles : ceux qui font les sacrifices pour la pluie (et il qualifie Pluie de Totem) en vue d'obtenir des récoltes abondantes et ceux qui sacrifient au totem Soleil pour demander la santé et la fécondité des femmes et du bétail. Curieusement, alors que c'est par l'acte sacrificiel que la classe s'affirme "Pluie " ou "Soleil ", Glazier se sent 
à un totémisme de type fonctionnel; quelque chose d'un peu différent se produit chez les Dinka où l'aspect fonctionnel est associé au totem Chair, hiérarchiquement supérieur aux autres divinités claniques ; chez les Shilluk, le totémisme s'efface au profit de la division des tâches rituelles exclusivement vouées au culte de Nyikang, c'est-à-dire de la royauté; chez les Lulubo enfin, on assiste à une espèce de retournement qui nous fait passer d'une fonction spécifique, rituelle ou directement utilitaire, à une propriété ayant pour son possesseur une valeur discriminante qui évoquerait plutôt le totémisme de type classificatoire. Au terme de cette première partie de notre analyse, le point décisif à nos yeux, est que l'attribution aux clans de fonctions spécifiques ne trouve véritablement sa place que dans le cadre d'un système politique pourvu d'un centre qui peut n'être occupé que par un personnage du type du " maître de la lance de pêche " dinka ou par un roi du type shilluk au pouvoir coercitif nettement plus marqué encore qu'il soit, en droit comme en fait, extrêmement faible. Nous allons voir maintenant qu'une organisation clanique caractérisée par un totémisme tant classificatoire que fonctionnel n'est pas incompatible avec l'institution d'une royauté puissante.

\section{Le totémisme moundang, un totémisme clanique.}

Il nous semble nécessaire de présenter les grands traits de l'organisation clanique des Moundang en signalant d'abord que la notion de clan est une notion propre par laquelle la société moundang se décrit elle-même ; elle est désignée par un terme, bane qui ne comporte aucune connotation de parenté. Elle n'est pas, comme on le voit assez souvent dans la littérature africaniste, une notion analytique approximative

tenu d'écrire que les Mbeere "thus construct certain natural and cultural relationships in totemic terms, in the Levi-Straussian sense ". Nous devons reconnaître qu'en raison de l'insuffisance des données ethnographiques, il nous est difficile d'apprécier la pertinence de la notion de totem utilisée par l'auteur, mais nous n'avons aucune raison de la rejeter. Les Nyangatom d'Ethiopie étudiés par notre collègue Serge Tomay font un usage massif des noms d'animaux pour désigner leurs classes d'âge mais nous ne trouvons pas de référence au totémisme sous sa plume. Sa démarche est linguistique et elle se veut cognitiviste. 
employée par l'ethnologue pour nommer une unité sociale aux contours mal définis, une unité de type intermédiaire entre le lignage, terme précis dont l'emploi se justifie par référence à l'extension sociale des liens de parenté unilinéaire et la tribu, terme beaucoup moins précis, renvoyant à une communauté d'origine territoriale et culturelle de groupes divers se reconnaissant unis par des traits particuliers (institutionnels et rituels, par exemple) symbolisant cette identité ou prétendue identité d'origine. Nous nous bornerons ici à reprendre la définition suivante du clan (Adler, 1982) : l'unité constitutive et " constituante " tant de l'ethnie (être au monde, être né moundang, c'est être d'un clan) que du système sociopolitique qui a pris forme dans la royauté instituée à Léré où être d'un clan, c'est occuper telle place dans un ensemble ordonné de fonctions sociales et de tâches rituelles. Nous avons, d'autre part, une royauté dont le mythe d'origine, qui lui fournit sa " charte ", nous présente de la façon suivante les deux partenaires qui en sont les créateurs : un chasseur étranger, généreux donateur de viande, et des clans maîtres de la terre qui lui donnent d'abord leurs filles pour épouses, puis lui confient la charge politique et rituelle du pouvoir. Le totémisme est bien le prédicat qui convient pour qualifier le système clanique moundang car il combine avec l'exogamie, un ensemble d'appellations variées (animales, végétales ou autres) auxquelles sont associées des attitudes déterminées par une forme d'interdit et un certain nombre de spécialisations correspondantes, purement rituelles ou techniques et rituelles. La division de la société en clans apparaît comme une manière de répartir les "travaux " affectés à ces spécialisations fondées sur ou articulées avec un mode d'appropriation des puissances de vie de l'univers. Chaque clan détient donc en vertu de ses attributs totémiques une aptitude et un pouvoir particuliers (forger le fer, couper des arbres pour fabriquer une pirogue, chasser l'hippopotame et le lamantin, creuser les fondations d'une maison, faire les « médicaments " pour favoriser la croissance de telle variété de mil ou celle de l'arachide, etc.) ou une fonction particulière prenant place dans l'organisation rituelle générale dont le roi et le palais constituent le centre dynamique lors des cérémonies agraires fixées par le calendrier traditionnel.

Morphologiquement, les clans moundang sont des unités de taille très variable composées de groupes localement dispersés mais dont 
certains, parmi les plus petits, sont néanmoins concentrés dans un nombre très restreint de villages. Les clans les plus importants, par leur taille comme par leur fonctions, sont parfois divisés en grands secteurs géographiques ("ceux de l'eau ", " ceux des collines") et en sous-clans (ces derniers se distinguant tantôt par un nom propre ajouté, tantôt par un sobriquet) qui peuvent être disséminés sur tout le territoire du royaume et même au-delà. Les membres d'un même clan ne se reconnaissent pas d'ancêtre commun et quelquefois même, ils disent avoir des origines géographiques différentes. Il n'existe pas de rôle de chef de clan mais seulement des rencontres plutôt informelles d'anciens en vue de régler des affaires concernant le clan dans son entier (très rarement) ou sa section villageoise. Ce qui fait l'identité d'un clan est déterminé par un certain nombre d'attributs que nous allons énumérer. Le premier d'entre eux est évidemment le nom propre, qui est parfois précisément d'allure totémique (Buffle, Ficus, Singe, Serpent, Chien, Oiseau, Pirogue, etc.) mais ce n'est pas le cas le plus fréquent. Tous les clans respectent un ou plusieurs interdits, généralement alimentaires (liés, par exemple, à l'espèce totémique) mais pas exclusivement, on le verra. A ces interdits s'ajoutent d'autres traits ayant une valeur distinctive et dont tous ne sont pas nécessairement réunis en chacun. Ainsi, les masques sont par nature, quel que soit leur rôle dans les cérémonies publiques ou les rites royaux, la propriété d'un clan, mais il existe des clans qui n'en possèdent pas et qui, pour une raison ou pour une autre, ne veulent ou ne peuvent en acheter, en raison des frais élevés que cela implique : on dit alors que tel de leurs fétiches (un instrument de musique ou bien tels outils du forgeron) leur en tient lieu. La plupart des fonctions rituelles dans les fêtes du calendrier agraire, la responsabilité de la plupart des institutions dans la communauté villageoise sont réparties entre les clans, mais tous ne sont pas également pourvus. Néanmoins, si grands que puissent être les écarts entre les différents clans relativement aux fonctions qu'ils remplissent - ce que l'on pourrait appeler leur rendement social différentiel - ils sont tous formellement équivalents. $\mathrm{La}$ " citoyenneté " moundang est obtenue par l'appartenance à un clan et cette appartenance confère à chacun, quel que soit son clan, des droits qui lui garantissent sa sécurité (selon les règles qui définissent les obligations mutuelles de solidarité dans la vengeance), l'accès aux ressources et, d'une manière générale, la participation 
à toutes les manifestations de la vie collective. Quelles sont les présomptions d'ordre logique qui permettent au clan de réunir toutes ces vertus? Nous dirons que nous avons là comme un axiome de la société moundang consistant à affirmer que c'est en lui que résident les forces ou qu'en lui sont investis les pouvoirs de légitimation qui donnent à l'individu sa personnalité sociale, morale et juridique. Si le terme employé est celui d'axiome, c'est pour marquer qu'il n'est pas possible, sauf à sombrer dans les spéculations les plus abstruses, de répondre à la question pourquoi il en est ainsi en remontant une chaîne de raisons ou en se livrant à d'hasardeuses conjectures prétendument historiques. Il est toutefois possible d'appréhender de plus près ce type d'institution en dressant, si l'on peut dire, la fiche signalétique du clan moundang. Celleci comprend :

1) Un nom qui est pour certains d'entre eux de type totémique et pour les autres du type "Moundang de.. " suivi le plus souvent d'une indication du lieu de provenance.

2) Un interdit associé au nom et qui peut être alimentaire ou appliqué à un usage quelconque de "l'objet totémique ".

3) Un ou plusieurs masques à fonctions rituelles spécialisées ou non et, à défaut, un emblème doté de propriétés analogues.

4) Une relation à plaisanterie avec un ou deux autres clans donnant lieu à une alliance de type cathartique qui se manifeste notamment dans l'institution du personnage du gõ beii qui, à l'occasion des funérailles, s'installe en maitre et purificateur de la maison du défunt.

5) Une devise, sorte de poème cantilé en des occasions rituelles et festives par les épouses des za luri, "les grands " du clan. Cela signifie qu'un homme ne peut avoir l'honneur et le plaisir de l'entendre que de la bouche d'une étrangère au clan. $\mathrm{La}$ devise fournit des indications précieuses sur les origines et les caractères spécifiques que le clan se reconnaît à lui-même.

6) Des usages particuliers insérés dans certaines séquences des rites funéraires. Quelques-uns, on va le voir, sont liés à l'attribut totémique du clan.

7) Enfin, et l'on passe des dimensions symboliques aux dimensions sociologiques de l'institution, il y a les différents droits et notamment ceux qui sont liés aux relations que les clans, quelle que soit leur origine 
ou leur provenance géographique supposées, entretiennent avec certains points du territoire historique des Moundang. Ces relations sont conçues sous la forme d'un pacte conclu par les ancêtres premiers occupants - " ceux qui ont coupé les bois de construction " - avec les " génies de lieu ", les cok-syinri qui sont considérés comme les possesseurs et maîtres invisibles de la terre. Ces génies sont l'objet, de façon régulière ou occasionnelle (selon les prescriptions des devins kendani), de sacrifices propitiatoires ou expiatoires. C'est sur le nom de leurs cok syinri claniques (donc sur des lieux-dits, à proprement parler) que les membres d'un clan prêtent serment, car c'est par ce nom, symbole du point d'ancrage de leur identité, qu'en tant que personnes, ils se voient dotés d'un statut social, juridique et moral. Il en est ainsi en raison du rôle que la pensée moundang attribue à ces génies dans le cycle parcouru par les âmes des mortels et, par conséquent, dans la reproduction (Adler 1982).

$\mathrm{Au}$ vu de cette énumération, l'idée s'impose qu'il faut aborder la question du totémisme en partant de l'interdit. Il existe trois sortes d'interdits dans la société moundang. 1) Ceux qui sont communs à tous les membres de l'ethnie et qui les différencient des ethnies voisines. Un Moundang ne consomme pas la chair des herbivores qui n'ont pas le sabot fourchu ${ }^{14}$, tels l'âne et le cheval. Il ne consomme pas de viande de chien, contrairement à de nombreux groupes voisins vivant au NordCameroun, dans la région du Mandara. Enfin et surtout, un Moundang ne mange d'aucun serpent et il craint par dessus tout le python qu'il appelle ma-suo, "mère des serpents ", et dont il fait le génie responsable de l'ictère. Ajoutons que Python est l'une des principales catégories de " génies-maladies" qui affectent la santé des femmes. Celles-ci ne peuvent trouver des remèdes et aller vers la guérison que dans et par les traitements rituels que prennent en charge des associations féminines qui organisent notamment des séances de danses de possession (Adler et Zempléni, 1972). 2) 1 existe des interdits individuels qui sont énoncés par le devin lors de consultations demandées par un client frappé par une

${ }^{14}$ Cet interdit rappelle celui, bien connu, du Lévitique. La surprise de l'observateur s'accroît encore lorsqu'il apprend qu'en certaines circonstances (il s'agit des sacrifices propitiatoires pour la pluie), le rituel moundang proscrit, également comme le Lévitique, la consommation de poissons sans écailles. 
maladie ou toute autre forme d'infortune. Le patient apprend, entre autres choses, que son traitement exige qu'il s'abstienne de consommer de la chair de mouton, par exemple, pour garantir l'efficacité des rites thérapeutiques. Pour le reste de ses jours, le mouton sera son interdit. Il est des cas, dit-on, où cet interdit doit être transmis du père au fils. 3) La troisième catégorie est celle des interdits claniques, c'est-à-dire totémiques. Ceux-ci sont d'une nature différente parce que non exclusivement alimentaires ; ils sont, dirons-nous, modulables et déterminés par les caractères particuliers du totémisme dans sa version moundang. On peut parler, en prenant quelque distance, de version moundang car ce totémisme nous offre l'exemple d'un mélange déconcertant de traits totémiques qu'on peut qualifier de très classiques et, par ailleurs, de traits plutôt fonctionnels qui font du clan moundang une unité politico-rituelle de même nature que le lignage dans sa forme de corporate group telle qu'on la trouve dans la société tallensi étudiée par Meyer Fortes (1945). Nous verrons aussi de façon plus détaillée que ce totémisme présente des ressemblances frappantes avec celui qui est associé avec le clan tel qu'on l'a décrit chez les Baganda (Roscoe, 1911). Qu'en est-il donc?

Une première constatation s'impose : sur la vingtaine de clans existant aujourd'hui dans le pays moundang de Léré, seuls cinq d'entre eux portent des noms d'animaux mais nous devons préciser qu'il s'agit de ceux qui sont donnés aux clans et non aux sous-clans dont nous parlerons plus loin. La plupart des autres clans sont dits clans moundang, ban-mundan, à quoi s'ajoute le plus souvent un autre nom. Voici quelques exemples : $\sin$ " d'en haut, des collines " (gens originaires de la région de Lara au Nord-Cameroun) dont la spécificité est de fournir le chef de terre (pa seri) de Léré, qui est le village de résidence du roi ; gwö̈ (dont l'étymologie nous est inconnue mais qui se divise en " rouges " et en * noirs ", les premiers ayant le rôle de fossoyeurs des chefs, les autres étant associés à une variété de mil) ; za tekuri, "ceux qui se sont installés sur le sable ", sol inhospitalier dont ils ont dû se contenter car ils fuyaient leur village pour cause de crime (ce clan comporte également des gens originaires de la région de Lara qui furent plus tard surnommés tereli, "crapauds" du fait qu'ils étaient prolifiques) ; yere, dérivé du nom de la montagne de Yera, dont les membres ont en charge des fonctions rituelles essentielles qui sont liées à la royauté (Adler, 1982) ; leere, Léré : 
ces " Moundang de Léré » sont des captifs du roi dont les descendants affranchis dès la première génération et mariés aux enfants du pays forment un clan ayant exactement les mêmes devoirs et prérogatives que les autres (Adler, 1987) etc. Le propre de ces clans, ce qui explique le nom qu'ils portent, est qu'ils se sont constitués au sein du royaume à l'intérieur duquel ils se sont vus assigner nom, rôle et attributs divers parmi lesquels un interdit spécifique. Mais il faut dire que les premiers à être des ban mundan, ce sont les descendants des rois de Léré et des chefs de village issus de la lignée royale; ils forment aujourd'hui trois clans de mundan gõ ae, c'est-à-dire royaux. De façon rigoureusement symétrique et par une démarche inverse, ils sont " rabaissés " au statut de clan, comme les Moundang-Léré d'origine captive y sont rehaussés, selon le principe que nous avons appelé la "clanification généralisée ". Cette dualité hétérogène que l'on ne doit attribuer, on le voit, ni à l'origine géographique ou ethnique des divers clans, ni à la plus ou moins grande ancienneté de leur formation, empêche-t-elle l'ensemble de ces clans de constituer un tout cohérent, un système au sens fort du terme et qui, incontestablement, porte la marque du totémisme? S'il convient, comme nous le pensons, de répondre par la négative, il ne faut pas pour autant imaginer un processus quasi mécanique d'extension du caractère totémique des attributs du sous-ensemble des cinq à l'ensemble des vingt. On serait ainsi conduit à affirmer que les Moundang Sin, par exemple, ont par rapport au trait spécifique qui apparaît dans leur devise : la barre à mine permettant de creuser les fondations d'une maison à quoi s'associent les rites qui demandent à la terre de ne pas rejeter ou de ne pas anéantir ceux qui construisent sur elle, la même position que les hommes du clan du Singe ont par rapport, non à l'animal du même nom, mais aux fonctions initiatiques que subsume cette catégorie. Cette hypothèse ne nous paraît pas satisfaisante car elle réduirait les appellations animales à de simples noms métaphoriques et ôterait du même coup toute justification à une relation quelconque entre l'animal et la règle de conduite imposée aux membres du clan qui porte son nom, qu'il s'agisse d'un interdit alimentaire ou non. Du coup, on n'aurait plus affaire qu'à un jeu gratuit et le système basculerait dans le vide. Plus conforme à la logique de ce type d'organisation sociale nous paraît l'hypothèse suivante : en combinant des associations totémiques et des spécialisations diverses 
(processus que l'on peut envisager comme un double mouvement de "totémisation" de certains aspects de la division sociale des techniques et des savoirs et de " spécialisation"fonctionnelle des différences marquées d'abord par le symbolisme rituel), les Moundang auraient conservé et consolidé un système de clans dont la raison d'être, à leurs yeux, est l'appropriation des puissances de vie et des énergies du monde naturel indispensables au fonctionnement de la société humaine. Quel que soit son nom, le clan détient en vertu des attributs qui sont les siens, un pouvoir spécialisé dont le fondement ultime est d'ordre cosmique.

Présenter un à un les clans moundang dans leur singularité revient ainsi à décrire par fragments, parfois minuscules, quelques-unes des principales composantes de l'univers moundang dans sa réalité sensible aussi bien que dans sa réalité invisible. Entre la force dont l'homme s'assure ou, dans certains cas, s'approprie la maîtrise et le clan, il existe un rapport ontologique. Il n'est pas possible de concevoir comment telle force ou telle chose a pu être appropriée et utilisée par la société sans que cela se soit fait par la médiation d'un clan, premier signataire, si l'on peut dire, d'un pacte avec le monde. De même que l'individu " brut ", nous l'avons vu, se voit doté d'une personnalité juridique, c'est-à-dire d'une existence sociale légitime, par le seul fait de son appartenance à un clan, les éléments, la matière (souvent conçue comme une substance vivante pour autant qu'elle est travaillée), un certain nombre de techniques et de pratiques rituelles n'ont d'usage légitime, et par conséquent, efficace que par le truchement d'un clan qui possède le secret de son origine. Le clan engendre, met au monde, disent les Moundang, la chose dont il est le propriétaire. Cette relation de " filiation" ne renvoie pas à des théories étranges ou abstruses de la conception mais plutôt à une sorte de philosophie cognitive à laquelle on serait tenté d'appliquer le célèbre jeu de mot de Paul Claudel qui fait de la connaissance une co-naissance.

Prenons un exemple. Il serait absurde de penser (pour un Moundang comme pour quiconque) que le mil, ou toute autre espèce végétale, est engendré par tel clan. Que l'on y reconnaisse ou non l'influence de l'Islam ou de tel autre monothéisme, la pensée religieuse moundang affirme l'existence d'un dieu céleste, ma sin, "la chose d'en haut ", créateur ou plutôt source de toute vie sur terre. Ainsi donc, le mil est l'œuvre de dieu qui en a fait don aux hommes. Mais si les religions révélées 
conçoivent l'homme comme créé à l'image de dieu et opposé au reste de la création dont il peut et doit se rendre maitre et possesseur, elles impliquent du même coup une relation d'altérité de l'homme à l'univers qui s'écarte totalement de la pensée moundang (et plus généralement de la pensée africaine) et rend inintelligible la fonction d'appropriation qui est celle des clans. Le mil est la nourriture de l'homme, il est aussi sa substance. Il est doué d'une âme et la destinée de cette âme doit être prise en charge pour que soit assuré son retour saisonnier. Il existe un grand rituel annuel, appelé précisément " l'âme du mil ", cie swore, où celle-ci est associée aux principes spirituels de la personne du roi de Léré qui est ainsi mis en mesure de conserver les semences pour la prochaine campagne. Par ailleurs, il y a une variété de mil jaune, gebana, qui est la chose des Moundang-Gwoï (les "noirs ", ceux qui ne sont pas les fossoyeurs des chefs) et une autre variété, weri, qui est associée à un sous-clan des Dwé auquel est donné le nom de ban swore, le clan du mil. Les gens de ce sousclan ont pour coutume de jeter quelques poignées de grains de mil sur la tombe de leurs morts. L'explication que les intéressés en donnent est que leurs ancêtres, pressés de se retrouver au travail dans leurs plantations de mil, s'étaient contentés de ce geste pour honorer l'un des leurs fraîchement enterré. Leur devise vante inlassablement la qualité de ce mil que seules les " grandes " femmes de leur clan peuvent écraser et que * les hommes pournus de gros testicules" (souffrant de certaines filarioses) ne peuvent manger sous peine de graves constipations tant la farine en est sucrée. On peut, certes, dire que le mil est un bienfait de dieu dont l'homme s'acquitte par son travail et des témoignages de gratitude envers son créateur (les rites des prémices de fing moundang), mais on constate aussi que par l'une de ses variétés, il s'apparente à un objet totémique. II est donc rattaché au corps social par trois " prises ", si l'on peut dire : un rite royal de régénération et de perpétuation, la connexion de l'une des variétés avec un clan, et un usage funéraire avec un autre qui est un clan éponyme. Ce sont là autant de modalités de son appropriation conceptuelle et pratique.

Un autre exemple s'impose également, c'est celui du fer et de ses rapports avec les clans et sous-clans de forgerons. Ceux-ci sont originaires du sud, de la région de Lamé où l'on extrayait le métal en abondance et où ont été élaborées les techniques de fonte du minerai et de fabrication 
des outils, armes et bijoux divers. Ce qu'on peut appeler leurs objets totémiques, c'est la forge elle-même et l'outillage pour forger : ils sont dangereux pour les autres et c'est pourquoi aucun voleur ne serait tenté de s'y introduire et de s'emparer de quoi que ce soit. Dans le cas des artisans bijoutiers qui travaillent le cuivre et qui utilisent la technique bien connue de fonte à la cire perdue, c'est la consommation du miel qui constitue leur interdit et s'ils passaient outre, ils auraient les yeux gonflés.

Venons-en aux clans qui portent des noms d'animaux. Nous avions évoqué plus haut le mythe de fondation de la royauté moundang qui met en scène un chasseur et des représentants des clans en qui il faut voir les premiers occupants de ce qui deviendra le royaume de Léré. Contrairement à ce que l'on trouve dans d'autres cultures africaines, il n'y a pas ici de référence à une quelconque notion d'autochtonie. Le clan du Buffle, ban se, et celui des Oiseaux, ban ju, font partie de ces premiers occupants qui avec les Teure et les Moundang ge Rumaï (Moundang vivant auprès des Peuls et donc, introducteurs d'usages peuls dès la constitution même du royaume de Léré) forment le noyau primitif d'une population réduite, composée d'agrégats provenant de différentes régions et faiblement organisée sous la houlette des Kizere (nous donnerons plus loin les indications utiles sur tous ces clans) dont l'ainé détenait une forme rudimentaire de chefferie. Ce côté rudimentaire est évoqué dans la formule de plaisanterie qu'on leur adresse : « ceux qui ont des jambes grêles (kize bal hin), ceux qui donnent pour la fête la sauce de haricots $\$ 15$. Ils sont malgré tout des chefs comme le suggèrent les noms que portent leurs deux sous-clans : Lion et Panthère. Contrairement à ce que l'on pourrait s'imaginer, ces appellations ne nous livrent nullement la clé du totémisme moundang. Le nom de ces Buffles, ban se, qui se proclament premiers arrivants dans la terre qui sera celle des Moundang, n'est peutêtre que le surnom que leur ont donné les Peuls qui appelaient du nom de cet animal, mbana, leurs plus farouches adversaires, ceux dont la force et la bravoure guerrières forçaient leur étonnement. Certes, leur interdit alimentaire est l'animal dont ils portent le nom, mais il n'est pas respecté

${ }^{15}$ C'est pour cette raison que l'un des interdits de ce clan est d'allumer un feu avec des cosses de haricot sous peine de voir leurs pieds fendillés de plaies. 
par tous les sous-clans et des anciens affirment que le seul interdit strictement observé par tous les membres du clan quel que soit le nom de leur sous-clan est d'utiliser la peau du buffle pour en faire un siège ou un tapis de repos. En ce qui concerne la prohibition alimentaire, on peut penser qu'elle n'est pas totalement différente de celle qui frappe le chien pour les gens du clan du Chien, ban guo, puisque, nous l'avons indiqué, la chair de cet animal n'est consommée par aucun Moundang. Bien sûr, les Moundang mangent du buffle (ou plutôt, en mangeaient car il est devenu très rare aujourd'hui) mais cette consommation est soumise à de très fortes contraintes et c'est pourquoi il existe un sous-clan de "purs chasseurs " appelé ban se ci furmi, "Buffles de la poterie à charbon ". Cette désignation renvoie à l'obligation, pour les chasseurs d'un gibier réputé " difficile ", c'est-à-dire dangereux non seulement pour ceux qui l'abattent mais aussi pour ceux qui vont en consommer la chair, de découper et de faire cuire (la poterie à charbon est réservée à la cuisine de brousse) certaines parties de la bête avant de rapporter la carcasse au village.

On dit bien que chaque membre du clan est zumi, " parent " de l'animal qui lui donne son nom, mais cette parenté évoque, dans un certain nombre de cas, une forme de parenté à plaisanterie. Par exemple, si quelque individu appartenant au clan des Oiseaux, ban ju, est vu en train de manger un oiseau et si celui qui l'a surpris lui demande ce qu'il fait, il répond : "j'enterre mon frère ". La situation est toute autre si un oiseau de l'espèce dont son sous-clan porte le nom (grue couronnée, calao, pélican, vautour, mange-mil, différentes variétés de passereaux, tels les étourneaux, les corbeaux, etc.) est aperçu perché sur son toit ou tournoyant autour de sa maison, car alors le fait sera considéré comme un signe de mauvais augure : l'oiseau de malheur, c'est le cas de le dire, est annonciateur d'une mort prochaine, la sienne ou celle d'un des siens. S'il est vrai que la devise du clan des Oiseaux (commune à tous ses sousclans) exalte métaphoriquement la plume dont est coiffée leur grand masque Mayahé, s'il est vrai aussi qu'il existe un sous-clan dont le nom (traité, en l'occurrence, comme celui d'une espèce d'oiseaux parmi d'autres) est mweviki, sorte de sifflet qui joue le rôle de masque psychopompe dans le rituel funéraire (Adler, 1994), il n'en reste pas moins quelque chose d'irréductible à une figure métaphorique dans la relation 
de l'homme d'un clan avec son animal ou son objet totémique, quelque chose comportant un certain degré de réalité.

Un aspect partiellement mais plus classiquement totémique se révèle dans la relation que le clan ban-suo, Serpent, entretient avec son animal éponyme. Le python est considéré comme l'incarnation de l'un des principes vitaux (certains l'appellent le ma zwe su, fluide véhiculant l'énergie qui maintient le corps en activité) du chef de village de Tézoko, localité qui était déjà celle des ancêtres de ce clan. Lors des funérailles de ce chef, des libations de bière de mil sont versées en l'honneur du python considéré comme son double : ce reptile est censé, tout au long de son règne, résider sous le grand grenier central de sa demeure et s'il fait une apparition dans la cour de l'enclos, on y lit le signe de la mort prochaine du maitre des lieux. Il est frappant de constater que la devise de ce clan se contente d'une simple allusion au Serpent présenté comme la métaphore de la puissance du chef : on redoute d'en faire rencontre et si l'on apprend qu'il a quitté son séjour caché, on reste chez soi comme à l'heure du soleil brûlant de midi, qui est celle de tous les dangers. En revanche, la fonction de forgeron, qui est celle du clan du Serpent, est exaltée comme son attribut essentiel, son attribut noble. Elle seule possède aux yeux de ses membres une véritable valeur emblématique. La prohibition alimentaire spécifique des Serpents est le silure rouge et, par ailleurs, rappelons-le, la consommation de la chair du python, comme de tous les serpents, est l'interdit majeur de tous les Moundang.

Le cas du clan du Singe, ban-ping-ni, apporte encore un autre exemple du type de relation du groupe social au nom de l'animal qui lui donne son nom. Les anciens fournissent plusieurs explications de l'origine de cette appellation. Les ancêtres de ce clan sont venus de l'ouest de Léré, des collines du pays Mambay qui forment aujourd'hui frontière avec le Cameroun. Les gens de Léré les ont vus arriver portant sur la tête des melons qu'ils tenaient à deux mains. Ils marchaient ainsi à la manière des cynocéphales qu'on peut rencontrer en brousse dans cette posture. On dit couramment que ces singes "font le travail des hommes ", qu'ils se conduisent comme des humains. D'où une deuxième explication d'une toute autre portée que la première : il ne s'agit pas de dire que ces singes imitent les hommes mais, au contraire, que ce sont les hommes qui ont 
pris, ou plutôt, qui ont appris chez eux certaines techniques fondamentales pour la survie et l'épanouissement de l'humanité. Deux petits récits étiologiques nous indiquent comment les cynocéphales ont, d'une part, enseigné aux mères l'art de la sage-femme, c'est-à-dire celui de maintenir en vie le nouveau-né comme sa mère alors qu'auparavant la parturiente mourait en couches et, d'autre part, l'art d'opérer la circoncision en gardant les garçons en bonne santé. On ne postule donc aucune identité entre l'homme et l'animal dont il porte le nom mais, sur fond d'une ressemblance entre l'espèce singe et l'espèce humaine, une homologie fonctionnelle selon laquelle des qualités appartenant à la première sont transférées à la seconde par le truchement de ce clan justement dénommé singe. Ce sont les Singes, dans la culture moundang, qui sont propriétaires des rites (en association avec d'autres clans qui prennent en charge d'autres aspects du rituel initiatique) de la circoncision. Leur interdit alimentaire est, bien entendu, la chair du singe mais là encore, il nous est maintes fois arrivé de discuter avec des anciens qui n'hésitaient pas à dire avec quelque humour que si, par hasard, un homme du clan trouvait de la viande de singe bonne à manger, il en mangeait mais, qu'en tout cas, il se garderait de la façon la plus stricte de consommer des fruits qu'un singe aurait touchés.

Un dernier exemple touchant aux appellations animales révèle encore une toute nouvelle modalité de la relation entre clan et emblème totémique. Il s'agit d'un clan qui n'existe plus dans les cantons tchadiens dépendants de Léré mais dont on trouve des représentants chez les Moundang du Nord Cameroun, dans le village de Léra. Les Guney, dénomination dont nous n'avons pu trouver l'explication, racontent le mythe d'origine suivant : "Il y avait un chasseur, habitant du village de Léra, qui avait l'habitude de se poster aux aguets près d'une mare appelée ma sie sie, située non loin de cette localité. Un jour, il vit sortir de l'eau une énorme grenouille de la taille d'un bébé. Cette grenouille géante sortait régulièrement de la mare pour se mettre au soleil. L'ayant ainsi aperçue plusieurs fois, le chasseur décida de l'attraper. Il demanda à sa femme de préparer de la bouillie de mil fermentée, tedire, mais ne lui en donna pas la raison. La femme obéit et le chasseur alla déposer au petit matin le canari de tedire près de la mare. Comme à son habitude, la grenouille sortit de l'eau et avala gloutonnement la bouillie fermentée 
jusqu'à en être complètement soûle. Alors, l'homme ficela la bête ivre morte pour en faire un solide paquet qu'il rapporta à la maison. Il demanda ensuite à sa femme de faire bouillir le fa beremi, les écorces amères que l'on utilise pour soigner les plaies. Avec cette décoction il soigna les membres palmés de la grenouille qu'il avait découpés afin de donner à l'animal des mains et des pieds humains. La grenouille guérit et le chasseur lui fit don d'une servante comme épouse. Celle-ci mit au monde un garçon. Les descendants de ce jeune homme et d'une grenouille sont les membres du clan Guney qui existe encore aujourd'hui dans le village de Léra ". Le batracien en question, qualifié de Goliath par les naturalistes qui le considèrent comme le plus grand de son espèce, vit effectivement dans le Nord Cameroun. Il est interdit à la consommation pour les membres du clan Guney qui, au surplus, n'ont le droit ni de pêcher ni de manger les poissons de cette mare.

En somme, six appellations animales, six relations de nature différente : une allégorie de la force et du courage (le buffle), un motif de plaisanterie ou un signe néfaste (les oiseaux), une analogie fonctionnelle (les cynocéphales sont parmi les singes comme les gens du clan du Singe parmi les autres Moundang), l'incarnation d'un principe spirituel (le python pour la personne du chef de Tezoko), enfin une relation de filiation avec la grenouille partiellement transformée dans son anatomie. Quant aux Chiens, ban guo, qui sont l'un des clans de forgerons, nous ne trouvons guère d'indications sur la relation qu'ils entretiennent avec leur nom. Seule une petite phrase de leur devise nous parle des " chiennes aux gueules rouges " pour décrire la face menaçante des tueurs de Peuls qu'étaient, à les en croire, leurs belliqueux ancêtres. Nous aurions donc affaire à une ressemblance du même ordre que celle du buffle avec le terrible guerrier. Avec une nuance, cependant : entre le buffle et le guerrier, la relation est directement et globalement métaphorique, tandis qu'entre le tueur et le chien, il n'y a qu'un trait commun : la gueule rouge, signe de rage et d'agressivité. Il faut ajouter que le buffle est hautement valorisé en raison de ses attributs de force et en tant que gibier alors que le chien ne l'est pas du tout. Il faut écarter toute idée de rapprochement avec la fonction du forgeron qui est celle des hommes de ce clan. Les forgerons moundang ne sont nullement des gens de caste qui inspireraient crainte et mépris, mais, au contraire, des hommes éminents 
placés au même rang que les maîtres des masques et les maîtres de l'initiation et parfois même, comme dans leur devise, égalés à des chefs.

Il n'est pas impossible que le lecteur s'amuse (ou s'agace) du caractère quelque peu fantaisiste de ce "totémisme "à la manière moundang qui peut apparaître comme un simple jeu de l'esprit. Il me semble que l'on doit corriger cette impression en considérant l'ensemble des données qui comprend les noms des clans et des noms de sous-clans et en voyant les diverses façons selon lesquelles les Moundang font jouer ce qu'on pourrait appeler, suivant l'expression de Lévi-Strauss, l'opérateur totémique. Auparavant, il importe de souligner que derrière l'hétérogénéité de ces types de relations, il y a une opposition fondamentale entre un nominalisme construit sur différentes formes de rapports analogiques et un substantialisme affirmant l'identification du groupe avec le signifiant qui le désigne, substantialisme qui surenchérit, pour ainsi dire, sur la nature spécifique du groupe clanique. Dans la voie du nominalisme, l'opérateur permet de démultiplier la famille ou l'espèce en recourant aux variétés pour désigner les sous-clans. Nous avons mentionné plus haut un certain nombre d'espèces d'oiseaux; il est intéressant de noter que ce clan des Oiseaux comprend aussi un sous-clan nommé ban ju mweviki, " oiseau-sifflet " qui désigne non une espèce naturelle mais un sifflet confectionné avec des herbes très dures (tegil-bi) poussant dans les basfonds humides, sifflet que les Moundang rangent au nombre des masques, au même titre que les rhombes et d'autres catégories de sifflets faits en terre cuite. Il est clair qu'aux yeux des intéressés, mweviki n'est pas un terme hétérogène dans la série des oiseaux car il est doublement lié à cette famille, en tant que siffleur et en tant que masque, c'est-à-dire un objet qui, par sa forme ou l'un de ses aspects (aile, plume, sons émis) est rattaché à la gent ailée. Dans le même ordre d'idées, l'exemple du clan des Masques, précisément, les ban mundere, illustre bien ce procédé qui permet d'insérer dans une même série des termes de nature différente mais équivalents métonymiquement, c'est-à-dire équivalents moyennant un changement par translation de signifiants de l'axe associatif ou paradigmatique à l'axe syntagmatique. Dans quelques villages du sud du pays moundang, il existe ainsi des représentants d'un clan issu d'une scission d'avec les Bamundere : on leur a donné le nom ban su, "clan du fil " ou, plus exactement, de la fibre du cannabis avec laquelle sont fabriqués les 
masques-costumes. L'interdit du clan des Mundere est de se chauffer avec les graines de cette plante, l'interdit des gens du Fil est de faire du feu avec les tiges de ce cannabis; ils doivent même s'éloigner au plus vite à la simple vue d'un tel feu.

Prenons encore un autre exemple du même type et qui apparaîtra comme un jeu très pur de signifiant : il nous est offert par un clan allié à plaisanterie, guru, des ban su, celui des ban we qui habitent le village de Guélo. Avant de traduire le mot we, il faut raconter l'histoire que voici : l'ancêtre de ce clan était un fils du chef de l'important village de Lamé, " capitale " du pays des Pévé, les voisins méridionaux des Moundang. Des circonstances très particulières entourent la naissance de ce prince dénommé Gumbaï. L'une des épouses du chef de Lamé était enceinte et sur le point d'accoucher. L'attente se prolongeait et le père impatient fit demander si l'enfant était né et de quel sexe il était. La mère qui craignait que son mari ne fût enclin à voir dans le fils qu'elle venait de mettre au monde un rival de ses frères aînés, mentit et déclara qu'elle avait eu une fille. Une coépouse qui avait accouché à peu près en même temps, osa dire qu'elle avait eu un garçon. Alors le chef fit battre le grand tambour de la chefferie et proclama celui-ci son héritier. Lorsque plus tard il apprit qu'il avait eu aussi un autre fils, il fit aussi battre le tambour et dit à la mère qui avait menti : "Voilà, j'ai fait battre le grand tambour de la chefferie et maintenant c'est à toi d'inscrire (le verbe we signifie tracer des signes sur le sable, inciser une poterie ou une calebasse) le nom de ton fils ". La mère menteuse eut honte et s'enfuit de Lamé vers le pays moundang. On donna à son fils le nom de we qu'il transmit à toute sa descendance. L'interdit des membres de ce clan, on ne saurait en être très surpris - quel autre objet usuel est en rapport direct avec " l'écriture " ? mais quand même, est de manger dans des calebasses pyrogravées. Comme, d'autre part, le pluriel were est homophone d'un mot qui désigne une espèce de mouches piquantes, il leur est également interdit d'avaler de la nourriture dont on aurait d'abord chassé avec les mains ces mouches posées sur elle. La devise des ban we met en garde plaisamment les voisins : "Gens de Guélo, mettez-vous les doigts dans le nez, les mouches were sont sorties, elles vont pénétrer dans vos narines".

L'aspect de ce qu'on peut appeler le substantialisme du totémisme moundang, ne se rencontre sous une forme accusée que dans deux cas : 
chez les Bamundéré qui sont, on vient de le voir, les " inventeurs " du masque de fibres (Adler, 1998) et chez les Teuré, clan lié aux génies ou aux esprits de l'eau et qui font partie du groupe des premiers occupants évoqué dans le mythe de fondation du royaume. Les rites funéraires de l'un et l'autre clan (Adler, 1994) comportent une séquence au cours de laquelle l'âme du défunt est censée prendre la forme de l'objet totémique : pour le premier, un masque, ou plutôt, une partie du costume de fibres qui laisse le torse découvert et constitue seulement une ébauche, comme un état naissant de la forme véritable du masque, et pour le second, une pierre-génie aquatique, à peine rendue visible quelques instants avant de retourner dans son élément liquide pour $\mathrm{y}$ demeurer cachée aux yeux des vivants. Nous sommes ici en présence de deux modalités que j'appellerais " larvaires " (en pensant aux divers sens $\mathrm{du}$ mot latin larva, fantôme, revenant, masque) du passage du mort au monde des ancêtres, les mwe-zuwuñri, qui sont aussi des esprits errants qui viennent parfois hanter les vivants en se manifestant dans leurs rêves. Chez les Teuré, le moment d'apparition de la pierre-génie est suivi d'un rituel de manducation par tous les hommes de ce clan d'un gâteau de mil baignant dans une sauce faite avec les déchets d'un poisson et l'eau sale qui a servi à le nettoyer. Cette nourriture est comme la chair du clan et celui qui ne la supporterait pas et la vomirait se révélerait du même coup comme un bâtard. Chez les Bamundéré, le départ de l'âme du défunt est suivi de la fabrication dans le plus grand secret d'un nouveau masque de fibres qui reçoit sa consécration dans un repas sacrificiel auquel sont conviés des hommes des autres clans dits "mères des masques".

Ces deux cas (auxquels on peut joindre celui du python du chef ban suo) ne doivent pas conduire à boucher l'horizon en se disant qu'on a affaire à une croyance en une sorte d'« incarnation totémique " qui serait le propre de deux ou trois clans seulement et étrangère au reste de l'ethnie. Il s'agit plutôt d'une mise en acte de quelque chose d'implicite dans les représentations communes touchant aux relations entre la personne et le clan. Nous avons vu plus haut que tous les éléments qui sont inclus dans la fiche signalétique du clan sont autant de traits qui définissent les composantes de la personne. Les données que nous venons de fournir le montrent aussi, les éléments totémiques qui se présentent sous une forme animale n'occupent pas chez les Moundang une place 
privilégiée. Dans le cas de la pierre-génie des Teuré, dans celui du costume de fibres noircies des Bamundéré comme dans celui du python, nous avons affaire à des symboles dont la puissance tient sans doute à cette propriété qui est la leur de réunir en eux des attributs contradictoires qui les motivent comme signes de vie et de mort, de mors immortalis. La pierre " vit " sous l'eau et en sort sans changer d'état, éternellement pourrissante et éternellement vivante, comme nous le suggère l'étymologie que l'on nous a proposée du nom Teuré : te-be, " chose qui pourrit ". Le masque est une chose animée, dansante et parfois parlante : il peut brûler mais il renaîtra de ses cendres, toujours le même. Quant au serpent, qui sert si souvent en Afrique de symbole d'immortalité (l'exemple dogon est particulièrement célèbre en raison du grand masque qu'on taille pour commémorer la renaissance du premier ancêtre), on le voit ici représenté blotti en permanence sous le grenier du chef où il demeure invisible en attendant l'heure ultime pour faire son office de " passeur d'âme " puis retourner dans son trou jusqu'à la fois suivante.

Meyer Fortes (1945) avait noté dans sa conclusion sur le totémisme des Tallensi du Ghana que " les animaux sont des symboles particulièrement appropriés du caractère vivant et vivace (livingness) des ancêtres, de leur immortalité [...] Ils symbolisent en particulier (l'auteur fait allusion aux fauves, aux bêtes à crocs) l'agressivité potentielle des ancêtres comme sanction suprême des valeurs culturelles tallensi ". Il est clair que la culture moundang nous donne à penser une situation bien différente où les animaux n'ont ni l'exclusivité ni même une place prépondérante, nous le disions à l'instant, dans la communication des vivants avec le monde de l'ancestralité. La place qu'elle fait à l'agressivité du monde animal vis-àvis de l'homme, nous la trouvons dans le tableau des catégories de génies qui apportent le désordre et les maladies : les syinri des femmes et les tegwari des hommes. Ce sont essentiellement des espèces animales qui constituent ces catégories nosologiques : gibiers de brousse (panthères, antilopes telles le céphalophe et l'hippotrague) et gibiers d'eau (hippopotames et lamantins); grands volatiles au vol lourd incertain (l'autruche et l'outarde); poissons (différentes variétés de silures, capitaine, lates niloticus) ; reptiles (tortue, varan et certains serpents dont le principal est le python). Bien entendu, ni le serpent, ni le buffle, ni les oiseaux, ni le 
chien, ni le singe et, encore moins la grenouille, ne sont dans un rapport d'agressivité avec les membres du clan qui porte leur nom. En revanche, et là nous abordons un autre aspect du système clanique moundang, il y a un certain nombre de clans qui entretiennent avec des animaux agressifs et dangereux en vertu d'attributs qu'ils ne doivent pas uniquement à la nature, une relation éminemment positive. Avec ces animaux qui prennent pour eux valeur d'emblèmes et qu'ils exaltent dans leurs devises, ces clans ont des rapports réels et pratiques. Nous passons donc maintenant des espèces à fonction classificatoire aux espèces dont la fonction est utilitaire, en l'occurrence alimentaire, autrement dit, nous glissons d'un usage diacritique du symbole totémique à l'expression, pour des clans particuliers, d'une marque de reconnaissance pour les services qu'ils rendent à la société toute entière. Les clans Teuré et Tezun (ce dernier nom est celui d'une variété de Ficus) sont deux clans associés l'un à l'autre en tant que détenteurs d'une maîtrise de l'eau; accessoirement, il faut leur adjoindre les gens de la Pirogue, ban-dabe, qui forment un sous-clan des ban-suo, les forgerons. Ils ont pour tâche spécifique d'effectuer les rites magiques indispensables pour qui veut aller sans risque chasser les grands mammifères aquatiques, l'hippopotame et le lamantin. Les Moundang les rangent dans une catégorie qu'ils désignent par les termes gon woke, la chair froide, la chair humide, et qui inclut le crocodile, la tortue d'eau et certains reptiles de rivière. Les syinri, les génies de ces animaux, nous l'avons dit, sont porteurs de maladies, mais les traitements rituels exécutés par les clans chasseurs (notamment la préparation culinaire de certaines portions de viande grillées sur feu de charbon de bois en brousse) rendent la chair de l'hippopotame et du lamantin consommable par tous sans danger. Le clan Gwere (auquel, d'ailleurs, se rattache le héros fondateur Damba) est un clan de chasseurs de gibiers de brousse et deux de ses sous-clans portent des noms d'espèces sauvages: Gwe mabele, les Gwere de la mangouste, et Gwe ban nemini, les $\mathrm{Gwere}$ de la biche. Mais pour l'ensemble des membres de ce clan, l'animal emblématique est l'hippotrague (l'antilope-cheval), gibier noble mais extrêmement dangereux à chasser car il est pourvu d'un génie qui rend son contact presque mortel tant les maux qui vont frapper l'imprudent chasseur sont graves : insupportables céphalées, cécité, etc. 
Si toutes les précautions rituelles sont prises, tout le monde peut consommer de sa chair, à l'exception de la tête, interdit qui vaut pour toutes les espèces porteuses des maladies classées tegrwari, c'est-à-dire qui concernent la tête. Ce n'est sans doute pas malgré mais à cause de ces dangers que la devise des Gwere chante l'antilope-cheval comme "le bœuf contre lequel on ne peut obtenir aucune femme, le bœuf que l'on ne peut attraper avec aucune corde ". Les Teuré et les Tezun exaltent dans des métaphores du même type l'hippopotame qu'ils décrivent comme " la princesse de l'eau, la vache sans bosse ", celle en échange de laquelle on ne peut obtenir aucune femme. C'est une étrange opposition (surtout quand on sait que la bouche qui doit la proférer ne peut être que celle d'une épouse, donc d'une étrangère au clan) que fait ici la devise entre l'animal noble que les hommes du clan sont seuls habilités à capturer et à tuer et auquel ils s'identifient et le vil bovin (comme nous disons le vil argent) que l'on fournit en échange d'une fermme ou que l'on reçoit quand on donne sa fille ou sa sœur. Cette figure de rhétorique semble évoquer un échange social d'un autre ordre, plus noble, plus glorieux que l'échange des femmes. De quoi peut-il bien s'agir ? L'antilope-cheval ou l'hippopotame, que la technique et les rites appropriés accomplis par les clans de chasseurs spécialisés rendent aptes à la consommation pour tous les Moundang, sont pour ces clans qui en font leur emblème quelque chose que nous définirions comme des interdits inverses. Si l'on peut définir l'interdit totémique par la transformation d'une espèce non interdite pour tous en un interdit possédant une valeur diacritique pour un clan, l'inverse dont nous parlons consiste dans la transformation d'une espèce interdite (ou du moins si dangereuse que cela revient au même) pour tous en une chair consommable par tous moyennant le travail et les rites de certains clans spécialisés. Les devises des chasseurs tendent ainsi à esquisser un ordre hiérarchique qui va à l'encontre de l'ordre clanique, en plaçant, au-dessus de l'animal ou de l'objet totémique dont l'interdit symbolise l'exogamie clanique, l'animal qui symbolise le don particulier et précieux que leurs clans font au reste de la société. Dans la conception que se font les Moundang du monde et 
de la société, seul le roi est dans cette relation d'échange inégal ${ }^{16}$ avec l'ensemble de la population de son royaume. Il ne s'agit pourtant que d'une esquisse car nous sommes loin ici, très loin, d'une véritable différenciation fonctionnelle entre clans, qui conduirait à la formation d'une organisation en castes. Nous sommes quand même en présence de différences qui ne sont plus, dirions-nous, indifférentes car elles sont chargées d'un contenu social effectif. La tendance des clans liés à la chasse, à la forge et aux masques à faire prévaloir la fonction - donc leur contribution spécifique au bien commun - sur le trait distinctif comme tel n'infirme pas ce qui a été dit sur les caractères formels du système clanique moundang. Elle rend compte du fait suivant, signalé dès le début de cette analyse, à savoir que l'existence d'importants écarts entre les fonctions remplies par certains clans conduit ceux-ci à transformer en supériorité sur les autres la différence dans leur " rendement social ". La royauté sert, en quelque sorte, de rempart contre l'institutionnalisation de cette supériorité symbolique auto-affirmée en supériorité sociale et, à plus forte raison, en supériorité politique. Nous ne croyons pas que la royauté " protège " le reste de la société contre l'inégalité mais que c'est l'égalité formelle entre les clans, tous les clans, y compris ceux issus de Damba, qui protège la royauté. Comment ? en réduisant les spécialisations techniques et professionnelles à des spécialisations rituelles ${ }^{17}$ lesquelles renvoient à un ordre cosmique dont le roi est le garant. Toute

16 Cette inégalité qui se manifeste essentiellement dans le domaine économique et matrimonial, ce qui est tout un, se résume dans la formule : le roi est hors-clan et donc il prend (ou plutôt il prenait avant que la loi le lui interdise) sans verser de compensation matrimoniale toute femme qui a l'heur de lui plaire. Etant hors-clan, le roi n'a pas d'interdit totémique, il n'a que des interdits individuels qui lui sont indiqués par le devin à l'occasion d'une consultation motivée par une maladie ou une autre infortune. C'est d'une variété de silure rouge que doit s'abstenir le roi actuel mais, au dire des informateurs que confirme l'intéressé, cette prohibition alimentaire s'étend à tous ses descendants.

17 Il s'agit évidemment de processus qu'on ne saurait relier simplement à une volonté ou à une intentionnalité politiques émanant du pouvoir ou de l'appareil qui fait cortège à la personne royale. On serre de plus près la réalité ethnographique en disant que les activités économiques qui sont en cause, telles que la chasse et la forge, sont à considérer avant tout comme génératrices de différenciation symbolique et non de différenciation sociale. La première, il n'est pas inutile de le rappeler, peut avoir pour le groupe, autant sinon plus d'importance que la seconde. 
la puissance dont la royauté est investie est présentée comme le résultat de l'échange inaugural exposé dans le mythe de fondation, échange inégal dont la finalité est l'instauration de la seule coupure sociale possible et acceptable, celle des clans d'avec la personne et l'institution royales. Une rapide comparaison avec le système clanique du Buganda sera des plus éclairantes.

\section{Le totémisme dans le royaume du Buganda}

Dans "Totem et caste", l'un des chapitres les plus forts et les plus étonnants de virtuosité structuraliste de La Pensée Sauvage, Lévi-Strauss invoque le cas des Baganda au moment où il va aborder le problème posé par le titre même de ce chapitre et dont il nous donne la formulation suivante (p.150) : " [...] il est clair que, d'un point de vue superficiel, il y a certaines analogies entre les tribus australiennes et les sociétés à castes : chaque groupe y exerce une fonction spécialisée, indispensable à la collectivité dans son ensemble, et complémentaire des fonctions attribuées aux autres groupes. "Cela suffit pour concevoir un très vaste groupe de transformations où les deux systèmes présentant une opposition maximale, notamment sous le rapport exogamie/endogamie, trouvent ensemble leur place et donc, c'est le but poursuivi par ce type d'opération logique, un gain de mutuelle intelligibilité. Que viennent faire ici les Baganda, quelle est la place qui leur est assignée ?

On l'aperçoit sans peine en indiquant seulement les principales caractéristiques de ce peuple de l'Ouganda : il est divisé en une quarantaine de clans totémiques dont plus des trois quarts ont des appellations animales et les autres végétales (une seule appellation fait exception : Cœur) ; chacun d'entre eux est lié à un territoire dominé par une ou plusieurs collines et sur lequel ses droits sont reconnus et sacralisés par la présence de son cimetière (celui de ses chefs, notamment) et celle des sanctuaires de ses divinités propres (il ne faut pas oublier qu'il existe, par ailleurs, des dieux " nationaux "). En outre, chacun de ces clans est pourvu d'interdictions alimentaires correspondant à ses totems et de prohibitions matrimoniales. Un grand nombre d'entre eux est investi de fonctions techniques (la forge, la confection des vêtements d'écorce 
battue et la fabrication des pirogues, par exemple) et de tâches rituelles particulières. Des clans de ce type seraient déjà presque des castes, en tout cas, des groupes relevant encore de la formule totémique mais tirant vers ce pôle opposé qu'est la société constituée de castes.

Ce n'est évidemment pas dans une perspective comparative aussi large et imposante que nous envisageons le cas du Buganda. Néanmoins, la position prise par Lévi-Strauss nous intéresse dans la mesure où elle nous permet de préciser une divergence théorique et d'apporter ainsi un argument supplémentaire en faveur du choix de notre démarche. La leçon du cas ougandais se résume pour lui à ceci : une société composée de clans totémiques qui sont aussi des castes fonctionnelles (l'auteur ajoute même l'adverbe " incontestablement ") n'est pensable dans ses aspects apparemment contradictoires que si l'on voit en elle une forme intermédiaire entre une "structure totémique pure " (qui n'est évidemment qu'une pure notion logique exigée par le recours au groupe de transformations) et une société à castes, c'est-à-dire "où chaque groupe social tendra à former système, non plus avec les autres groupes sociaux mais avec certaines propriétés différentielles conçues comme héréditaires. "(op.cit., p.154). Ce qui nous frappe d'abord est le fait que l'auteur raisonne sur ce cas comme si le facteur royauté, qu'il mentionne, bien sûr, était quelque chose de tout à fait secondaire par rapport à ce type d'organisation clanique. Or qu'en est-il si l'on regarde le texte de Roscoe d'un peu plus près ? La royauté est première, peut-on y lire immédiatement, et fondatrice, à tous égards : c'est d'elle que procède l'organisation de la société, la mise en place des clans et l'attribution à chacun d'entre eux d'un statut propre. Kintu, le fondateur de la dynastie régnante et qui fut la seule à régner sur le Buganda, est le premier homme $^{18}$ et le héros culturel auprès de qui les ancêtres des clans actuels

18 Kintu est un personnage qui appartient entièrement à la mythologie du Buganda qui en fait un héros céleste source de tous les biens, mais dont l'épouse eut une conduite inconsidérée qui fut la cause de la présence de la mort (Wamumbe, la Mort, est le frère de Kintu) dans le monde humain. Il apparaît aussi dans le cycle des récits légendaires ayant trait à "l'empire des Bacwezi n. Nous y apprenons qu'il règne sur un royaume souterrain et qu il a fait don aux hommes des semences et du bétail. Le premier des rois que l'on peut qualifier d'historico-légendaire est le troisième des souverains de la liste dynastique " officiellement " reconnue par la tradition; il porte 
ont appris les principaux arts de la civilisation. C'était tout d'abord un chasseur (mais le mythe le présente aussi comme le premier possesseur de vaches) et, dans ces temps primitifs de l'humanité, on ne vivait que de la chasse. Comme la population devenait de plus en plus nombreuse, Kintu dut établir des règles de vie collective et, notamment, des interdits de chasse spécifiques pour chacun des clans qui eut ainsi son totem. Cette réglementation, en rationnant partiellement le gibier disponible, répondait à la nécessité de sauvegarder autant que possible les ressources cynégétiques de la région. Que l'instaurateur de ce " totémisme écologique "19 soit le détenteur du pouvoir politique n'est nullement indifférent. Cela réaffirme sur le plan du discours mythique ce que dit la tradition orale et donc, dans une certaine mesure, la chronique historique : l'établissement d'une relation avec le roi est le passage obligé de tous les groupes qui sont à l'origine des clans qui peuplent le royaume, ceux qui nous sont présentés comme immigrants (venant généralement du royaume voisin du Bunyoro ou, plus rarement, de celui du Busoga) et les autres, réputés " indigènes " mais auxquels l'autochtonie ne confère aucun privilège particulier, car elle est ici, comme chez les Moundang, une détermination sans pertinence ${ }^{20}$. Nous venons de le dire, ce sont les cimetières et les

le nom de Kimera, personnage qui se rattache aussi à la généalogie des héros de la légende des Bacwezi qui régnèrent sur l'empire du Kitara (J. P. Chrétien, 1985). Dans cet article dont le seul titre indique déjà la position catégorique qui est la sienne sur l'historicité de cet empire : "L'empire des Bacwezi. La construction d'un imaginaire géopolitique ", J.P. Chrétien écrit : " Les maîtres du légendaire Kitara apparaissent plutôt comme les ancêtres des dynasties régnantes du XIX siècle : Babito ("Wawitu") au Bunyoro... et même les rois du Buganda, issus de Kimera ".

19 La notion de totémisme "écologique " a été employée de façon convaincante par M. Dupire (1991) dans un article intitulé justement : "Totems sereer et contrôle rituel de l'environnement ". Il faut noter que dans cette société Sereer Ndut dépourvue de pouvoir politique centralisé, il existe une certaine hiérarchie entre trois ensembles de clans d'origine différente. La prééminence appartient à ceux qui ont suivi la voie maritime et sont liés de ce fait aux éléments cosmiques : mer, pluie, feu et soleil ; puis viennent ceux qui exercent leur contrôle sur les insectes et les oiseaux nuisibles aux cultures; et enfin, ceux qui sont liés aux charognards, amis des bergers, et au vent violent.

${ }^{20} \mathrm{La}$ note qu'on a lue plus haut semble suggérer que la seule autochtonie qui se puisse concevoir chez les Baganda est celle de Kintu décrit dans le rôle d'un dieu " infernal ". En tout cas, il est intéressant de relever que ces Baganda qui se sont donnés Kintu comme fondateur de leur dynastie royale sont les seuls, parmi les populations qui les entourent, à se présenter comme un groupe homogène tant du 
sanctuaires qui font loi dans le rapport entre clans et territoire. Une minuscule anecdote peut simplement servir à indiquer le fait qu'une rencontre a eu lieu entre le premier arrivant et Kintu, ou l'un de ses successeurs, et qu'un lien amical s'est créé entre eux, ou bien mentionner qu'il s'agit d'un parent du roi ou de quelqu'un ayant exercé telle activité à son service (un berger, par exemple) qui, pour une raison ou une autre, va se trouver à l'origine de tel clan.

Sans nous arrêter à chacun des noms de clan de la liste apparemment complète que nous fournit Roscoe, nous allons donner quelques cas pour illustrer ce mode de "clanification" opérée par le roi du Buganda. Les Léopards et les Lions sont, comme l'on peut s'y attendre, des clans royaux. Chez les Léopards, seule une branche, un lignage, fournit des rois, les autres sont appelés "princes-paysans " et leurs héritiers en ligne directe : "princes des tambours royaux ". Jadis très (trop) nombreux, ces princes paysans étaient, pour une grande partie d'entre eux, mis à mort pour que leur masse ne mette pas en danger le trône à chaque succession. Une seule charge officielle incombe aux membres masculins de ce clan : l'entretien du sanctuaire de Magonga où, dit-on, Kintu avait vécu et d'où il avait subitement disparu. Les Lions nous sont présentés comme un clan dont l'ancêtre est issu d'un de ses fils auquel il avait confié, à la fin d'une partie de chasse, le soin d'écorcher et de faire sécher la peau d'un lion qu'il venait de tuer. $C^{\prime}$ est donc à des membres de ce clan que revient la tâche de confectionner avec cette peau des sièges et des tapis destinés au roi exclusivement. A eux également, revient la garde de sanctuaires royaux importants. Aucun d'entre eux n'est éligible au trône mais ils doivent donner une de leurs filles au roi et si celle-ci met au monde un garçon, il est aussitôt tué par strangulation. Le sort fait à ces deux clans montre bien l'un des aspects " très moundang " de la clanification à la mode du Buganda : des marques de reconnaissance symbolique, des charges rituelles honorifiques, certes, mais surtout des précautions et des mesures énergiques pour les éloigner du pouvoir, car si la mise en clan y contribue, à elle seule, elle n'y suffit pas.

point de vue social qu'économique et il n'est question chez eux ni d'étrangers envahisseurs qui auraient statut de conquérants ni de conquis qui seraient des autochtones. 
Un cas tout différent est celui de la Loutre. Leur ancêtre fut katikiro $\mathrm{du}$ roi, titre que l'on donne au dignitaire qui est une sorte de premier ministre. Kintu l'assassina lors d'une de ces terribles crises de colère dont il était coutumier. Les hommes de ce clan ont pour tâche de fabriquer les vêtements d'écurce battue que porte le roi. Ils ont aussi la charge de lui fournir du tabac. Certains de leurs prêtres desservent le culte de temples où sont honorés des dieux nationaux. Passons au clan de la Sauterelle qui a comme caractère spécifique des obligations qui nous rappellent étrangement les célèbres coutumes australiennes dites de l'intichiuma : les insectes éponymes constituent, en effet, une nourriture très appréciée des Baganda, aussi bien, au moment de leur reproduction, un ancien doit-il avoir un rapport sexuel avec sa femme afin de favoriser la multiplication de cette espèce. A quel point cette obligation est consubstantielle au clan, on le voit dans la règle qui autorise une femme Sauterelle à attraper et faire cuire des sauterelles pour son mari mais lui interdit strictement d'en manger elle-même.

Le clan de la Vache sans queue est celui qui fournit les forgerons héréditaires du roi. Ils sont astreints à payer un tribut en houes qu'ils envoient à la Cour. D'autres clans ont également le travail de la forge dans leurs attributions spécifiques : celui de l'Hippopotame qui fabrique les armures pour le roi et celui de la Genette qui forge des armes. Le clan de l'Eléphant doit fournir au roi son poisson favori, le beurre servant aux pratiques d'embaumement et un certain type très particulier d'habit en écorce battue. Il y a d'autres clans pêcheurs qui doivent fournir une part de leur production au roi : celui du Coeur et celui du Protoptère (le dipneuste). Ce dernier est aussi l'un des principaux fabricants de canots, notamment des grandes embarcations capables d'affronter les eaux parfois tumultueuses du lac Victoria. De son côté, le clan du Haricot se voit attribuer la tâche d'assurer la maintenance de ces canots et de fournir leurs équipages. Le clan du singe Colobe fournit le chef des bouchers du roi, mais aussi l'un des hommes que l'on met à mort lors des funérailles royales. Enfin, et nous nous en tiendrons là, le clan du Champignon (appelé ainsi parce que des champignons avaient poussé sur la tombe de leur ancêtre au lendemain de son inhumation) est réputé avoir introduit dans le pays la banane plantain et une certaine variété de figuier (précisément celle dont l'écorce est travaillée pour la confection de vêtements). 
Les membres de ce clan font donc aussi des vêtements d'écorce ; ils fabriquent, par ailleurs, le tabouret sur lequel le roi siège en certaines occasions. Ils ont la charge rituelle de transporter quotidiennement l'un des grands tambours royaux depuis son abri en brousse jusque dans l'une des cours du palais, d'où il est retiré la nuit venue.

En résumé, tous les clans ont des charges ou des tâches rituelles qu'ils doivent assurer au service du roi et certains, des spécialisations techniques qui ne sont jamais exclusives, qui ne constituent donc pas de monopoles, comme on vient de le voir. Les forgerons, les fabricants de canots, les tailleurs d'habits en écorce battue sont des artisans qui mettent également leur technique au service du roi. Comme chez les Moundang, les clans sont les détenteurs de tous les savoirs et de tout savoir-faire, mais le mythe du Buganda évoqué plus haut attribue leur invention à Kintu qui fut le premier roi et le premier bénéficiaire des compétences réparties entre les clans. Une telle modalité d'articulation entre royauté et clans, qui n'est qu'ébauchée dans le royaume de Léré, trouve ici une forme plus achevée, dans la mesure où l'institution royale absorbe, si l'on peut dire, aussi complètement que possible la substance sociale des clans en polarisant sur elle-même la multiplicité des spécialisations fonctionnelles et rituelles qui leur sont dévolues. Nous n'avons pas affaire, comme le dit Lévi-Strauss, à des clans totémiques, qui seraient en même temps des castes professionnelles, mais seulement à des clans d'un type sui generis, certainement fort proche du type moundang. Le trait qui caractérise ce type est la présence d'un roi, d'une part et, en relation causale avec cette présence, d'autre part, la mise à égalité de toutes les spécialisations rituelles et technico-économiques par réduction de celles-ci à la fonction de marques différentielles de chacun des clans. Nous parlons délibérément de relation causale parce que le roi - qu'on nous permette ici de faire un emprunt, sans que cela soit pris avec un trop grand sérieux, à la très célèbre théorie aristotélicienne des quatre causes - est à la fois cause finale et cause efficiente de ce mode de répartition des tâches entre groupes sociaux. La cause finale, nous la trouvons dans le contenu idéologique manifeste du mythe de Kintu, héros en qui sont réunis l'homme 
des compétences et le principe de souveraineté21 ${ }^{21}$ quant à la cause efficiente, c'est le poids spécifique dans la structure sociale, d'une telle institution politique capable d'enchainer, si l'on peut dire, les clans au pouvoir central. La question essentielle que soulève ce " totémisme avec castes " (même s'il ne peut s'agir que de formes très embryonnaires), est de savoir s'il peut ou non exister en dehors d'une royauté et, si la réponse est que ce cadre est nécessaire, de se demander pourquoi il en est ainsi.

Une chose est certaine, dans les sociétés d'Afrique occidentale où l'on peut légitimement parler de castes (cf. Tal Tamari, 1997, ouvrage qui reprend une thèse soutenue en 1988 et Olivier Kyburz, auteur d'une thèse sur les Haalpulaaren du Sénégal, soutenue en 1995), on a affaire à des ensembles hiérarchisés comprenant au moins trois groupes distincts : les hommes libres formant ou non une véritable aristocratie, les gens de caste (ceux qu'on désigne comme nyamakala dans le monde mandingue) et les esclaves ou personnes non libres dont le statut est assimilable à celui d'un captif. Toutes ces sociétés sont composées de clans ${ }^{22}$ et coiffées

${ }^{21}$ La conception qu'ont les Baganda de la souveraineté royale est très proche de celle des Moundang, du moins en ce qui concerne son rapport avec le système clanique. Fallers (1964), dans un texte consacré à la "stratification sociale dans le Buganda traditionnel ", nous rappelle les métaphores employées pour désigner le roi, le $k a b a k a$ : " lion ", " reine des termites" et aussi " feu du charbon de la forge "; ce sont autant de manières de décrire la force et la cruauté qui sont les siennes. Il ajoute cette remarque très significative : " le caractère unique du Kabaka est souligné par le fait que les princes, à la différence des membres des clans du commun, n'ont pas un symbole totémique collectif. Plutôt, ils n'ont que les totems de leurs mères, lesquelles appartiennent à divers clans roturiers. Le royaume appartient, non aux princes en tant que groupe, mais au kabaka".

22 Contrairement à ce que nous avons vu dans le cas moundang, la notion de clan dans le cas manding n'est pas une notion simple dont on peut dire clairement ce qu'elle recouvre. Le clan bambara ou malinke ne relève pas du type segmentaire comme c'est le cas, en théorie, chez les Nilotiques et il ne relève pas non plus du type moundang dont il est cependant beaucoup plus proche, en raison de sa profondeur historique et de son caractère supra-ethnique. Nous trouvons chez C. Monteil (1924) des éléments très utiles à la compréhension des caractères spécifiques du clan dans la société soudanaise traditionnelle. D'un mot, on peut dire que c'est sa dimension politique qui est essentielle. Il rejoint ici la position de Delafosse lui-même qui, dans le texte cité, se livre à une analyse très fine de la notion de dyamu qu'il traduit par " titre d'honneur" ; il s'agit d'une devise qui ne renvoie pas directement à une catégorie sociale définissable comme clan mais à un ensemble susceptible d'une très grande extension, même "internationale ", tout en ayant une référence ancestrale et 
d'une forme de royauté ou de chefferie où se combinent des traits extrêmement anciens remontant au moins à la constitution de l'empire du Mali et très probablement à l'antique royaume du Wagadu avec des traits résultant de l'islamisation qui a été parfois très précoce dans la zone sahélienne et qui s'est toujours faite par le haut. Nous avions signalé en commençant cette étude que Delafosse (1920) s'était refusé à voir dans l'interdit (tana) qui est spécifique à chaque clan, quelque chose qui relève de la notion de totémisme ${ }^{23}$. Son attitude était alors fondée sur une stricte adhésion à la définition qu'en donnait Van Gennep (1908) ; il jugeait celle-ci " précise " et en prenait toutes les propositions à la lettre, notamment la croyance en l'existence d'un lien de parenté entre le totem et les membres du clan éponyme. Mais ce qui nous importe, en l'occurrence, c'est que, totémiques ou non, certains des clans (ou des fractions de clans) du Mande pourvus d'une spécificité professionnelle ont été transformés en castes et ce, sous l'impulsion ou de par la volonté du pouvoir ${ }^{24}$. L'idée que des unités sociales de base doivent leur existence

qui peut être qualifié comme une " maison" avec des connotations comparables aux anciennes maisons nobiliaires de l'Europe médiévale.

23 Ce n'est pas le point de vue d'un chercheur comme M. Jackson (1974) qui s'interroge au contraire sur la nature des rapports qui existent dans le système clanique des Kuranko, population mandingue islamisée de la Sierra Leone, entre totémisme, alliance senankuya (dite parenté à plaisanterie) et groupes castés. La caractéristique de ce système clanique est qu'il englobe dans un même ensemble des clans hiérarchiquement ordonnés : ceux qui sont détenteurs du pouvoir, ceux qui sont musulmans, ceux qui sont roturiers et ceux qui constituent des groupes castés de musiciens et de forgerons. Mais cet ordre hiérarchique est contrebalancé et, en quelque sorte, corrigé par les liens de senankurya et les symboles totémiques qui jadis, c'est l'hypothèse de l'auteur, auraient œuvré sur une vaste étendue géographique, dans le sens d'une certaine unité et d'une plus forte solidarité entre clans, tribus et groupes ethniques dont les rapports avaient été bouleversés sinon presque complètement défaits par les guerres et les migrations de populations qui s'ensuivaient.

${ }^{24}$ La conception que se fait Hocart (1978) des rapports entre castes et royauté nous paraît aller dans le même sens que celle que nous faisons nôtre ici. Son intérêt est de nous faire comprendre qu'aux yeux mêmes des membres du groupe casté, la primauté est accordée aux aspects rituels et magiques des fonctions qui sont les leurs et non à leurs aspects économiquement utiles. Ainsi, nous apprenons que : " le barbier n'est pas plus, pour eux, le propriétaire d'une échoppe de barbier que le blanchisseur le gérant d'une blanchisserie, comme ils le sont pour nous : ils officient dans le cadre du rituel en tant que prêtres mineurs. Il en va de même des autres castes. Les forgerons fabriquent les statues des dieux.[...] les potiers officient comme prêtres dans 
à la volonté du pouvoir, on la trouve déjà exprimée chez les Kuranko mentionnés dans la note qu'on vient de lire : Jackson (loc.cit.) nous dit, en effet, que selon leurs traditions orales, c'est Dieu lui-même ( $\mathrm{Ala}$ ou Altala) qui, au commencement du monde, créa dans le Mande les différents clans en donnant à chacun son statut et sa profession. Ainsi les Mansaray reçurent la chefferie et leur totem fut l'hippopotame, les Mara la richesse avec le totem léopard, les Sise furent des marabouts ayant pour totem le crocodile et les Konde des guerriers avec pour totem le léopard, comme les Mara. En ce qui concerne les castes, leur apparition pourrait être la conséquence d'un événement majeur de l'histoire médiévale de l'Afrique de l'Ouest. Telle est, au grand étonnement de nombreux chercheurs africanistes, l'interprétation très personnelle que nous propose Tal Tamari (loc. cit.) de l'épopée de Sunjata, le héros qui défit sur le champ de bataille le roi-forgeron Sumanguru Kante et qui, fort de cette victoire, donna de nouvelles fondations à l'empire du Mali. L'enclume et le balafon, symboles et moyens de la puissance magique du roi déchu, furent transformés par le vainqueur en outils et instruments réservés à des groupes endogames de spécialistes mis à part des autres clans, les forgerons et les griots et musiciens de toutes espèces. Ceux-ci étaient ainsi, de façon radicale et définitive, mis hors d'état d'émettre la moindre prétention au pouvoir. Si l'on admet cette hypothèse qui nous semble très ingénieuse (et qui a aussi, notons-le au passage, quelque chose de satisfaisant pour l'esprit dans la mesure où structure et histoire y ont chacune leur part), une partie du chemin est faite, nous pouvons nous représenter (ou imaginer, diront certains, de préférence) par quel processus un ordre social nouveau peut advenir. Encore faudrait-il ne pas réduire complètement ce processus de la "fonctionnalisation " des groupes professionnels à un moyen politique de subordination ou d'assujettissement à la classe aristocratique et au pouvoir royal qu'elle soutient. Il existe d'autres possibles que l'on peut inscrire dans le système de transformations que nous évoquions plus haut et on en arrive même à un cas de figure montrant une sorte de réversibilité entre le fait

les temples des déesses villageoises et du dieu à tête d'éléphant. A Ceylan, le minimum, c'est d'avoir un barbier, un blanchisseur et un tambourinaire. "(loc. cit. 187-188). 
d'assigner à un groupe social une fonction technique ou rituelle et celui de lui attribuer un symbole totémique comme caractère distinctif.

Dans un article tout récent intitulé "La fabrication de la foulanité ", O. Kyburz (1998) développe une telle idée qui nous semble apporter du nouveau dans ce domaine. Il la résume ainsi dans sa conclusion : "L'examen de l'ensemble des "castes" artisanales de la société Haalpulaar (Toucouleur) montre que leur développement obéit à un processus de différenciation interne à la société qui relève de la distinction bien plus que de la spécialisation fonctionnelle. Une interprétation nouvelle du mythe d'origine des Boisseliers et des Joueurs de luth met en évidence le lien qui existe entre la création de " castes " artisanales et l'affirmation de la foulanité ". La foulanité (pulaaku) renvoie à un système de valeurs éthiques et de valeurs de civilisation qui dépassent le cadre socio-politique de tel groupe particulier peul ou toucouleur. Dans le cas des Haalpulaaren de la vallée moyenne du Sénégal qu'il a étudiés, O. Kyburz a recours à une argumentation tout à fait intéressante. L'analyse des groupes que l'on appelle "castes artisanales " montre qu'il n'y a pas toujours congruence entre la fonction et le statut, autrement dit que le groupe n'est pas simplement défini par l'activité professionnelle qui sert à le désigner pas plus que par le statut correspondant. Même dans le cas approchant qui est celui des forgerons et des cordonniers, il y aura des différences statutaires liées à leurs origines ethniques. Sinon, on rencontrera des cas où il y a un statut et plusieurs fonctions et des cas où c'est l'inverse. L'exemple des Boisseliers et des Joueurs de luth nous conduit au mythe qui a été invoqué plus haut et qui nous dit ceci : il y avait trois frères, fils d'un père et d'une mère peuls qui, à la suite de certaines circonstances, vont devenir l'un boisselier, l'autre joueur de luth et le troisième restera Peul. Le boisselier " ustensiliaire ", distinct du harangueur et du piroguier, se distingue bien sûr du Peul en " quittant la pulaaku"; le joueur de luth, distinct, quant à lui, du tisserand joueur de luth (comme ce dernier se distingue du tisserand tisseur), se distingue évidemment aussi du Peul, pour la même raison que le boisselier. Seul le Peul se définit par la pulaaku, en opposition avec le statut qui est celui que ses deux frères se sont vus attribuer en raison de l'activité qu'ils ont "choisie ", nous dit le mythe. On voit ainsi comment une spécificité professionnelle peut, par l'effet de ce que nous qualifierions comme un 
surcodage symbolique, prendre une valeur distinctive qui semblait réservée au symbole totémique. Il nous semble aussi que nous devons accorder une grande importance théorique à une ultime remarque de Kyburz qui touche au problème du pouvoir. Il met, en effet, ce qu'il appelle le foisonnement des catégories peules en relation avec des événements politiques majeurs de l'histoire de cette population : d'abord la domination mandingue qui avait mis au premier plan la caste des forgerons et celles des griots que les Peuls ont supplantées par la paire boisseliers-joueurs de luth, puis la montée en puissance (vers le milieu du $\mathrm{XVIII}^{\mathrm{e}}$ siècle, après la chute des Deeniyankoobe) de l'Islam. Cet Islam contre lequel la foulanité a eu à se réaffirmer parce que, nous dit-il, "il nie la distinction".

Si nous revenons maintenant à nos "Etats claniques", il nous reste à déterminer ce qu'il en est des cas comme celui des Moundang et des Baganda où l'apparition de la royauté n'a pas bouleversé de fond en comble l'ordre ancien et n'a engendré qu'un strict minimum de hiérarchie sociale (du moins chez les premiers; nous reviendrons sur cette différence essentielle qui touche à la nature de l'Etat dans chacun des deux royaumes) et où aucun clan ne s'est détaché du reste pour se constituer en un groupe fermé et endogame. C'est précisément sur le fait même qu'il existe un lien très direct entre les deux caractéristiques que sont la réduction de la hiérarchie à la seule opposition roi/clans et la non hiérarchisation de ces derniers entre eux qu'il convient de s'interroger. En guise de réponse, nous nous contenterons de suggérer que cette conjonction peut apparaître comme la condition d'émergence d'une forme d'état social à peu près stable, dans laquelle royauté et clans demeurent compatibles en tant que forces en elles-mêmes animées de mouvements allant dans des directions opposées ${ }^{25}$. Nous disions plus haut à propos des

25 Il ne s'agit évidemment pas pour nous d'un recours à une conception évolutionniste telle que la résumerait le titre d'un ouvrage bien connu et aujourd'hui quelque peu oublié : Des clans aux empires (Davy et Moret, 1922). Des clans, comme de très nombreux exemples africains ou autres en témoignent, peuvent bien subsister dans le cadre de structures étatiques fortement développées mais avec des fonctions amoindries ou, en tout cas, tendant à s'amoindrir. Dans les cas comme ceux dont nous parlons, nous nous risquons à avancer l'idée qu'il y aurait une sorte d'équifonctionnalité entre roi et clans correspondant à un point d'équilibre, au demeurant fort instable, des deux forces. 
Moundang que l'égalité formelle entre tous les clans, ceux issus de rois, comme ceux issus d'esclaves, ceux pourvus de fonctions d'un haut rendement social, comme ceux qui en sont presque dépourvus, tendait plutôt à protéger l'institution de la royauté qu'à les protéger eux-mêmes d'une menace venant de celle-ci ; la même analyse peut s'appliquer au Buganda. Nous en voulons pour preuve le fait que plus un clan donneur d'épouses au roi est proche de la dynastie, plus strictes sont les mesures prises à l'encontre des ambitions politiques qu'il pourrait nourrir sous le prétexte qu'il fournirait le fils qui lui succéderait sur le trône. Un seul honneur est réservé aux clans, celui de servir le roi, le servir au palais, dans les sanctuaires, dans les diverses cérémonies, sur les champs de bataille.

Chez les Moundang comme chez les Baganda, on assiste ainsi à un double mouvement qui anime chacune des deux institutions en présence, l'un tendant à la complémentarité fonctionnelle (exprimée surtout en termes d'obligations rituelles) entre la royauté et l'organisation clanique, l'autre accentuant leur opposition en tant que formes concurrentes de la souveraineté politique. Nous avons essayé de montrer ailleurs (Adler, 1987) que les événements politiques et les tendances démographiques poussaient le système moundang (pour autant qu'on puisse avec quelque certitude reconstituer son évolution tout au long du $\mathrm{XIX}^{\mathrm{e}}$ siècle) vers une monarchie despotique accompagnée de signes évidents d'un délabrement de l'organisation clanique (pour ce qui touche, par exemple, aux coutumes liées à l'exercice effectif du droit de vengeance). Ce que nous savons de l'histoire du Buganda, montre avec plus de précision un phénomène du même ordre.

C. Tardits (1981-82), à qui nous devons un bon résumé des données historiques les plus sûres que nous possédions aujourd'hui, rappelle, pour aussitôt marquer son désaccord, que dans les années cinquante, les anthropologues considéraient que le Buganda constituait " un excellent exemple du développement de l'Etat entraînant l'élimination politique des clans ". Bien sûr, nous l'avons déjà dit, les choses ne sont pas aussi simples et surtout, il n'y a rien qui ressemble à un enchaînement mécanique tel que cette formule le laisserait penser. Pourtant, qu'apprenonsnous à cet égard du passé de ce royaume ? Si la tradition en fait remonter au XIII ${ }^{\mathrm{e}}$ siècle la fondation qu'elle attribue, comme nous le savons, au héros légendaire Kintu, il nous faut attendre le milieu du XVIII ${ }^{e}$ pour 
avoir une idée précise et des rapports politiques existant entre les clans et la royauté et de leur évolution jusqu'à l'arrivée des Européens. D'abord primus inter pares par rapport aux chefs des clans, le roi devient petit à petit, à la faveur de guerres victorieuses qui permettent au pays de s'étendre et à la population de s'accroître, une sorte de monarque dont le pouvoir tend vers l'absolutisme. Il met en place une organisation administrative territoriale dont les agents exécutifs désignés par lui vont s'arroger de plus en plus les prérogatives politiques qui étaient celles des chefs de clan : ils rendent la justice, assurent la collecte des impôts, font faire les corvées et mobilisent les guerriers. Simultanément, du fait de la concentration du pouvoir et de l'absence de règles successorales strictes au sein d'un patrilignage royal que les Baganda refusent de reconnaitre comme lignage dynastique, les luttes entre prétendants au trône s'intensifient et les princes s'entre-tuent quand ils ne sont pas assassinés par le roi régnant. On a donc bien affaire, mais à une échelle plus importante et dans un tout autre contexte culturel, à un schéma du type moundang : le pouvoir royal s'absolutise et se fragilise en même temps tandis que les clans perdent leur substance politique en perdant leur autorité territoriale; ils subsistent néanmoins, mais en changeant de fonctions, c'est-à-dire en prenant la figure du totémisme associé à des fonctions rituelles et techniques spécifiques telle qu'elle se dessine dans la description de Roscoe sur laquelle notre analyse s'est appuyée. Celle-ci, nous en sommes bien conscient, est non seulement très sommaire mais a le défaut de laisser complètement dans l'ombre le contexte régional, historique et politique, dans lequel s'inscrit le royaume du Buganda. Il n'est pas possible, dans le cadre de ce travail, de nous livrer à de longs développements sur la diversité des situations sociales et politiques qui se rencontre dans cette aire culturelle et qui, en toute rigueur, seraient indispensables à la poursuite de notre propos. Nous nous contenterons de renvoyer le lecteur à l'ouvrage de Luc de Heusch (1966) que nous mentionnions dès les premières lignes de cette étude : Le Rwanda et la civilisation interlacustre.

Prenant appui, comme nous l'avons fait ici, sur le texte de LéviStrauss où il est fait référence aux clans totémiques du Buganda, il relève la singularité de ce royaume qu'il oppose à la plupart de ses voisins où le pouvoir royal s'appuie sur un véritable système de castes, comme c'est le 
cas au Rwanda, au Burundi et en Ankole, ou sur une division en classes sociales (c'est-à-dire dont la détermination est essentiellement d'ordre économique), comme c'est le cas au Bunyoro et au Buhaya où l'on a affaire à un clan royal d'origine nilotique (luo) et à une différence de classe, à proprement parler, entre pasteurs hima, d'une part et paysans iru, d'autre part, ces derniers occupant le bas de l'échelle. On observera, par ailleurs, que toutes ces formes d'organisation sociale laissent une place importante sinon décisive, aux relations de clientèle, c'est-à-dire à des rapports de dépendance personnelle. Luc de Heusch met en évidence cette singularité du Buganda en indiquant qu'il :

" [...] est le seul royaume de la civilisation interlacustre où la différenciation socio-ethnique (pasteurs-paysans) fait radicalement défaut. N'étant pas paralysé par ce système de différences culturelles, les clans totémiques ont conservé leur vitalité. Assez curieusement, le nombre de clans ganda relève d'un ordre de grandeur intermédiaire entre celui des sociétés à castes vraies ( $R$ wanda, Ankole) et celui des sociétés à classes (Bunyoro, Buhaya). [...] Les services que les clans se rendent mutuellement sont typiquement «totémiques" : ils échangent les femmes et certaines nourritures. L'assimilation des clans ganda à des castes fonctionnelles nous parait donc fallacieuse. A l'inverse des castes authentiques, ils ne sont pas rangés en ordre hiérarchique. L'Etat ganda s'est édifié sur une infrastructure clanique en fortifiant le système des différenciations totémiques; l'aspect égalitaire du système a été conservé, mais son aspect illusoire s'est concrétisé. " (loc.cit., 397-98)

Si l'on est en droit de se demander ce que peut bien être un " aspect illusoire " dont on dit qu'il s'est " concrétisé ", dans la suite de ce texte, l'auteur insiste, à juste titre, pensons-nous, sur cet aspect égalitaire du clan ganda qu'il oppose à la forme que prend le totémisme chez les Nyoro.

" Au Bunyoro, en effet, écrit-il, les clans se distinguent par un certain type collectif de comportement (tel clan est " tempéré ", tel autre " violent ", "fécond ", etc.). La société ganda ne fait qu'accentuer cette dernière tendance en substituant au système de différenciations psychologiques illusoires des Nyoro l'ébauche d'un système de différenciations sociales qui conserve le caractère égalitaire de l'ordre clanique. Tantôt les clans totémiques sont rongés par la nostalgie de la biérarchie, tantôt par celle de la spécialisation fonctionnelle". 
Disons pour nous résumer, qu'en regard de la structure clanique qui caractérise les deux sociétés que nous avons étudiées, le totémisme, qui combine les traits classificatoires (tendant à un nominalisme) avec les traits fonctionnels (pouvant ressembler à l'ébauche d'un système avec castes mais qui en demeure fort éloigné), nous semble devoir être traité comme une catégorie à part entière et qu'il faut considérer comme appartenant de plein droit à " la nature sociale ", pour parler comme LéviStrauss et non comme le résultat d'un découpage arbitraire effectué par un observateur victime d'une " mauvaise abstraction " léguée par les auteurs anciens. Nous ajoutons que cette " nature sociale " est dotée d'une dimension politique que jusqu'à présent nous avons trouvée absente de toute théorie du totémisme. Quelle est la pertinence de cette dimension politique qui semble ou qui a dû sembler à la plupart des auteurs peu significative ou peut-être même incompatible avec toute forme de totémisme ? Pour la mettre en évidence, il est indispensable de revenir sur les aspects formels qui le caractérisent et qui ont retenu notre attention tout au long de ce travail. Les meilleurs théoriciens dans ce domaine, et en particulier A. Goldenweiser qui a largement inspiré les positions critiques de Lévi-Strauss, comme ce dernier l'indique lui-même (L-S, 1962a, 6-7.), insistent sur l'idée qu'il existe une identité structurale entre les différentes unités qui composent un système totémique. Warren Shapiro, dans un très intéressant article (1991) consacré précisément à la proximité des idées de Lévi-Strauss et Goldenweiser sur ce sujet, cite un texte d'un troisième auteur chez lequel il trouve une même inspiration "boasienne " exprimée d'une façon particulièrement vigoureuse et, à nos yeux, très éclairante. II s'agit d'A. Kroeber qui écrit ces lignes à propos des Indiens Zuni (1971 : 182-183) : "leurs clans ne sont pas tant des unités reposant sur la consanguinité et la localité et fondues dans une masse au sein de laquelle elles auraient conservé leurs privilèges et leurs activités distinctives, mais plutôt des divisions coordonnées dotées de fonctions spéciales mais parallèles et équivalentes au sein de l'entité que constitue la communauté ". Plus loin, cet auteur souligne que pour lui le mot clé est celui d'équivalence, idée dans laquelle il faut voir la conséquence du principe qui intègre les divers clans dans un ensemble coordonné et systématisé. "Si les clans ont été autrefois des unités séparées, ils devaient 
avoir des privilèges inégaux et des fonctions différentes comme c'est le cas des castes, des classes et des guildes " (loc.cit.). Autrement dit, nous sommes, si nous comprenons bien ce texte de Kroeber, placés devant l'alternative suivante : ou bien nous avons affaire à des clans et nous nous trouvons en face de systèmes dont les unités relèvent du principe d'équivalence, donc d'une égalité formelle dont nous dirons qu'elle ne constitue " pas encore " un principe proprement politique d'égalité ; ou bien nous sommes en présence d'unités sociales d'une autre espèce qui sont soit naturellement (c'est-à-dire spontanément et hors de tout ordre préétabli) différentes et inégales (comme des bandes de chasseurs collecteurs ou des communautés locales de petite taille ne rassemblant que quelques familles) en raison de données contingentes et extérieures à la société considérée (liées, par exemple, à des facteurs géographiques et/ou climatiques), soit culturellement et politiquement inégales (comme le sont les castes et les classes dans des systèmes socio-économiques plus complexes) en raison des fondements idéologiques que la société considérée s'est donnée à elle-même. Dans le cas du royaume moundang de Léré comme dans celui du Buganda, le principe d'équivalence devient un principe pleinement politique dans la mesure où les clans qui sont des unités pourvues " naturellement "d'une dimension politique (par l'exercice du droit de vengeance dans l'un, ou celui d'une autorité territoriale dans l'autre), sont confrontés à l'institution de la royauté qui possède une légitimité et des pouvoirs dont la source est étrangère à l'ordre clanique sur lequel se fonde l'organisation sociale. On peut imaginer que cette confrontation, grosse de fission sinon de scission, conduit nécessairement à un arbitrage dont le résultat est cette forme de compromis que représente le mixte de clan totémique et de clan fonctionnel. Peut-être l'idée de cette forme de compromis permet-elle de mieux différencier nos deux exemples en conduisant à la supposition que si chez les Moundang, comme nous l'avons vu, les fonctions rituelles et techniques des clans sont moins marquées que chez les Baganda et surtout moins directement assujetties au pouvoir royal, cela est à relier au caractère nettement moins développé de l'institution de l'Etat chez les premiers que chez les seconds. Mais nous ne croyons pas que la présence ou l'absence de l'Etat soit le critère le plus décisif pour qui voudrait proposer une typologie des systèmes sociaux pourvus d'aspects totémiques. Certes, il ne faut pas 
sous-estimer l'importance de l'emprise qu'a l'institution étatique sur les groupes qui composent la société et elle doit être prise en considération dans la mesure où, pensons-nous, l'équilibre des pouvoirs entre les parties constituantes de l'ensemble (les rapports d'égalité entre les clans, entre les lignages) dépend de celle-ci. Le totémisme - ou ses traces - pourrait constituer une sorte d'instrument de repérage du rapport des forces existant entre une société civile dans laquelle perdure une organisation clanique et la forme qu'y prend le pouvoir politique (le pouvoir dit étatique n'étant qu'un cas de figure parmi d'autres). Un dernier exemple nous permettra d'illustrer brièvement ce propos sur lequel nous concluons ce travail.

Avant d'étudier la société nuer qui, à la suite des travaux qu'il lui a consacrés, est devenue le modèle académique des sociétés segmentaires dépourvues de chefferie, Evans-Pritchard avait poursuivi, à la fin des années vingt, d'importantes recherches sur les groupes zandé qui vivent aux confins du Soudan Khartoum, du Congo-Kinshasa (ex-Zaïre) et de l'actuelle RCA. Les Azandé, comme les Shilluk, les Moundang et les Baganda dont nous venons de parler, sont une société formée de clans et dont le système politique est fondé sur une royauté puissante qui fut capable au siècle dernier d'édifier un Etat conquérant et quelque peu esclavagiste. A la suite de deux très brèves notes sur les noms de clans (1956), Evans-Pritchard publia un article plus consistant intitulé Zande clans and totems (Man, 1961). I y recense pour la seule partie soudanaise, une liste de 188 clans et de 127 totems (comprenant surtout une grande variété de reptiles et d'oiseaux, des singes et quelques carnassiers) et note que le même clan peut porter des noms totémiques différents selon les lieux. De fait, la situation est extrêmement embrouillée en raison des guerres endémiques qui entraînèrent des migrations au cours desquelles les clans arrachés à leur territoire se divisèrent, se fractionnèrent et perdirent des membres qui se réinsérèrent dans des clans étrangers où parfois ils conservèrent leur nom d'origine. Deux siècles de bouleversements incessants ont tellement secoué ces populations que leur organisation clanique en est ressortie pour ainsi dire broyée. Il est donc impossible d'en reconstituer l'histoire et de se faire une idée précise de ce qu'était le totémisme zandé au temps où il connaissait, dirions-nous, son plein épanouissement et son plein " rendement " comme mode 
d'organisation de la société. Les seuls clans dont nous pouvons savoir quelque chose ou plutôt " le seul ", celui dont tous les membres donnent le même nom totémique, est le clan royal des Avongara. Tous ses membres ont pour totem le léopard et il n'est pas pensable, nous dit-on, " qu'un homme du commun s'identifie à la classe aristocratique " (ibid. 118). En revanche, comme beaucoup de clans partagent le même totem (par exemple rungbu, un long serpent à tête très étroite), il n'y a plus guère moyen de différencier les clans par leurs totems si bien qu'il faut en conclure que le totémisme a pratiquement perdu son importance, qu'il n'en reste que des listes de noms, certes précieuses pour l'ethnologue mais dont les intéressés ne tiennent compte ni dans l'énoncé des interdictions de mariage ni dans celui des prohibitions alimentaires. Pour EvansPritchard, les raisons de cet état de choses sont claires :

"La société zandé est essentiellement une société politique dans laquelle le statut politique, l'autorité, les fonctions, les charges et l'allégeance comptent plus que l'appartenance à un clan, et dans laquelle les clans n'ont ni statut politique ni fonction. Le seul clan qui comme tel ait de l'importance est celui des Avongara et la raison en est que ses membres sont partout, où qu'ils soient, des représentants de l'aristocratie dirigeante (aux yeux desquels les autres Azandé ne sont que des gens du commun et non des membres de tel ou tel clan); et l'importance de cette appartenance clanique ne tient qu'au privilège de classe et au pouvoir qu'elle apporte."

Il est néanmoins hors de doute qu'il n'en fut pas toujours ainsi et qu'il fut un temps où les clans étaient attachés à un territoire sur lequel ils exerçaient pleinement ou partiellement leur souveraineté et où les appellations totérniques avaient une utilité sociale proportionnelle à leur valeur comme symbole d'identité. Mais de ce temps, grâce aux restes de totémisme qui s'offrent encore à l'enquêteur du vingtième siècle, nous ne parviennent que de faibles lueurs. 
Cette analyse d'Evans-Pritchard nous paraît très convaincante ${ }^{26}$. Si nous la rapprochons de celle que les travaux de Roscoe nous ont permis d'esquisser sur le royaume du Buganda qui constitua au $\mathrm{XIX}^{\mathrm{e}}$ siècle l'un des grands et puissants Etats traditionnels de l'Afrique orientale, nous pouvons redire, en tout cas, que le critère purement institutionnel la présence d'un pouvoir et d'une administration d'Etat capables d'exercer une emprise plus ou moins forte sur la société) n'est pas absolument décisif pour rendre compte des tendances générales de l'évolution de l'organisation clanique. Totémisme classificatoire, totémisme de type fonctionnel qui se manifeste par une certaine répartition des fonctions rituelles et/ou techniques spécialisées et qui, à ce titre, préfigurerait de façon plus ou moins nette un système à castes, toutes ces formes correspondent sans doute à des moments du rapport des forces entre clans et pouvoir politique sur lesquels nous ne pourrons jamais avoir que de faibles lueurs. Ce n'est certainement pas en conservant l'illusion d'une sorte d'âge classique du " moment totémique " que nous pourrions projeter une lumière plus vive sur un état de la société dont nous chercherions en vain à fixer l'image. Il y a bien, comme le dit Lévi-Strauss, une illusion totémique mais elle ne réside pas dans la construction d'un faux objet que les anthropologues se seraient acharnés à faire tenir debout

26 Les analyses qu'Eric de Dampierre (1967) a consacrées aux Nzakara de la République Centrafricaine, groupe apparenté aux Azande, vont tout à fait dans le même sens. Faisant l'historique du système politique qu'il étudie, il nous parle d'un certain " délabrement " de l'organisation clanique dont il est difficile de savoir s'il faut $\mathrm{y}$ voir une cause ou une conséquence de l'avènement du royaume de Bangassou consécutif à la conquête de la région par le clan aristocratique Bandia. Dampierre nous fournit une liste des clans existant alors et des interdits qui sont les leurs : panthère (totem du clan Vukpata qui avait la prééminence avant la conquête), lion (totem du clan Bandia), reptiles de toutes sortes (serpent rouge, iguane, lézard), lamantin, poulpe, singe, gros écureuil, etc... Il s'agit toujours d'espèces animales (à la seule exception de Foudre) mais le mot totem que l'on s'attend à rencontrer n'est pas employé bien qu'il figure dans les titres des articles d'Evans-Pritchard que nous avons cités et auxquels, bien entendu, il fait référence. Comme chez les Zandé, en tout cas, ces données ne constituent plus la base de la vie rituelle des Nzakara qui placent au premier plan le culte des ancêtres dont le cadre social est le lignage. L'ancienne société clanique symbolisée par les noms totémiques s'est pratiquement effacée au profit d'une société dominée par l'opposition des statuts personnels : ceux de seigneur, de client et d'esclave. Corrélativement, le mariage par échange des sours a fait place au système de l'échange différé, qui est au fondement de la relation de clientèle, et au mariage par compensation de biens entre partenaires échangistes. 
en lui tendant, si l'on ose dire, béquilles après béquilles. L'illusion est une illusion de perspective - on pourrait tout aussi bien parler d'illusion archaïque, pour reprendre le titre d'un célèbre article de Lévi-Strauss (1958) - qui amène le chercheur à remonter toujours plus haut vers un état social où l'institution se serait manifestée sous sa forme la plus " complète " et offrant une parfaite cohérence, depuis une base constituée par un état déterminé de l'organisation clanique jusqu'aux nuances les plus fines du système des croyances et des pratiques rituelles censées lui correspondre de la manière la plus adéquate.

Récapitulons : $1^{\circ}$ ) Les faits nilotiques ne permettent nullement de dire que le totémisme chez les Nuer (population dépourvue de toute forme de chefferie) aurait quoi que ce soit de plus "primitif " et donc de plus authentique que celui des Dinka chez lesquels s'esquisse un commencement de hiérarchie sociale et où émerge une autorité singulière dans la personne du " maître de la lance de pêche ". Nous pouvons même avancer que c'est sans doute le contraire qui est vrai puisque un grand nombre de totems qui se rencontrent chez les premiers proviennent des seconds. Dans le royaume shilluk, comme dans d'autres systèmes politiques du même type qui existent dans le voisinage, on n'a plus affaire qu'à des traces de totémisme, mais nous n'avons aucune raison de penser que cette situation est la conséquence de l'apparition des royautés. Les Moundang et les Baganda nous ont appris que royauté et totémisme ne sont nullement incompatibles et, mieux encore, qu'ils peuvent mutuellement s'épauler et se renforcer, du moins pendant un certain temps. Il s'agirait donc plutôt d'une transformation (dans le sens d'une logique structurale comme dans le sens d'un devenir historique) au terme de laquelle les symboles totémiques (dont il ne serait peut-être pas sans intérêt de se demander pourquoi et comment ils perdent leur efficacité sociale) auraient laissé place aux fonctions rituelles spécifiques.

$\left.2^{\circ}\right)$ Dans aucun des cas que nous avons envisagés dans cette étude, le totémisme ne constitue " la " religion de la population considérée. Aux yeux d'Evans-Pritchard comme de Lienhardt, il en constitue assurément un aspect chez les Nuer et les Dinka, mais pas le plus important et ailleurs, en Afrique occidentale ou dans les royaumes d'Afrique orientale (ou chez les Moundang), il s'agit avant tout d'un trait marquant du symbolisme de l'organisation sociale et politique. Il est, si l'on peut dire, 
" encadré " par les cultes dominants; chez les nilotiques, nous nous trouvons en face de deux situations : ce sont, d'une part, des rites sacrificiels adressés à certaines catégories d'esprits et des relations de possession entretenues avec d'autres catégories liés au monde céleste et, d'autre part, des cultes " nationaux " centrés sur la royauté, la personne du souverain, les ancêtres dynastiques et les temples et sanctuaires qui leur sont consacrés. En Afrique occidentale, on aurait plutôt affaire au culte des ancêtres ou, dans certains cas, comme chez les Tallensi, à un culte d'ancêtres lié aux structures lignagères, combiné avec celui des bosquets sacrés et des autels constitutifs du culte de la Terre.

En somme, parler du totémisme en Afrique noire n'a consisté ni à porter son attention à des formes d'organisation clanique que l'on pourrait considérer comme le propre de sociétés parmi les plus "primitives" ni à s'attacher aux croyances et pratiques religieuses auxquelles on attribuerait également un caractère particulier de primitivité. Nous avons vu aussi que ce ne sont pas les rapports d'homologie entre les espèces animales ou végétales et les groupes sociaux (clans et/ou lignages) qui nous ont fourni les clefs du problème totémique tel qu'il se présente en Afrique. De quoi s'agit-il, en fin de compte? A quoi avons-nous abouti au terme de ce parcours à travers des régions et des aires culturelles les plus variées du continent noir ?

S'il est vrai que notre intérêt pour le totémisme a été entièrement motivé et, croyons-nous, justifié par nos propres données de terrain recueillies chez les Moundang, nous n'oublions évidemment pas que notre questionnement théorique ainsi que nos analyses comparatives ont pris appui sur et se sont développés dans une large mesure contre (dans le double sens d'apposé et d'opposé à) le point de vue structuraliste de Lévi-Strauss. Le lecteur ne s'étonnera donc pas que nous y revenions in fine. Avec Le totémisme aujourd'bui, on devait, selon le propos de l'auteur, en avoir fini avec une illusion, celle d'avoir affaire à un authentique objet de la nature sociale et aussi, et à plus forte raison, celle de toucher au fait social primitif, dans l'ordre de la structure comme dans celui des représentations. En ce qui concerne ce dernier point, nous venons de réaffirmer notre complet accord, en revanche, nous pensons et espérons avoir montré que le totémisme est bel et bien un caractère qui appartient à un "objet de la nature sociale ", en l'occurrence, ce type de 
groupe social que les ethnologues s'accordent à appeler clan (en justifiant l'emploi de cette dénomination) et pour autant que le clan prenne corps dans un ensemble qui fasse système. Avec La pensée sauvage, comme l'indique le titre même de cet ouvrage (dont l'auteur ne manque pas de nous signaler qu'il ne renvoie pas exclusivement aux sociétés dites primitives ou traditionnelles), nous étions invités à explorer le champ de l'activité intellectuelle où se déploie une pensée concrète liée à une observation fine et précise du monde de l'expérience sensible et qu'il qualifie de sauvage parce que non domestiquée, non assujettie aux contraintes et aux disciplines formelles fondées sur un corps de connaissances scientifiques. Dans ce cadre très élargi, les faits illustrant le "prétendu totémisme " servaient surtout d'exemple de la façon dont les populations pouvaient mettre sur pied des systèmes de classification parfois hautement performants, en vertu d'opérateurs permettant de jouer avec les différents signifiants (espèces et parties du corps des animaux, notamment) sur plusieurs axes simultanément. Cela rendait possible, du même coup, des manipulations et des transformations nécessaires pour faire face aux changements, notamment démographiques, imposés par l'histoire et maintenir envers et contre tout un semblant de permanence à des structures sans cesse bousculées par les événements.

Curieusement, c'est dans cet ouvrage qui annonce et, dans une certaine mesure, prend déjà place dans les recherches de type cognitiviste, que Lévi-Strauss, dans un chapitre dont nous avons fait grand cas dans ce travail, s'est le plus avancé dans le domaine de la sociologie du totémisme en proposant d'inscrire totem et caste, c'est-à-dire les cas de figure les plus opposés dans le champ des " rapports empiriquement observables entre endogamie et exogamie ", dans un groupe de transformation. Cet outil, emprunté aux mathématiciens dans le but d'affiner et d'amener à un degré supérieur de rigueur l'analyse comparative dans le domaine des sciences humaines, n'était pas, en l'occurrence, mis au service d'une tentative vraiment sérieuse pour l'appliquer de façon stricte aux notions 
de totem et de caste ${ }^{27}$. C'est sans doute la raison pour laquelle, aussi audacieuse et suggestive qu'elle soit, cette idée nous est apparue comme une pure spéculation, une sorte d'expérimentation mentale non motivée par les données de l'ethnographie (ou la sociologie des castes de l'Inde) et dont le principal ressort est l'opposition entre nature et culture et les façons opposées dont elle se manifeste. Comme nous l'affirmions plus haut, et comme nous l'avons lu sous. la plume de Luc de Heusch, la référence au Buganda ne peut en aucune manière valider sa thèse du passage graduel du clan totémique au système des castes en passant par le clan fonctionnel. Peut-être les données sur les castes en Afrique occidentale, que nous avons seulement évoquées ici mais sur lesquelles un premier travail d'une certaine ampleur a été effectué (Tamari, 1997), permettraient-elles une avancée décisive dans ce domaine ? Mais quoi qu'il en soit, il nous paraît évident que l'opposition entre nature et culture ne saurait être appliquée telle quelle et de façon similaire au clan totémique et à la caste professionnelle. Cette opposition est, certes, au cour de la problématique de l'identité clanique dont le symbole totémique, qu'il s'agisse ou non d'une espèce naturelle, renvoie toujours, en définitive, à un système de correspondances entre des éléments de l'univers et les divisions du monde social. En revanche, elle nous semble complètement étrangère à la caste, et sa fonction, si l'on tient à la maintenir, ne peut qu'être réduite à une simple métaphore. La profession n'est pas à la caste ce que le symbole totémique est au clan, tout au plus pourrait-on lui comparer le statut des gens de telle caste dont nous savons qu'il dépend du degré d'impureté qui s'attache aux activités qui leur incombent. De même on ne saurait dire que l'exogamie qui caractérise

27 La notion de groupe de transformation, dans l'usage qu'en fait ici Lévi-Strauss, relève, pensons-nous, d'une méthode ou d'un procédé d'argumentation : elle nous est présentée comme la condition logique requise pour une analyse comparée des relations entre la paire clan-totem d'une part, et la paire caste-occupation ou profession, d'autre part. Mais en l'absence d'une mise en ouvre de l'outil mathématique ou, plus simplement, de tout appareil formel comme celui qu'il utilisera dans ses Mythologiques, avec l'éclatante réussite que l'on sait, la démarche réellement suivie par Lévi-Strauss nous apparaît plutôt comme intuitive. D'un mot, nous dirons qu'il a tiré le plus grand parti d'une analogie entre deux rapports afin d'étayer une intuition sur la nature du social fondée sur l'examen des extrêmes ramenés à des équivalents. 
dans de nombreux cas le clan totémique est dans un rapport de symétrie inversée avec l'endogamie à laquelle sont tenues les castes ${ }^{28}$. Enfin, le contenu des représentations associées au totémisme et qui justifient les interdits quelle que soit leur nature (alimentaires et/ou matrimoniaux) n'est pas de même nature que celui des idées qui sont au fondement de la caste.

Les clans totémiques moundang comme ceux du Buganda sont pleinement des clans et c'est à ce titre qu'ils sont totémiques. Les activités spécifiques qui les distinguent les uns des autres leur assignent à ce même titre les services qu'ils doivent rendre à la royauté. Autrement dit, les clans ne changent pas d'identité et leur nature totémique, qui est liée chez les Moundang comme chez les Baganda, nous l'avons vu, à leur ancrage territorial, n'est nullement entamée par l'adjonction d'une ou plusieurs fonctions qui, elles, sont domestiquées. Elles le sont dans l'exacte mesure où, étant assujetties à la machine royale, elles sont politisées. Mais la machine royale est aussi une maison où naissent et se développent de multiples fonctions. Dans l'enceinte du palais du gõ de Léré, comme dans celui du kabaka ganda, il n'y a pas seulement un grand nombre d'épouses dont la place est primordiale dans la production économique (qui n'est pas seulement destinée à la consommation intérieure mais permet surtout une redistribution cérémonielle massive), il y a aussi des hommes de cour, c'est-à-dire des individus qui sont détachés ou dépossédés de leur appartenance clanique (il peut s'agir d'une perte de statut sanctionnant un crime ou d'une capture à la guerre) : ce sont, d'une part, des notables dont certains sont réduits au rôle de courtisans qui doivent à leur souverain tous les avantages dont ils jouissent et, d'autre part, des hommes (qui

28 Rappelons seulement ce que Lévi-Strauss lui-même nous a enseigné dans Les structures élémentaires de la parenté: "On voit donc à quel point il est impossible, comme on le fait souvent, de considérer exogamie et endogamie comme des institutions du même type ; c'est vrai seulement pour cette forme d'endogamie que nous avons appelée fonctionnelle, et qui n'est autre que l'exogamie elle-même, envisagée dans ses conséquences. "(op.cit. : 64). Immédiatement après il ajoute que l'endogamie " vraie" est un principe inerte de limitation. Citons en regard de ce texte ces lignes de L. Dumont : " Notons au passage que par rapport à une tribu se décompensant en clans, la sociétés des castes représente un ordre supérieur de complexité, puisque chaque caste a généralement ses clans exogames, ou l'équivalent " (L. Dumont, $1979: 147)$. 
peuvent compter ou non parmi les notables) possédant les compétences rituelles et techniques les plus diverses - administratives, économiques, militaires, policières, diplomatiques, etc. - qui, eux, forment le noyau de la puissance royale. Le tout se divise et se déploie en un éventail de titres qui correspondent à autant de départements ${ }^{29}$ (comme nous parlons de départements ministériels) chargés d'exercer des compétences particulières et qui tendent à donner un caractère formel et nécessaire à une multiplicité plus ou moins aléatoire et, au demeurant changeante, selon les circonstances ou le bon plaisir du roi. Au dehors, la "société civile " organisée en clans, se voit attribuer des fonctions spécifiques, indissolublement techniques et rituelles, qui forment à leur tour un ensemble de compétences en relation de miroir ou de complémentarité avec la titulature des notables et hommes de cour. Ces derniers, du dedans du palais, se partagent des fonctions politico-administratives dont le champ d'action s'étend à l'ensemble du territoire sur lequel le roi exerce, en principe, son autorité ; les attributs spécifiques des clans sont, quant à eux, domestiquées, mises au service de la personne royale. On assiste ainsi, de façon simultanée, à une politisation de fonctions qui sont, à l'origine, des tâches réservées à la domesticité du palais et à une domestication des fonctions technico-rituelles des clans. Nous n'avons plus du tout affaire à une problématique qui relèverait de l'opposition nature-culture mais à une dynamique proprement politique qui est mise en branle par un processus que nous avions vu déjà vu à l'œuvre dans les exemples zande et nzakara chez lesquels la perte des repères totémiques, la " détotémisation ", correspond à ce que nous caractériserions volontiers, en reprenant les expressions forgées par Deleuze et Guattari, comme un processus de " déterritorialisation ". Inversement, nous dirions que nous nous trouvons face à un processus de * reterritorialisation " dans la promotion de l'espace domestique de la résidence royale comme ombilic d'un monde (ou du monde, comme cela se manifeste dans les grands rituels de circumambulation dont l'orientation est celle du mouvement apparent du

${ }^{29}$ Nous nous autorisons ici du langage employé par Hocart dans Rois et courtisans, où il n'hésite pas à sauter hardiment les barrières qui séparent le vocabulaire qui relève du domaine de l'anthropologie religieuse de celui qui est en usage dans le champ du politique au sens le plus strict du terme. 
soleil) ${ }^{30}$. Ces néologismes quelque peu rébarbatifs mais que certains de nos collègues ont déjà adoptés, désignent des concepts que leurs inventeurs considéraient utiles aussi bien pour penser le bouleversement des repères symboliques définissant la modernité (qu'on peut appréhender comme une forme de dépossession) que ces repères eux-mêmes tels qu'ils furent déterminés par ce qu'ils appellent les investissements premiers de l'espace (et que l'on peut aussi définir comme une forme de prise de possession symbolique). Ils constituent, à nos yeux aussi, des notions à travailler dont les ethnologues peuvent ou pourraient se servir pour affiner celles que nous ont léguées les grands anciens de notre discipline, Maine et Morgan, pour citer les plus importants, sous la forme de l'opposition entre liens du sang et liens fondés sur le territoire. Nous avons analysé les rapports entre clans totémiques et clans fonctionnels en prenant en considération leur dimension diachronique et donc, la dialectique qui les anime et c'est ainsi que nous avons débouché sur la question du changement de nature du pouvoir. Il est possible et peut-être tentant de la formuler comme étant celle de la formation de l'Etat. Il nous semble

30 Contrairement à ce que l'on serait tenté de penser, la "reterritorialisation " ne correspond pas toujours et nécessairement à une centralisation du pouvoir et à ce que l'on pourrait appeler une marche vers la constitution de l'Etat. Nous avons vu plus haut qu'une certaine forme de totémisme clanique combinée avec l'établissement de liens inter claniques de parenté à plaisanterie pouvaient, dans le cas des Kuranko étudiés par M. Jackson, compenser la dispersion des clans et des lignages consécutive aux guerres ou autres calamités d'envergure et recréer entre eux des liens de solidarité et un sentiment d'unité. Il nous faut reconnaître que cette idée qu'avance Jackson en guise de conclusion de son article (conclusion typiquement fonctionnaliste pour un développement qui ne l'est pas), n'est pas tout à fait en accord avec sa déclaration liminaire selon laquelle le totémisme clanique des Kuranko doit être compris comme un système cognitif plutôt que comme une structure de comportement car, écrit-il "clanship is a thought of order rather than a lived in order". Une telle opposition entre le pensé et le vécu, pour courante qu'elle soit, n’est pas absolument convaincante. En témoignent, selon nous et si l'on nous permet de sortir du domaine africain dans ces dernières pages de notre parcours, les travaux remarquables de certains de nos collègues sur ce qu'on peut appeler la " territorialité totémique " telle qu'elle se révèle dans le "dreamtime" australien (que certains ont appelé le " temps des êtres éternels ") dans lequel les Aborigènes retrouvent aujourd'hui aussi bien les sources les plus profondes de leur identité culturelle ancestrale que les raisons de leurs luttes politiques pour faire respecter leurs droits à la terre. Nous renvoyons le lecteur à l'ouvrage de l'une des plus brillantes représentantes de la jeune génération des chercheurs spécialistes de l'Australie, Barbara Glowczewski (1991) dont le 2ème chapitre s'intitule précisément "Terre et Totem en Australie ". 
que les données africaines que nous avons examinées dans cette optique nous conduiraient plutôt à voir dans ces transformations sociales et politiques qui affectent le système clanique un processus qui rend possible et donc, dans une certaine mesure, " annonce " non pas l'Etat à proprement parler, mais l'apparition de formes de gouvernement et de territorialités quasi ou préétatiques, ce que sont les chefferies (cbiefdom et non chiefship) et la plupart des royautés, pour nous en tenir au vocabulaire habituel des africanistes. Nombreuses sont les sociétés, en Afrique comme ailleurs, où ce processus - qui peut aussi se résumer dans la formule : "Concentration des rituels et centralisation du pouvoir ", utilisée par Hocart comme titre du chapitre VII de Rois et courtisans - n'a jamais abouti à la constitution de ce qu'on peut appeler un Etat ${ }^{31}$. Précisément, que peut-on, que faut-il appeler " Etat ", la question reste ouverte pour un anthropologue et ce ne serait pas pure facétie si l'on s'essayait à examiner cette notion avec le même souci critique que celle de totem ${ }^{32}$.

31 Une illustration de ce propos sur les rapports entre totémisme et pouvoir nous est fournie par un texte de Goldenweiser (1918) qui nous ramène au coeur même du débat historique sur le totémisme, au moment où il va connaître la fin de son " âge d'or". Cet auteur, dont nous savons le rôle capital qui a été le sien dans la réflexion critique qui a précipité le déclin de la question du "totémisme "dans les préoccupations des anthropologues, fait l'observation suivante : "Les communautés totémiques, en tant que complexes d'ensembles de traits historiquement et psychologiquement hétérogènes, manifestent certaines similitudes frappantes avec une autre forme d'associations socio-religieuses assez communes dans les groupes primitifs, à savoir, les confréries religieuses". L'auteur évoque avant tout le cas des Indiens des Plaines dont il signale qu'ils constituent également des groupes totémiques et se demande s'il n'y aurait pas dans cette distribution géographique des deux institutions * des possibilités d'une relation génétique ". Or nous savons par Lowie (1927) auquel dans ce même texte, Goldenweiser fait référence, que ces confréries ont représenté dans ces sociétés dépourvues de chefs permanents, la forme la plus marquée du pouvoir de coercition dont le besoin se faisait sentir au temps de la chasse comme au temps de la guerre. Il y a donc bien, selon notre auteur, passage (passage dans les deux sens, nous dit-il, selon que l'on considère les Indiens du SudOuest des Etats-Unis ou ceux de la zone orientale des Plaines) entre l'organisation en clans totémiques et celle en confréries religieuses qui s'avèrent ainsi toutes deux exercer des formes différentes de pouvoir.

32 Bien sûr, en ce qui concerne le concept d'Etat, nous n'ignorons pas que le débat a porté et porte toujours non sur le fait de savoir s'il correspond ou non à un objet véritable de la nature sociale - ce qui est une question que les anthropologues avaient tranchée ou cru trancher en se contentant du grand partage entre sociétés sans et sociétés avec Etat - mais sur la détermination des conditions historiques de l'apparition de cet objet très spécial dont la particularité est précisément son 
Nous n'allons évidemment pas nous adonner à cet exercice et nous préférons nous rallier au point de vue de Hocart dans l'ouvrage que nous venons de citer et dont, plus de soixante ans après sa publication, les chercheurs sont loin d'avoir épuisé toute la fécondité. Dans la longue et passionnante introduction rédigée à l'occasion de sa réédition en 1970, $\mathrm{R}$. Needham rend hommage à la hardiesse de pensée de Hocart en ces termes :

"Son hypothèse la plus particulière (le gouvernement découle d'une organisation rituelle et doit sa forme au besoin d'assurer la vie), pour conditionnelle qu'elle soit, est aussi la plus originale et la plus frappante. C'est en effet une réussite de premier ordre que d'être parvenu dans Rois et Courtisans à énoncer, après Aristote, Locke, Rousseau et Hume, une théorie originale sur l'origine du gouvernement. "

Cette théorie strictement anthropologique, qu'il n'hésite pas à hisser au même rang que celles des penseurs politiques les plus importants de l'histoire de l'Occident, Needham en résume avec force et clarté la substance :

" Hocart prétend qu'il y a eu une évolution systématique de la société : de la segmentation à la centralisation; de la non différenciation à la spécialisation; de la préséance à l'autorité ; de la complémentarité à la hiérarchie ; de la représentation à l'administration. C'est là une théorie générale et cohérente du développement de l'organisation sociale centralisée, s'achevant dans la forme étatique. "

Nous pensons que nos analyses du totémisme clanique en Afrique noire peuvent s'inscrire dans ce schème général et qu'elle trouvent dans cette manière de penser l'évolution historique et, plus précisément, de dessiner les lignes du développement politique d'un certain nombre de sociétés, un fondement théorique qui nous aura permis d'aller au delà d'une simple critique de la critique du totémisme.

\author{
Alfred Adler \\ EPHE - URA 221
}

universalité : l'Etat moderne. Il faut reconnaître que dans ce débat qui concerne au premier chef les sociologues, les juristes et les historiens, les anthropologues n'ont pas apporté une contribution qui fasse poids. 


\section{Références bibliographiques}

Adler, A.

1982 La mort est le masque du roi, Paris, Payot, $427 \mathrm{p}$.

1987 "Le royaume moundang de Léré ", in Claude Tardits éd., Princes et serviteurs du royaume. Nanterre, Société d'ethnographie.

1989 "La fillette amoureuse des masques ", Journal de la Société des Africanistes, LIX, 1/2 : 63-98.

1994 "Levée de deuil et consécration de l'héritier ", Systèmes de pensée en Afrique noire, $13: 89-119$.

1998 "Des rois et des masques", L'Homme 145: 169-203.

Adler, A. et Zempleni, A.

1972 Le bâton de l'aveugle, Paris, Hermann (Collection Savoir).

Arens, W. and Burton, J.W.

1975 "Death by suffocation ", Man (n.s.) $11: 313-15$.

Beidelman, T.O.

1976 "Death by suffocation" (correspondence), Man (n.s.) $11: 119$.

Calame-Griaule, $\mathrm{G}$.

1965 Ethnologie et langage. La parole chez les Dogon. Paris, Gallimard.

Chrétien, J.P.

1985 "L'empire des Bacwezi. La construction d'un imaginaire géopolitique " in Annales ESC, $\mathrm{n}^{\circ} 6: 1335-1377$

Chulliat, C.

1936 Bibliographie critique du totémisme, Paris, P.U.F. (thèse complémentaire pour le Doctorat es-Lettres, Faculté des Lettres de l'Université de Clermont).

Dampierre, E. de.

1967 Un royaume Bandia du Haut-Oubangui, Paris, Plon.

Delafosse, $M$.

1920 "Des soi-disant clans totémiques de l'Afrique occidentale ", Revue d'ethnographie et des traditions populaires, Vol. $1, \mathrm{n}^{\circ} 2: 87$ 104. 
Dieterlen, G.

1938 "Le duge, signe d'alliance chez les Dogon de Sanga ", Bulletin du Comité d'Etudes Historiques et Scientifiques de l'AOF, XXI (1), 108 129.

1962 "Note sur le totémisme dogon ", L'Homme, II (1) : 106-110.

Dumont, L.

1979 Homo Hierarchicus. Le système des castes et ses implications, Paris, Gallimard ("Tel ").

Dupire, $\mathbf{M}$.

1991 "Totems sereer et contrôle rituel de l'environnement ", L'Homme 118, XXXI (2), 37-66.

Evans-Pritchard, E.E.,

1940 The Nuer, London, Oxford University Press.

1956 A Nuer Religion, London, Oxford University Press.

1956b "Zande clan names" Man, LVI, 69-71.

1961 "Zande clans and totems", Man, LXI, 116-121.

Fallers, L.

1964 "Social Stratification in traditional Buganda " in The King's men, London, Oxford University Press.

Firth, R.

1966 "Twins, Birds and Vegetables : Problems of identification in primitive religious thought ", Man, New series, Vol 1, 1, 1-17.

Fortes, M.

1945 Dynamics of clanship among the Tallensi, London, Oxford University Press, $270 \mathrm{p}$.

1987 "Totem and Taboo " (1ère éd. 1966), in Religion, Morality and the Person. Essays on Tallensi Religion, New York, Cambridge University Press.

Fournier, $\mathrm{M}$.

1994 Marcel Mauss, Paris, Fayard.

Ganay, S. de.

1942 "Le Binou Yebene ", Miscellanea Africana Lebaudy, cahier 2, Paris, Geuthner. 
Glazier, J.

1976 "Generation Classes among the Mbeere of Central Kenya ", Africa, Vol 46, 4 , 327-339.

Glowczewski, B.

1991 Du rêve à la loi chez les Aborigènes. Mythe, rites et organisation sociale en Australie, Paris, P.U.F.

Goldenweiser, A.A.

1918 "Form an Content in Totemism ", American Anthropologist, New series, $n^{\circ} 20$, Lancaster, U.S.A.

Griaule, M.

1940 "Remarques sur le mécanisme du sacrifice dogon (Soudan français) "Journal de la Société des africanistes, Paris, VII, 127-130.

1948 Dieud'eau. Entretiens avec Ogotemmeli, Paris, Editions du Chêne.

1954 (en collaboration avec G. Dieterlen) " The Dogon ", in African Worlds. Studies in the Cosmological Ideas and Social Values of African Peoples, ed. D. Forde, Oxford University Press.

Heusch, L. de

1966 Le Rwanda et la civilisation interlacustre. Etudes d'anthropologie historique et structurale, Bruxelles, U.L.B., Institut de Sociologie.

1986 Le sacrifice dans les religions africaines, Paris, Gallimard.

Hocart, A.M.

1978 Rois et courtisans, Paris, Editions du Seuil.

Jackson, $M$.

1974 "The structure and significance of Kuranko clanship "Africa, XLIV, $n^{\circ} 4,397-415$.

Karp, I.

1977 "Levi-Strauss and Tallensi Totemism : A reanalysis ", in Antbropology, 1 (1), 33-40.

Kyburz, O.

1998 "La fabrication de la foulanité", Journal des Africanistes, 67 (2), 101-126. 
Lévi-Strauss, C.

1949 Les structures élémentaires de la parenté, 1ère éd., Paris, P.U.F.

1958 Anthropologie structurale, Paris, Plon.

1962a Le totémisme aujourd'hui, Paris, P.U.F.

1962b La pensée sauvage, Paris, Plon.

Liberski, D.

1993 "Remarques sur le totémisme kasena (Burkina Faso)" Exposé oral présenté au Séminaire général de l'URA 221 consacré au totémisme, (ron.).

Lienhardt, G.

1954 "The Shilluk of the Upper Nile" in African Worlds. Studies in the Cosmological Ideas and Social Values of African Peoples, ed. D. Forde, Oxford University Press.

1961 Divinity and Experience. The Religion of the Dinka., London, Oxford University Press.

Lowie, $\mathbf{R}$.

1929 The origins of the State, New York.

Monteil, C.

1924 Les Bambara du Segou et du Kaarta, Paris, Larose.

Paulme, D.

1988 Organisation sociale des Dogon, Paris, Jean Michel Place (1ère édition, 1940, Paris, Domat-Montchrestien).

Radcliffe-Brown, A.R.

1968 Structure et fonction dans la société primitive, Paris, Editions de Minuit.

Roscoe, J.

1911 The Baganda : An Account of their Native Customs and Beliefs, London, Macmillan and Co.

Schnepel, B.

1988 "Shilluk royal ceremonies of death and installation ", Anthropos, 83, 433-452.

1991 "Continuity despite and through death : regicide and royal shrines among the Shilluk of southern Sudan ", Africa, 61 (1), 4069. 
Seligman, C.G.

[1908-1926] deux articles publiés entre ces deux dates dans Encyclopaedia of Religion and Ethics (édité par James Hastings), New York, Charles Scribener's and Sons : 1) "Dinka " in Vol 4, 704-713, 2) "Shilluk" in Vol 11, 458-462.

Seligman, C.G. et Mrs . B.Z.

1932 Pagan Tribes of the Nilotic Sudan, London, Routledge.

Shapiro, W.

1991 "Claude Lévi-Strauss meets Alexander Goldenweiser : Boasian anthropology and the study of totemism", American Antbropologist, 93, 599-610.

Simonse, S.

1992 Kings of disaster. Dualism, Centralism and the Scapegoat King in Southeastern Sudan. Pays-Bas, Leiden, E. J. Brill.

Tamari, $\mathrm{T}$.

1997 Les castes de l'Afrique occidentale, Nanterre, Société d'ethnologie.

Tardits, C.

1981-82 Conférence, Annuaire de l'EPHE, Sciences religieuses, Tome XC.

Testart, A.

1985 Le communisme primitif, T.I Economie et idéologie, Paris, Editions Maison des Sciences de l'Homme.

Van Gennep, A.

1908 "Totémisme et méthode comparative ", Revue de l'bistoire des religions t. LVIIL., pp. 34-76 (republié in Religions, moeurs et légendes, t. II, Pp. 22-88).

1920 L'état actuel du problème totémique, Paris, Editions Ernest Leroux. 